
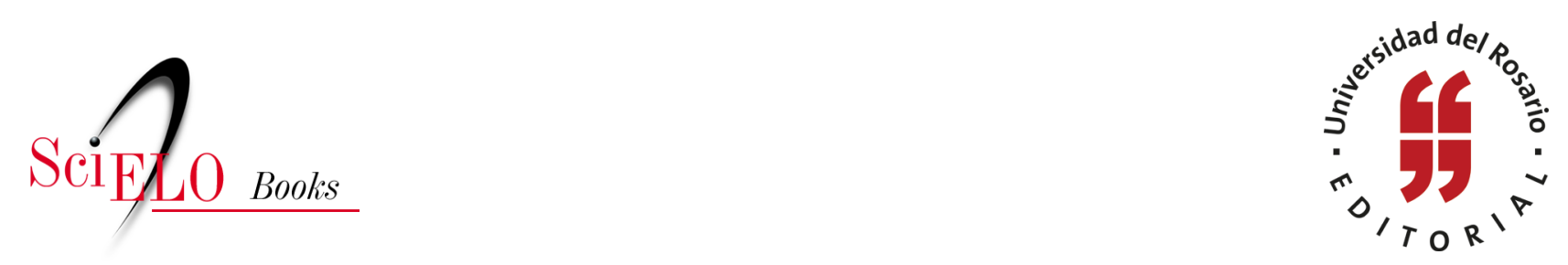

\title{
Caracterización de los adultos mayores privados de la libertad
}

\author{
Carol Iván Abaunza Forero \\ Mónica Alexandra Mendoza Molina \\ Paola Bustos Benítez \\ Giovanny Paredes Álvarez \\ Karla Vanessa Enriquez Wilches \\ Andrea Carolina Padilla Muñoz
}

\section{SciELO Books / SciELO Livros / SciELO Libros}

ABAUNZA FORERO, C.I., MENDOZA MOLINA, M.A., BUSTOS BENÍTEZ, P., PAREDES ÁLVAREZ, G., ENRIQUEZ WILCHES, K.V., and PADILHA MUÑOZ, A.C. Caracterización de los adultos mayores privados de la libertad. In: Adultos mayores privados de la libertad en Colombia [online]. Bogotá: Editorial Universidad del Rosario, Instituto Rosarista de Acción Social - SERES, 2014, pp. 100-216. ISBN 978-958-738-532-8. https://doi.org/10.7476/9789587385328.0008.

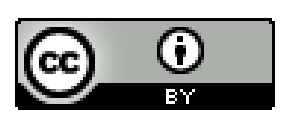

All the contents of this work, except where otherwise noted, is licensed under a Creative Commons Attribution 4.0 International license.

Todo o conteúdo deste trabalho, exceto quando houver ressalva, é publicado sob a licença Creative Commons Atribição $\underline{4.0}$.

Todo el contenido de esta obra, excepto donde se indique lo contrario, está bajo licencia de la licencia Creative Commons $\underline{\text { Reconocimento } 4.0 .}$. 


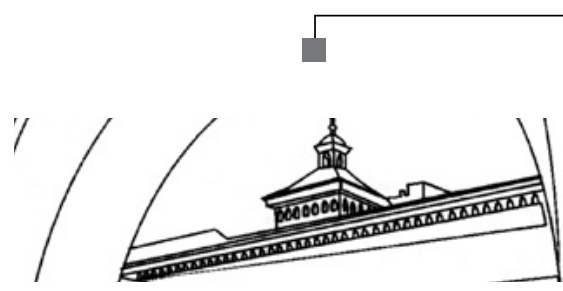




\section{Caracterización de los adultos mayores privados de la libertad}


Este capítulo se centra en describir los atributos particulares de la población AMPL. La caracterización realizada parte de una descripción cualitativa que se soporta con datos cuantitativos oficiales y recolectados en las diferentes visitas por medio de instrumentos utilizados por el equipo investigador, lo que permite profundizar de manera estructurada en las características de los AMPL. Dentro de una fase descriptiva, se identificó y contrastó la información conceptual que se tenía con lo evidenciado en las visitas a los diferentes EPC, a partir de lo cual se establecieron las características de los internos frente a sus derechos, y a sus condiciones de vida, psicológicas, sociales, económicas y jurídicas.

\section{Derechos humanos y fundamentales de los adultos mayores privados de la libertad}

A través del formato de priorización de derechos fundamentales, se recogió la percepción de los AMPL en cuanto a los derechos humanos; al respecto, se solicitó a los participantes que priorizaran de 1 a 7 , según su propia percepción de valoración, algunos de los derechos fundamentales que se encuentran consagrados en la Constitución Política de Colombia, que consideraban eran los más importantes, que se deberían respetar durante la reclusión y que habían sido vulnerados. En las figuras 8 y 9 se dan a conocer los derechos fundamentales ${ }^{1}$ que debían ser priorizados.

La información obtenida indica que se perciben como más vulnerados los siguientes derechos: salud (36\%), protección y asistencia (16\%), educación (15\%), familia (13\%), defensa (8\%), libertad de culto (7\%) y vida $(5 \%)$.

Cada participante tenía que colocar un número (del 1 al 7) con el fin de valorar el derecho que consideraba más importante; luego, con un círculo debía resaltar el derecho que, según su percepción, no se le había respetado durante su reclusión. En el cuadrado vacío el AMPL podía escribir algún derecho que consideraba fundamental y que no había sido incluido. 
Figura 8. Formato de priorización de derechos fundamentales

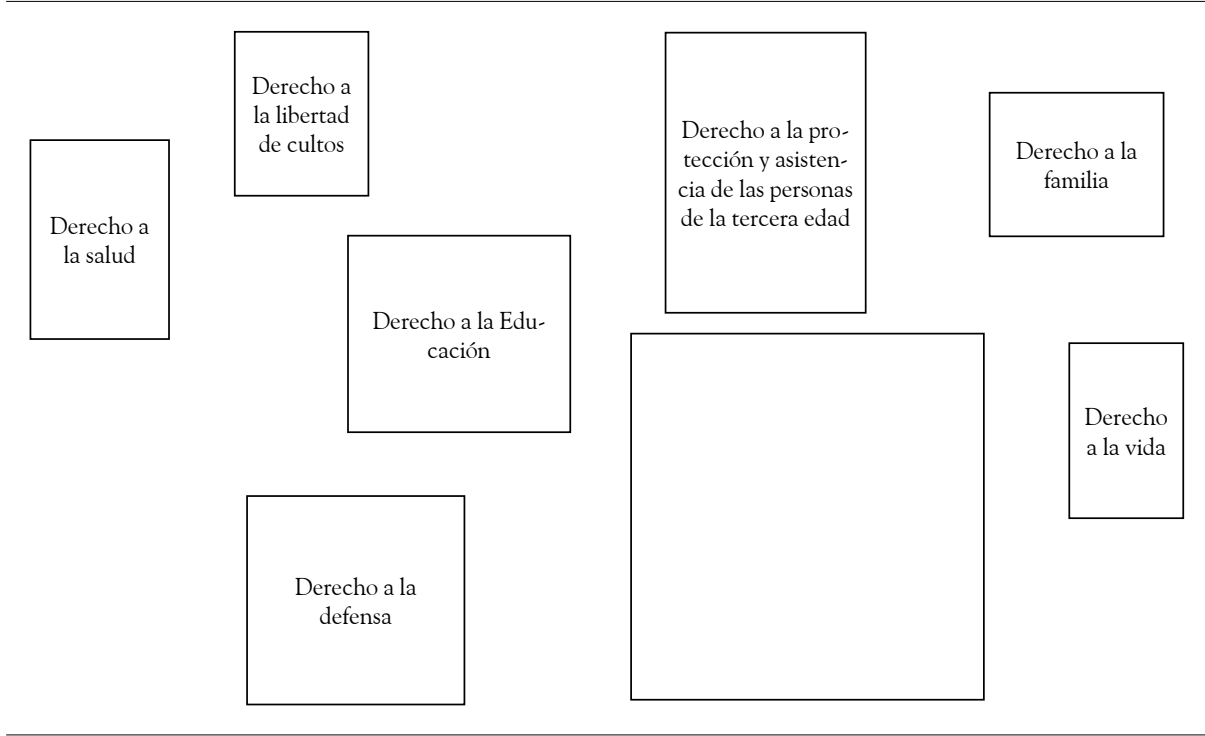

Fuente: elaboración propia.

Figura 9. Derechos humanos vulnerados

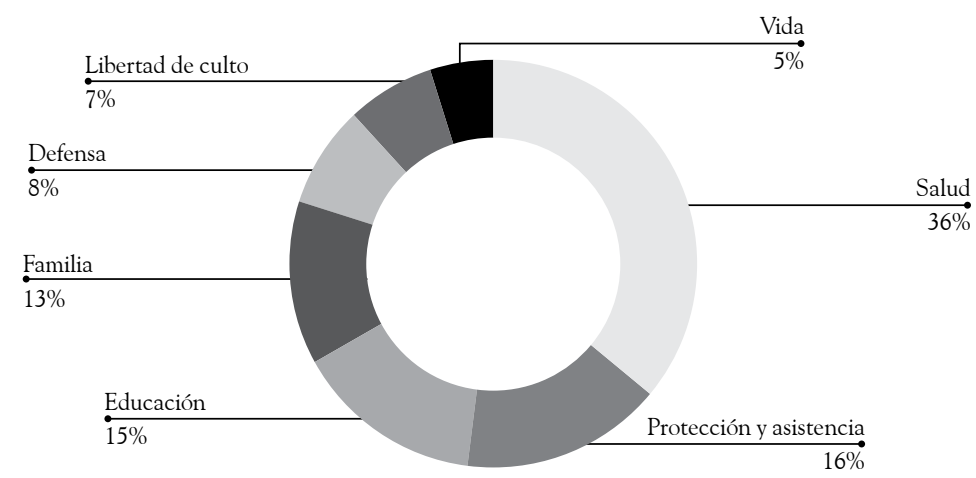

Fuente: grupos focales en los EPC visitados. Cálculo de los autores.

Los resultados encontrados son congruentes con lo que habitualmente se expone en los medios de comunicación, acerca del abandono en cuanto a la atención en salud, y la protección y la asistencia para esta población. En tercera instancia, hacen referencia a la educación, con un $15 \%$, lo que indica la necesidad de mejorar aspectos en este ámbito, que es, a nuestro parecer, primordial para una resocialización. 
Por otra parte, un $13 \%$ de los AMPL encuestados perciben que su derecho a tener cercanía con su familia está siendo vulnerado, lo cual tiene sentido por las limitaciones que existen para las visitas u otro tipo de interacciones. En materia de salud, por presentar patologías propias de la edad o padecimientos crónicos, requieren de una atención diferenciada, que incluya especialistas en salud mental, condiciones de salubridad óptimas, barandas en sitios específicos, pasillos, escaleras y rampas que se adapten a sus particularidades.

Junto con los derechos humanos fundamentales que, según los AMPL, son vulnerados, existen otros derechos que no fueron considerados en el formato, pero que se mencionaron como fundamentales y se considera que deberían haber sido incluidos; al respecto, el 72 \% de la población agregó uno más a la lista, de la que resultaron otros derechos fundamentales vulnerados (figura 10).

Figura 10. Otros derechos fundamentales vulnerados

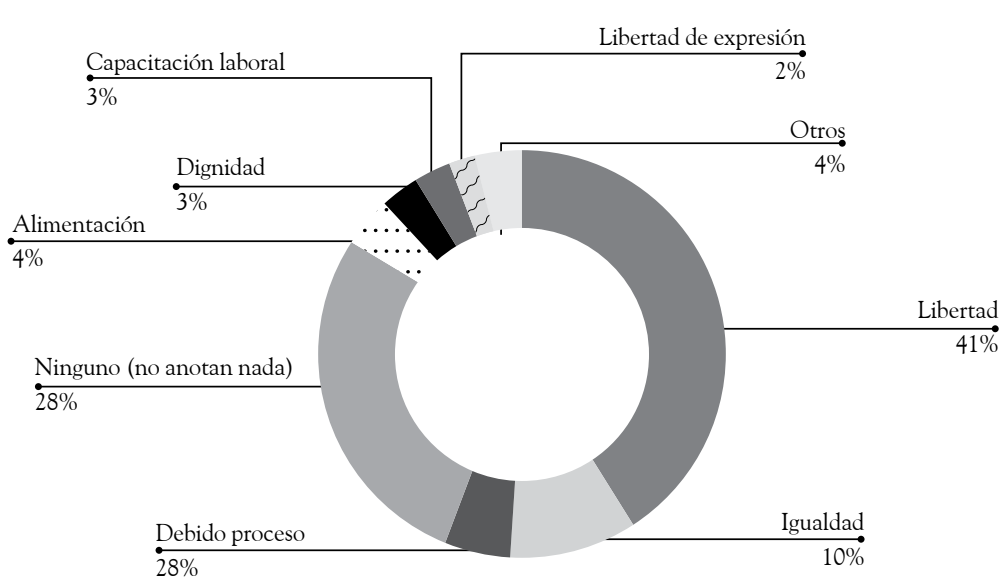

Fuente: grupos focales en los EPC visitados. Cálculo de los autores.

De estos derechos, el $41 \%$ corresponde a la libertad, lo cual sin duda responde a su situación; el 10\%, a la igualdad, y el 5\%, al debido proceso. Otros derechos nombrados por menos del $4 \%$ de los reclusos fueron: la alimentación, la dignidad, la capacitación laboral, la libertad de expresión y otros. Resulta interesante observar que el $28 \%$ de los reclusos no perciben 
ningún otro derecho fundamental que les haya sido vulnerado, lo que se podría interpretar como un desconocimiento de sus derechos.

Con estos resultados globales, se puede observar cómo los AMPL perciben varios de los derechos fundamentales vulnerados y, en relación con este aspecto, la sociedad y las ciencias jurídicas tendrían que realizar intervenciones efectivas que vayan en consononacia con las funciones resocializadoras que tienen los EPC. De igual forma, nos pueden sugerir alguna discrepancia entre la vulneración de los derechos que se perciben desde fuera de los EPC, contrastados con la realidad que enfrentan los hombres y las mujeres AMPL, sujetos de especial protección constitucional y que, en razón de sus relatos y respuestas, no se sienten incluidos dentro de esta categoría. Ahora bien, los resultados sobre los derechos que se consideran más vulnerados son concordantes con aquellos que los AMPL consideran más importantes (figura 11).

Figura 11. Derechos en orden de importancia

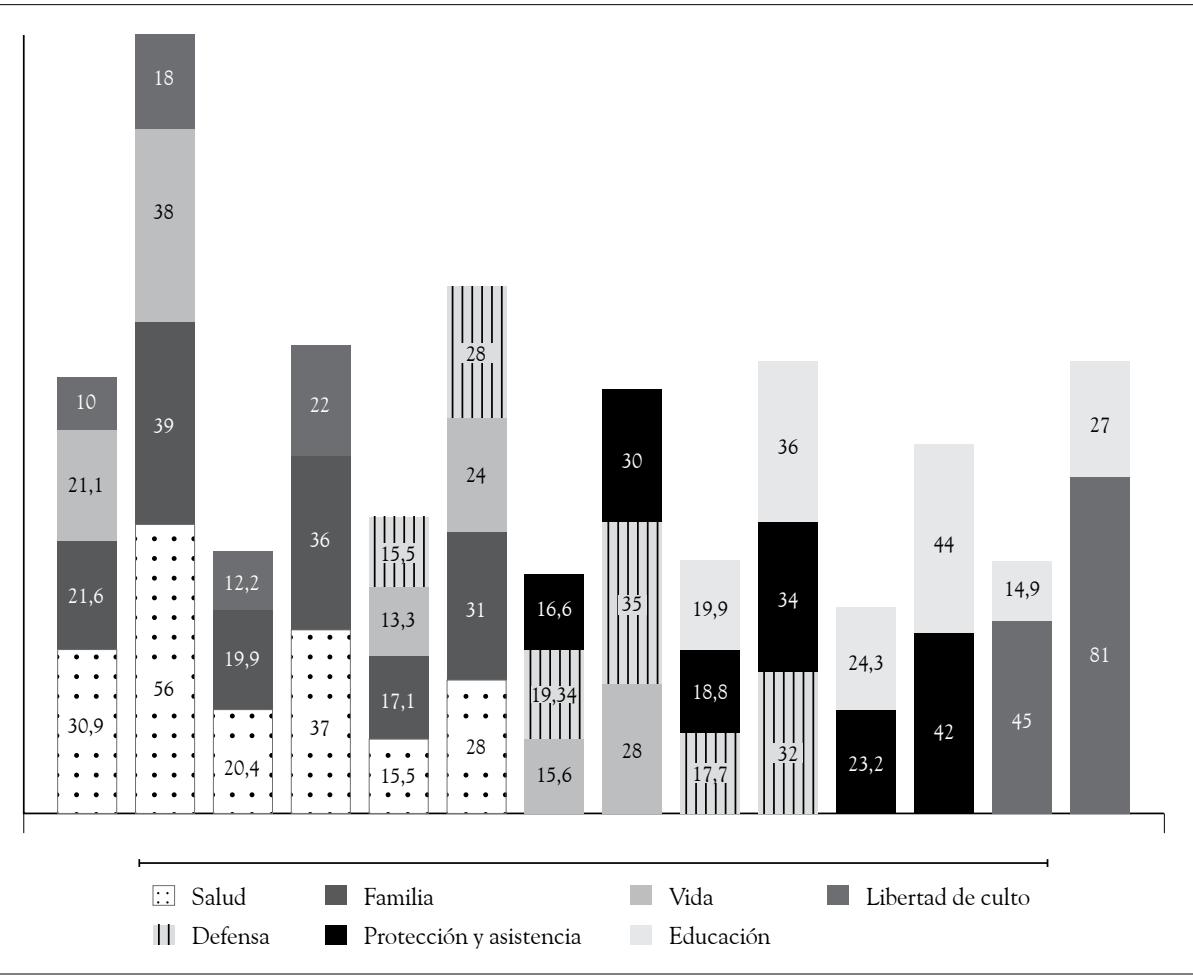

Fuente: grupos focales en los EPC visitados. Cálculo de los autores. 
El derecho que tiene una mayor importancia para los AMPL, con el $30,9 \%$, es el de la salud; seguido por el derecho a reunirse con la familia, con el 21,6 \%; el derecho a la vida, con el 21,1 \%, y el derecho a la libertad de culto, con el $10 \%$.

\section{El derecho a la atención en salud, el más vulnerado}

Durante los grupos focales salió a relucir, de forma repetitiva, la reclamación por la precaria o nula atención médica, categoría que se denominó como la prestación del servicio de salud, que, para el grupo de AMPL, se define como la dificultad para ser atendidos en sus dolencias relacionadas con la salud. Los problemas de salud son atribuidos, por los participantes, a factores como el hacinamiento, la mala alimentación y la falta de salubridad.

Al contrastar algunos estándares internacionales relacionados con este derecho con la percepción que tienen los AMPL, se encontró que una cosa es lo que se debería hacer, de acuerdo con las reglas mínimas para el tratamiento de los reclusos (Oficina del Alto Comisionado de las Naciones Unidas para los Derechos Humanos, 2002, pp. 172-187), y otra muy diferente es lo que mencionan los AMPL en los grupos focales (tabla 9).

Tabla 9. Estándares internacionales vs. opinión de los adultos mayores privados de la libertad

\begin{tabular}{|c|c|}
\hline Reglas mínimas para el tratamiento de los reclusos & Lo que manifiestan los AMPL \\
\hline $\begin{array}{l}\text { "El médico estará a cargo de velar por la salud } \\
\text { física y mental de los reclusos. Deberá visitar } \\
\text { diariamente a todos los reclusos enfermos, a } \\
\text { todos los que se quejen de estar enfermos y } \\
\text { a todos aquellos sobre los cuales se llame su } \\
\text { atención". }\end{array}$ & $\begin{array}{l}\text { "Aquí no hay ni servicio médico, aquí no } \\
\text { hay nada, va uno allí al puesto de salud, } \\
\text { a la enfermería y no hay una pasta que } \\
\text { le den a uno, le dan una fórmula y dura } \\
\text { por ahí tres cuatro meses que le den la } \\
\text { droga". }\end{array}$ \\
\hline $\begin{array}{l}\text { "El médico presentará un informe al director } \\
\text { cada vez que estime que la salud física o mental } \\
\text { de un recluso haya sido o pueda ser afectada } \\
\text { por la prolongación, o por una modalidad cual- } \\
\text { quiera de la reclusión". }\end{array}$ & $\begin{array}{l}\text { "Tengo } 74 \text { años cumplidos y yo sí me } \\
\text { siento mal, ya no oigo y ya no veo, aquí } \\
\text { me hicieron unos exámenes que para } \\
\text { darme gafas y firmamos la factura y esas } \\
\text { gafas nunca aparecieron”. }\end{array}$ \\
\hline
\end{tabular}




\begin{tabular}{|l|l|}
\hline Reglas mínimas para el tratamiento de los reclusos & Lo que manifiestan los AMPL \\
\hline "El médico hará inspecciones regulares y ase- & \\
sorará al director respecto a: & \\
a) la cantidad, calidad, preparación y distribu- & "Incluso aquí nos dan accesorios de aseo \\
ción de los alimentos; & cada 3 meses, y ahorita ya van 6 meses y \\
b) la higiene y el aseo de los establecimientos & nada, no nos dan es nada, ya hay mucha \\
y de los reclusos; & gente, mucho viejo". \\
c) las condiciones sanitarias; & \\
d) la calidad y el aseo de las ropas y de la cama & \\
de los reclusos". & \\
\hline
\end{tabular}

Fuente: grupos focales en los EPC visitados.

Es evidente que, a partir de los comentarios realizados, existe no solo una apreciación negativa en relación con la atención de la salud, sino también una incredulidad absoluta en cuanto al mismo sistema. Teniendo en cuenta las edades que en este grupo se representan, es claro que existe un riesgo mayor de adquirir problemas de salud. Asimismo, la omisión en la atención a la salud puede desencadenar casos que conduzcan a una discapacidad, lo que haría que no solo se reforzara el estatus de un sujeto como miembro de un grupo de especial protección constitucional, como lo es una persona AMPL, sino que además ahora se encontraría en condición de discapacidad, lo que aumentaría su vulnerabilidad.

Resulta interesante observar que el manejo de los aspectos de la salud, para los AMPL, se encuentra íntimamente relacionado con el trato digno que requiere la persona: "Refiriéndonos al aspecto carcelario, ya nosotros de avanzada edad, nos afecta la bulla, algunos alimentos, ciertas anomalías que no están en el círculo de nosotros, pero yo diría que si hablamos de la población a nivel nacional, claro, los niños deben tener un trato especial, su atención si hay un abandono de la niñez [...]" (grupo focal, Coiba Ibagué, junio de 2013). La dignidad es una categoría transversal a la atención en salud, así como a la no discriminación e igualdad; se puede afirmar, única y exclusivamente bajo el contexto de la presente investigación, que el trato no digno de la PPL está relacionado con una falencia en el enfoque diferencial. 


\section{Incredulidad ante el sistema judicial, la normatividad}

Teniendo en cuenta las vivencias en la privación de la libertad, llama la atención la reflexión que "internamente" se tiene con respecto a las normas y la justicia, siendo más relevante en la medida en que estas son herramientas de defensa. Los AMPL ven las normas, los derechos y el sistema en general como un ente administrativo que genera desconfianza y cuyos componentes fallan: "Hoy el sistema carcelario tiende a hacerse en ocasiones muy oportunista con relación a si la persona condenada tiene dinero, si está en disposición de colaborar con la justicia, de un poco de cosas que entre otras podrían llevar a una discriminación" (grupo focal, Coiba Ibagué, junio de 2013).

\section{Discriminación y no igualdad}

Junto con lo mencionado anteriormente, los AMPL consideran que no tienen las mismas oportunidades que otras personas que se encuentran en igual condición: "Que sea un trato más digno, más humano porque debe haber igualdad para todos, entonces, ¿qué sucede?, que nos quieren tratar lo mismo que a un muchacho, somos seres humanos y todos somos iguales, pero ya uno viejo merece el trato digno para la tercera edad" (grupo focal, Coiba Ibagué, junio de 2013). La no discriminación y el trato diferencial que deberían tener los AMPL se acentúan, categóricamente, en las condiciones de vida, que sin lugar a dudas exigen una respuesta necesaria, adecuada y proporcional a esta población, considerando aspectos de infraestructura, limitaciones físicas y condiciones psicológicas, que involucren personal especializado en el manejo de la edad geriátrica.

\section{Condiciones de vida}

Analizar condiciones de calidad o estándares de vida para una población es un asunto complejo, pero de gran importancia, pues se procura mejorar 
su forma de vivir, independientemente de la situación por la que esté pasando. Las diferentes perspectivas sobre las condiciones de vida responden al esfuerzo teórico de diversos autores, que explican el mejoramiento o empeoramiento de estas, basados en su entendimiento. Así, por ejemplo, la perspectiva de la libertad humana, vista como la última meta de la vida económica y como el medio más eficiente para lograr el bienestar (Sen, 1998), plantea que el mejoramiento en las condiciones de vida se debe entender como el conjunto de todas aquellas características materiales o no que facilitan tener determinado tipo de vida. Bajo esa perspectiva, las diferentes acciones que se emprenden deberían apuntar a mejorar tanto las características materiales como las que no lo son.

El mejorar las condiciones o el estándar de vida de las personas debe valorarse desde una perspectiva que involucra aspectos como el contexto o el ambiente donde se encuentran las personas, y aspectos sobre el modo de vida en sí mismo en ese entorno. Diversos estudios plantean formas de asumir las condiciones de vida, pero se pueden sintetizar desde dos perspectivas plurales: la competitiva y la constitutiva (Casas et al., 2001). La primera perspectiva privilegia el logro de condiciones personales sobre las demás, por lo tanto, cualquier medición de estándar de vida es entendida desde una visual utilitarista de bienestar como una elección de la persona según los satisfactores a sus deseos; por ello, el estándar lo establece el sujeto de acuerdo con sus satisfactores de bienestar en su vida. Esta perspectiva no resulta práctica para los AMPL porque el logro de los satisfactores se encuentra predeterminado por las oportunidades de decisión que tiene una persona en libertad, al poder elegir las condiciones o estándar de vida que desea tener.

Por otra parte, las condiciones de medición del estándar de vida, que es asumido para los AMPL, se toman desde la perspectiva constitutiva (Bliss, 1996; Seabright, 1996; Gamboa et al., 2000), que se caracteriza por establecer factores o variables que se han adaptado a las situaciones que están viviendo los AMPL, y que pueden simplificarse para un mejor entendimiento, en condiciones relacionadas con el capital físico y el capital humano.

Los profesionales y los directivos de la Subdirección de Tratamiento y Desarrollo-División de Desarrollo Social, hoy Subdirección de Reinserción Social-Grupo de Desarrollo Humano, con el fin de asumir una 
posición científica frente al contexto penitenciario, que tuviera en cuenta los factores criminológicos y penitenciarios, plantearon y desarrollaron la investigación Caracterización y perfilación criminológica y penitenciaria de la población condenada y privada de la libertad en los EPC del Inpec y propuesta para el direccionamiento del tratamiento penitenciario en Colombia, con el fin de conocer directamente la población condenada, caracterizarla, establecer los perfiles criminológicos y penitenciarios, y así proponer lineamientos en el diseño de programas de atención e intervención penitenciaria, teniendo en cuenta la perspectiva de género, los tipos de internos, así como también los tipos delictivos (Inpec \& Ministerio del Interior y de Justicia, 2011).

A partir de esta caracterización, se evidenció que la población AMPL debía tenerse en cuenta en el momento de formular un trato diferencial, acorde con las necesidades, el tratamiento y el proyecto de vida de estas personas, porque la pena no puede privar al ser humano de tener un crecimiento integral, a fin de desarrollarse dentro del mismo centro y estar preparado para salir.

Por ello, antes de establecer la características agrupadas en los tipos de capital mencionados, se plantea que la falta de condiciones adecuadas que fortalezcan a esta población hace que aumente, potencialmente, la probabilidad de discriminación; esto es más grave en las mujeres adultas mayores, pues la teoría económica y las políticas públicas prácticamente las omiten (Huenchuan, 2010) y, por esto, se plantea dentro de las condiciones de vida la discriminación en los AMPL como parte de estas políticas.

\section{Discriminación en la población de adultos mayores privados de la libertad}

La discriminación puede observarse desde diferentes definiciones que permiten entender argumentos que orientan de forma conceptual la manera como se puede evidenciar lo encontrado en la población de AM, y facilitan ver la efectividad de la política que se aplica en estas circunstancias.

Usualmente, cuando se habla de discriminación, esta se observa desde una perspectiva jurídica relacionada con la igualdad, entendida ante la 
ley como el "principio que reconoce a todos los ciudadanos la capacidad para los mismos derechos" (Real Academia Española, 2001), por lo que se podría pensar que todo lo que no cumpla esa igualdad, es un acto de discriminación, que requeriría un trato preferencial y una exigencia a la no discriminación, independientemente de la normatividad que lo acompañe. Sin embargo, el concepto de discriminación evidencia diversos sentidos e intenciones.

Desde el sentido léxico, el verbo discriminar no tiene una equivalencia negativa, debido a que se refiere a "separar, distinguir, diferenciar una cosa de otra" (Real Academia Española, 2001); por ello, discriminar no tendría valoración alguna de rechazo, sencillamente se discrimina cuando se distingue una cosa de otra, y esto es vital para la vida humana, tanto así que desde el preescolar, se enseña a discriminar por colores, tamaños, formas, etc., sin que se considere que una cosa es superior a otra, mucho menos se desprecia esa acción; al contrario, se valora que se pueda discriminar de forma correcta, como parte necesaria del proceso de aprendizaje. Es importante señalar este aspecto porque se utiliza la palabra discriminar como un elemento humillante, para argumentar acciones u omisiones sin ningún fundamento axiológico.

Sin embargo, también desde el léxico, el mismo diccionario da una definición con componentes sociales, al decir que discriminar es "dar trato de inferioridad a una persona o colectividad por motivos raciales, religiosos, políticos, etc." (Real Academia Española, 2001); esta es la definición más común en nuestra sociedad, en la que se le da un sentido valorativo a lo que es superior e inferior, y cuando una persona se encuentra en la segunda condición, es discriminada y estigmatizada por las características que no resultan interesantes para quien discrimina. Esa concepción y uso del término oculta el verdadero valor que se le da a una persona o población, y genera una conducta moral sobre ella con una valoración cultural.

Así, por ejemplo, una persona por su edad, AM, puede ser juzgada por una sociedad, que se basa en los prejuicios o estigmas que se tienen frente a ella, lo que implica que se da un valor humano menor a quien es juzgado, y se le niegan intencionalmente -aunque puede no ser explícitamente-derechos fundamentales, bien sea porque no se le permite directamente acceder 
a ellos o porque se generan mecanismos o acciones que indirectamente se lo impiden. Para subsanar esto, se busca "adoptar" medidas que protejan a estas personas; para ello, se formulan leyes y políticas públicas que impulsen la no discriminación (Rodríguez Zepeda, 2006) ${ }^{2}$ de esta población con condiciones excepcionales. ${ }^{3}$

Dentro de esas políticas de no discriminación, el Inpec cuenta con un Programa de Integración Social de Grupos con Condiciones Excepcionales donde se busca, entre otras cosas, "poner en conocimiento de las instancias competentes dentro del EPC, las solicitudes hechas por los(as) internos(as) Adultos(as) Mayores, en relación con posibles factores de riesgo de tipo físico, psicológico o social que afecten su adecuado desenvolvimiento en las actividades cotidianas, a fin de que se tomen las medidas correspondientes" (Inpec, 2012). Esas actividades cotidianas se encuentran asociadas a las capacidades físicas y mentales, las cuales se suelen relacionar, de manera común, con la disminución, debido al proceso de envejecimiento.

2 Dentro de las diferentes concepciones generales de lo que es "discriminación" y lo que es "no discriminación", Jesús Rodríguez Zepeda menciona que "la discriminación es una conducta, culturalmente fundada, y sistemática y socialmente extendida, de desprecio contra una persona o grupo de personas sobre la base de un prejuicio negativo o un estigma relacionado con una desventaja inmerecida, y que tiene por efecto (intencional o no) dañar sus derechos y libertades fundamentales" (2006) y que "la no discriminación es el derecho de toda persona a ser tratada de manera homogénea, sin exclusión, distinción o restricción arbitraria, de tal modo que se le haga posible el aprovechamiento de sus derechos y libertades fundamentales y el libre acceso a las oportunidades socialmente disponibles" (Rodríguez Zepeda, 2006). Asimismo, desde una lógica argumental del principio rawlsiano, se fundamenta la no discriminación como: "el derecho de toda persona a ser tratada de manera homogénea sin exclusión, distinción o restricción arbitraria, de tal modo que se le haga posible el aprovechamiento de sus derechos y libertades fundamentales y el libre acceso a las oportunidades socialmente disponibles; siempre y cuando un tratamiento preferencial temporal hacia ella o hacia su grupo de adscripción no sea necesario para reponer o compensar el daño histórico y la situación de debilidad y vulnerabilidad actuales causada por prácticas discriminatorias previas contra su grupo" (Rodríguez Zepeda, 2006).

3 La Constitución Política de Colombia de 1991, en su artículo 46, previendo lo que podría ocurrir con esta población, señala que: "El Estado, la sociedad y la familia concurrirán para la protección y la asistencia de las personas de la tercera edad y promoverán su integración a la vida activa y comunitaria. El Estado les garantizará los servicios de la seguridad social integral y el subsidio alimentario en caso de indigencia”. Basado en ese mismo artículo, se realiza una legislación que busca garantizar al adulto mayor el pleno ejercicio de sus derechos. Cfr. la Ley 1251 de 2008. Dentro de esa ley se menciona, en su artículo $4^{\circ}$ como principio rector la no discriminación, entendida como la "supresión de todo trato discriminatorio en razón de la raza, la edad, el sexo, la condición económica o la discapacidad (cursivas de los autores). 
Desde el escenario económico, las capacidades físicas y mentales se asocian a la capacidad productiva de un individuo. Al considerarse de manera generalizada que la persona que llega a ser $\mathrm{AM}^{4}$ se ve disminuida por el proceso de envejecimiento, esto hace que sufra de un trato diferenciado, lo que, a la luz de lo esbozado, se referiría a la discriminación, que es planteada, desde la economía, cuando una de dos personas con la misma capacidad productiva, pero que difieren por alguna característica personal (en este caso, la edad), recibe un trato inferior en cuanto a las posibilidades de acceder al empleo o la educación. Esa discriminación, usualmente, se da más por género, hay un desbalance entre hombres y mujeres, pero también por edad, por estrato o por niveles educativos; la sumatoria de todo lo anterior agudiza, aún más, la discriminación.

$\mathrm{Si}$ a ese escenario se le adiciona otro factor, el estar recluido en un EPC en diversas condiciones, la discriminación tiende a aumentar. Desde la economía se han desarrollado diversas teorías para tratar de explicar los tratos diferenciales, especialmente a nivel laboral, que no se justifican por la capacidad productiva, sino por características personales. Siendo este el caso, la discriminación se estudió, con el fin de evidenciarla, de diversas maneras en el trabajo de campo por el equipo investigador, y se llegó a una clasificación que, independientemente de la tipología, resulta importante mencionarla, debido a que la discriminación genera pérdidas tanto económicas como sociales, y reduce sustancialmente las posibilidades de desarrollo de las personas y, sobre todo, el mejoramiento del SPCC. Los tipos de discriminación observados y analizados fueron:

a) Discriminación por género: de acuerdo con este tipo de discriminación, las desigualdades no siempre se dan por diferentes niveles de productividad; aun cuando se tienen los mismos niveles, los hombres ganan mayores beneficios que las mujeres. A nivel teórico, esto se conoce como el modelo de poder de mercado (Robison,

4 La definición de adulto mayor es la tomada de la Ley 1276 de 2009, que en su artículo $7^{\circ}$, literal b), dice que: "Adulto Mayor. Es aquella persona que cuenta con sesenta (60) años de edad o más. A criterio de los especialistas de los centros vida, una persona podrá ser clasificada dentro de este rango, siendo menor de 60 años y mayor de 55 , cuando sus condiciones de desgaste físico, vital y psicológico así lo determinen" (cursivas de los autores). 
1965), donde se plantea que aunque los dos géneros pueden tener capacidades productivas, se supone que los hombres tienen mayor movilidad geográfica que las mujeres; en otras palabras, los hombres ven menos inconvenientes que las mujeres a desplazarse hacia otro sitio con mejores oportunidades. Asimismo, las mujeres tienen menor posibilidad de asociación en grupos de poder de negociación (ejemplo: sindicatos) que los hombres, lo que hace que sean controladas más fácilmente.

En cuanto a esta discriminación en los EPC visitados, esta no resulta evidente, no porque no exista como tal, sino porque la mayor parte de la población carcelaria es masculina; ${ }^{5}$ existen establecimientos especiales para mujeres, lo que evita una competencia por género relacionada directamente con ello (tabla 10).

Tabla 10. Población reclusa por género en Colombia

\begin{tabular}{|c|c|c|c|}
\hline \multirow{2}{*}{ Regional } & \multirow{2}{*}{ Población } & \multicolumn{2}{|c|}{ Género } \\
\hline & & Masculino & Femenino \\
\hline Central & 37.593 & 34.572 & 3.021 \\
\hline Occidental & 23.986 & 22.106 & 1.880 \\
\hline Norte & 13.338 & 12.899 & 439 \\
\hline Oriente & 12.470 & 11.530 & 840 \\
\hline Noreste & 15.918 & 14.536 & 1382 \\
\hline Viejo Caldas & 14.896 & 13.513 & 1383 \\
\hline Total & 118.201 & 109.158 & 9245 \\
\hline
\end{tabular}

Fuente: Sisipec Web, julio de 2013.

Lo anterior se apoya teóricamente (Blau et al., 1998) y se refuerza con la evidencia, que es casi inexistente, de la discriminación por género (masculino, femenino) en los EPC, al encontrar ocupaciones aplicables en sitios específicos, es decir, al existir división de establecimientos por género, las ocupaciones también se encuen-

5 De acuerdo con el Inpec, a julio de 2013, el 92,3\% de la población carcelaria estaba constituida por hombres, mientras que el 7,7\%, por mujeres (Inpec, 2013, p. 13). 
tran divididas, por lo que hay oportunidades para ambos géneros. Sin embargo, en el ámbito social, el hecho de que más del 92\% sean hombres -proporción similar con los AMPL-, genera una dificultad en las unidades familiares porque se generan menores posibilidades de ingreso y una disminución de la calidad de vida. Socialmente, el impacto familiar es diferente cuando termina en la cárcel un hombre y no una mujer.

b) Discriminación por edad: los AM, al pasar de la actividad económica a la aparente inactividad, se encuentran con barreras por su edad, lo que hace que estas personas tengan largos periodos sin actividad o tengan que ocuparse en aquellas labores que el resto de la población no desea realizar.

Al respecto, se evidencia aún más la discriminación hacia los AMPL, incluso cuando el mismo Inpec censa a esa población por debajo de lo que establecen los organismos internacionales y la propia legislación colombiana, ${ }^{6}$ lo que refleja la desocupación y la difícil entrada a los programas tanto educativos como laborales que sufre esta población; esto disminuye la productividad potencial entre 10 y 7 años antes de lo previsto, y se desperdician las capacidades que estas personas pueden tener por su experiencia. Curiosamente, este retroceso en el cálculo de la edad se da cuando la esperanza de vida estimada en Colombia va en aumento (Banco Mundial, 2013), y llega a los 74 años de edad. En varios establecimientos, pero no es la generalidad, existen AMPL con cierto grado de conocimientos y experiencias, y que sienten el

6 Aunque la definición de adulto mayor la reconoce el mismo Inpec en su documento Pautas Programas Grupo Desarrollo Humano 2012 (2012, p. 24), y menciona que se encuentra establecida en la Ley 65 de 1993, artículo 29; el informe de la Segunda Asamblea Mundial sobre Envejecimiento, de abril de 2002; la Política Nacional de Envejecimiento y Vejez 2007-2019 (2007), Ministerio Protección Social; la Declaración de Brasilia, Naciones Unidas, 2007; la Ley 1251 de 1996, que establece el 7 de marzo como el Día Nacional de las Personas de la Tercera Edad; la Ley 1251 del 27 de noviembre de 2008, por la cual se dictan normas tendientes a la protección y defensa de los derechos de los AM, toda esta legislación menciona que AM es aquella persona que cuenta con sesenta (60) años de edad o más; el Inpec en su propio censo modificó la edad para hombres, los reconoce como AM cuando tienen 53 años o más, y las mujeres cuando tienen 50 años o más (cursivas de los autores). 
efecto discriminatorio por su edad; esta discriminación los hace no productivos dentro de los propios EPC cuando afuera, probablemente, sí lo eran:

¿Qué hace uno acá estando encerrado todo el tiempo comiendo y durmiendo? Y uno sin trabajo...Yo por ejemplo a mi edad son setenta y pico de años pero yo todavía trabajo, que me permitan pasar materiales para trabajar la odontología o la farmacia o la medicina para ver enfermos, que en realidad uno si se ha especializado en ver en enfermos porque mi estudio fue práctica en los hospitales, yo atendía ortopedia, neurocirugía y órganos. Tres salones y estudié mucho la medicina, tengo buena vocación para ver a los enfermos pero acá estamos amarrados porque no tenemos derecho de nada. (Grupo focal, EPMSC, Bucaramanga (ERE), julio de 2013)

Al respecto, la desocupación de los AM que no están en EPC en sí ya es un fenómeno importante, que viene en aumento y se refleja con total claridad cuando están en la cárcel.

c) Discriminación de costo psíquico: la discriminación como preferencia o gusto (Becker, 1957) se conoce como el modelo del gusto por la discriminación, y plantea que a cierto grupo de personas se les hace difícil tolerar la presencia de otras con características diferentes a las propias, por lo que ejercen sobre ellas una especie de "costo psíquico" que se traduce en discriminación realizada por gusto. En los EPC existe un estigma marcado de los AM, de forma generalizada; la mayoría son distinguidos como los "violos"; cuanto mayor es la discriminación, mayor es el aislamiento que se genera en la población. Sin embargo, como lo plantea Arrow (1972), el gusto por la discriminación depende de cómo se encuentra compuesto un lugar. En relación con este aspecto, se observó mayor discriminación en aquellos EPC donde no existía una diferenciación de la población, ni se contaba con pabellones especiales - sin afirmar que la existencia de pabellones especiales para los AMPL en los EPC evita la discriminación porque, como sugieren Marshall (1974) y 
Thurow (1975), la "aversión" hacia cierta clase de personas puede depender más de una "distancia social" y no de una "distancia física"; el estigma generado hacia esta población hace que con pabellón especial o sin él esta sea discriminada.

d) Discriminación estadística: partiendo de la teoría asociada a la discriminación estadística (Phelps, 1973), se evidencia que los programas de integración social de grupos en condiciones excepcionales, incluyendo los relacionados con los AMPL, toman como punto de referencia las características promedio de los distintos grupos y no las individuales, lo cual, hasta cierto punto, tiene lógica; al contar con escasa información sobre las habilidades de cada individuo, es más práctico (o al menos eso se cree) tener un grupo promedio sobre el cual se prefiere asumir el riesgo de generar programas sobre condiciones especiales. De acuerdo con el Inpec (2013), el $8,6 \%$ de los internos del país pertenecen a la población reclusa en condiciones excepcionales, de ellos, el 28,5\% corresponden a la tercera edad (tabla 11).

Tabla 11. Población reclusa en condiciones excepcionales

\begin{tabular}{|l|r|r|r|r|r|r|r|r|r|}
\hline \multicolumn{1}{|c|}{ Regional } & $\begin{array}{c}\text { Indí- } \\
\text { genes }\end{array}$ & $\begin{array}{c}\text { Afroco- } \\
\text { lombianos }\end{array}$ & $\begin{array}{c}\text { Extran- } \\
\text { jeros }\end{array}$ & $\begin{array}{c}\text { Tercera } \\
\text { edad }\end{array}$ & $\begin{array}{c}\text { Madres } \\
\text { lactantes }\end{array}$ & $\begin{array}{c}\text { Madres } \\
\text { gestantes }\end{array}$ & $\begin{array}{c}\text { Discapa- } \\
\text { citados }\end{array}$ & $\begin{array}{c}\text { Inimpu- } \\
\text { tados }\end{array}$ & Total \\
\hline Central & 201 & 573 & 408 & 1080 & 12 & 53 & 253 & 5 & 2585 \\
\hline Occidente & 502 & 2412 & 140 & 554 & 13 & 18 & 187 & 10 & 3836 \\
\hline Norte & 121 & 152 & 108 & 248 & 2 & 12 & 69 & 5 & 717 \\
\hline Oriente & 20 & 167 & 123 & 323 & 0 & 12 & 136 & 6 & 787 \\
\hline Noroeste & 51 & 733 & 55 & 310 & 2 & 19 & 172 & 2 & 1344 \\
\hline Viejo Caldas & 118 & 233 & 35 & 390 & 3 & 19 & 132 & 1 & 931 \\
\hline Total & 1013 & 4270 & 869 & 2905 & 32 & 133 & 949 & 29 & 10.200 \\
\hline
\end{tabular}

Fuente: Sisipec Web, julio de 2013.

Sin embargo, al tomar estrictamente la edad cronológica, que legalmente se encuentra establecida en la definición de AM, es decir 60 años, se encuentra que a julio de 2013, el total de AMPL era de 1719 internos, distribuidos como se muestra en la tabla 12. 
Tabla 12. Población de adultos mayores privados de libertad

\begin{tabular}{|l|c|c|c|}
\hline \multicolumn{1}{|c|}{ Regional } & Mujeres & Hombres & Total \\
\hline Central & 15 & 661 & 676 \\
\hline Occidente & 15 & 267 & 282 \\
\hline Norte & 11 & 181 & 192 \\
\hline Oriente & 10 & 202 & 212 \\
\hline Noroeste & 11 & 197 & 208 \\
\hline Viejo Caldas & 19 & 130 & 149 \\
\hline Total & 81 & 1638 & 1719 \\
\hline
\end{tabular}

Fuente: Sisipec Web, censo de condiciones excepcionales, 31 de julio de 2013. Cálculos de los autores.

Con base en ello, se tendría que el 1,45 \% del total de la población de los EPC estaría ocupado por AM, con edad igual o superior a los 60 años. Por otra parte, el ser extranjero y AM podría aumentar una condición que genera un sesgo discriminatorio adicional; aunque son pocos los casos encontrados, resulta importante referenciar los 10 casos en hombres (figura 12).

Figura 12. Población de adultos mayores privados de la libertad extranjeros

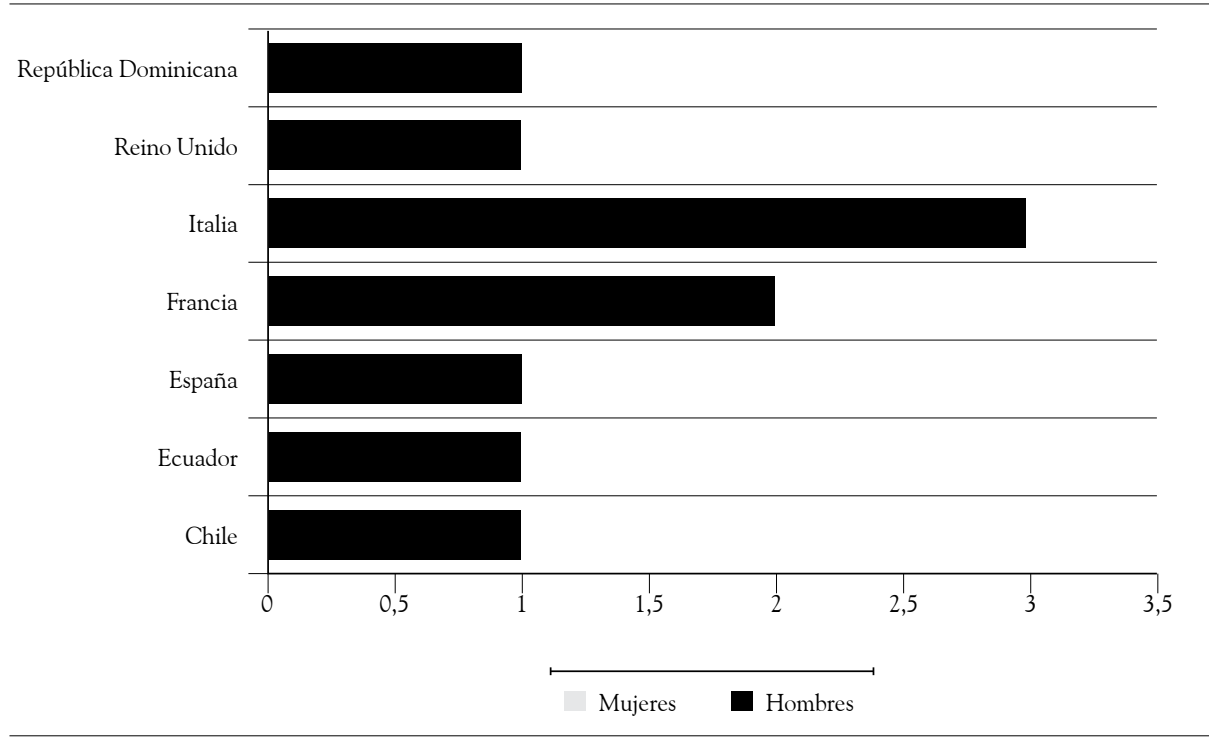

Fuente: Sisipec Web, 31 de julio de 2013. Cálculos de los autores. 
Aunque es posible que el Inpec se equivoque al no diferenciar la población de manera individualizada ni asumir su edad establecida, sino tomarla por promedios comunes, esta discriminación estadística lo beneficia y también a los EPC debido a que conocer la información más específica, como saber cuántos AMPL son personas con discapacidad y afrocolombianos e imputables, demandaría grandes recursos que el Instituto no posee; por lo que considerar características promedio observadas en la población demanda menos recursos e implica un menor riesgo en el momento de realizar programas de integración social, sin que deje de existir cierto grado de incertidumbre sobre lo que se puede y se debe hacer, y realmente sobre lo que se hace con cada población en condiciones excepcionales.

e) Discriminación ocupacional: junto con lo anterior, existe una teoría relacionada en cierta forma con la discriminación estadística y es el modelo de la concentración: la segregación ocupacional (Bergmann, 1974), donde se evidencia que al existir cierto grupo de personas limitadas por características estadísticas, se reduce el número de ocupaciones que estas personas pueden llegar a realizar, lo que induce a que los tomadores de decisiones -pueden ser los mismos directores de los EPC- las aparten o segreguen de distintas actividades, considerando, sin razón o con ella, que estos grupos pueden tener una productividad menor que la de otros internos. Básicamente, la conclusión de esta teoría (al realizar su aplicación en la población excepcional, de forma general) es que los internos que no se encuentran dentro de la población con condiciones excepcionales reciben mejores condiciones ocupacionales, lo que limita el campo de acción de las poblaciones excepcionales, sobre todo de los AMPL.

Si se eliminara el concepto de poblaciones con condiciones excepcionales, la discriminación a nivel ocupacional desaparecería, por lo que los AMPL se beneficiarían de las mismas ocupaciones que los demás internos. Se supone que estas poblaciones actualmente tienen acceso a las mismas ocupaciones, pero en realidad esto no 
es cierto; cuando no se es parte de estas, el beneficio para acceder a ellas resulta mejor, "uno ya mayor de 65 años... la cárcel es para los pobres que no tenemos plata y los que no tenemos estudio y que no podemos pagar, porque los grandes de cuello blanco, ellos sí tienen todos los beneficios y tienen todo a la perfección y el pobre campesino sobre todo que no tiene recursos de ninguna clase, a ese sí le va mal, le toca luchársela para que lo pongan a hacer algo" (grupo focal, EPMSC Acacias, junio de 2013). La asignación ocupacional en los EPC es selectiva; de acuerdo con los datos del Inpec (2013), el 66,68\% del total de la población reclusa se encuentra en trabajo, estudio y enseñanza, incluyendo a hombres y mujeres.

Teniendo en cuenta que del total de la población reclusa a julio de 2013, el 2,45\% corresponde a AM, y suponiendo que en el mismo porcentaje esa población tiene acceso a las diferentes ocupaciones, se podría concluir que cerca de 1931 internos estarían ocupados, siendo más notable esto en las mujeres que en los hombres; sin embargo, si esto fuera cierto, se estaría afirmando que el 95,93\% de la población condenada accede a trabajo, estudio y enseñanza, algo que normalmente no se puede presentar por la misma capacidad que tienen los EPC en el país (tabla 13).

Tabla 13. Población reclusa en trabajo, estudio y enseñanza

\begin{tabular}{|l|r|r|r|r|r|r|r|r|r|}
\hline \multirow{2}{*}{ Regionales } & \multicolumn{2}{|c|}{ Trabajo } & \multicolumn{2}{|c|}{ Estudio } & \multicolumn{2}{|c|}{ Enseñanza } & $\begin{array}{c}\text { Total } \\
\text { hombre }\end{array}$ & $\begin{array}{c}\text { Total } \\
\text { mujer }\end{array}$ & $\begin{array}{c}\text { Total } \\
\text { TEE }\end{array}$ \\
\cline { 2 - 10 } Combre & Mujer & Hombre & Mujer & Hombre & Mujer & & \\
\hline Central & 12.825 & 806 & 13.796 & 1216 & 542 & 45 & 27.163 & 2067 & 29.320 \\
\hline Occidente & 5728 & 666 & 6751 & 702 & 209 & 20 & 12.688 & 1388 & 14.076 \\
\hline Norte & 3016 & 175 & 3845 & 95 & 165 & 7 & 7026 & 277 & 7303 \\
\hline Oriente & 3575 & 489 & 4104 & 365 & 122 & 33 & 7801 & 887 & 8688 \\
\hline Noroeste & 3039 & 426 & 4415 & 504 & 128 & 16 & 7582 & 946 & 8528 \\
\hline Viejo Caldas & 4402 & 460 & 5187 & 777 & 151 & 23 & 9740 & 1260 & 11.000 \\
\hline Total & 32.585 & 3022 & 38.098 & 3659 & 1317 & 144 & 72.000 & 6825 & 78.825 \\
\hline
\end{tabular}


Indudablemente, una de las principales causas del problema de la desocupación de la población carcelaria ha sido el rápido crecimiento de internos en las cárceles; solo durante el último año hubo un incremento cercano al 7\%, se pasó de 111.005 (julio de 2012) a 118.201 (julio de 2013); en promedio, cada día ingresaron 20 personas a los EPC. Por lógica, solo este fenómeno tiene un impacto sobre las oportunidades de acceder a las actividades ocupacionales; la entrada de nuevos internos, bajo la misma capacidad de recursos con los que cuentan los EPC para atender a la población, disminuye significativamente la posibilidad ocupacional, principalmente de una población excepcional, como son los AMPL, cuyas posibilidades de libertad son casi inexistentes, y como las actividades ocupacionales apuntan a una resocialización para una probable salida, al ser ese escenario bajo, desestimula tanto a los internos como a los EPC en invertir recursos en esta población.

f) Discriminación de elegibilidad para la inversión en capital humano: teniendo presente lo mencionado sobre los tipos de discriminación y las diferentes teorías que se han desarrollado al respecto, es importante mencionar que elegir invertir en los AMPL termina siendo un asunto de eficiencia económica.

Para el Inpec, destinar recursos a una población que representa menos del $3 \%$ del total de la población reclusa, que cuenta con escasas posibilidades de resocialización y que por su edad productiva, económicamente hablando, no tiene probabilidades de volver al mercado laboral, lastimosamente, no es eficiente, al ser una inversión en capital humano que no posee un retorno, sin que el riesgo sea alto, y al serlo, el costo termina siendo mayor. De igual manera, la eficiencia proviene del mismo grupo discriminado, los AMPL; frente a la situación a la que se hizo referencia, y al ser conscientes de que son víctimas directas de perjuicios, tradiciones sociales, desplazamientos por la edad, su desmotivación aumenta, lo que genera una disminución de su esfuerzo productivo; esto impone costos de mantenimiento mayores (por enfermedad física o psicológica) al SPCC y al Estado en su conjunto; ante ello, 
la reacción es aumentar la discriminación y deteriorar aún más las condiciones que se les pueden generar; se crea así un círculo vicioso donde el sistema discrimina por eficiencia, pero esa misma eficiencia hace que se creen brechas de bienestar y baja productividad en la destinación de los recursos, lo que genera mayores costos en el sistema.

Es indudable que otra situación de discriminación que se presenta sobre los AMPL es la deficiente distribución entre las ocupaciones en los diferentes EPC; al respecto, no existe unidad de criterio, sino que el acceso a la ocupación que permita el mejoramiento de capital humano en este o cualquier tipo de población está más determinado por los contactos, las influencias o la dirección de turno existente en el establecimiento, lo que implica que no en todos los EPC se valora la inversión en los AMPL de manera idónea, y se traduce en una pérdida de eficiencia.

Teniendo presente estos diferentes tipos de discriminación observados y analizados en el entorno de los EPC con los AMPL, a continuación se establecen las condiciones de vida que tiene esta población, mediante una valoración que se definió con información que fue corroborada en las visitas de campo y que consideró ciertas características o factores de condiciones de vida que se agruparon en dos tipos de capital: capital físico y capital humano, los cuales se evaluaron desde su funcionamiento y capacidad en los EPC.

\section{Capital físico}

Las características físicas de los EPC explican ciertas variables que muestran los recursos y las condiciones de los internos; se aísla la percepción, que casi siempre es subjetiva, que ellos tienen y hay un sustento en la evidencia encontrada. El premio de paz Nelson Mandela dijo en su autobiografía: "Suele decirse que nadie conoce realmente cómo es una nación hasta haber estado en una de sus cárceles" (Mandela, 2010). El recorrido que hizo el grupo de 
investigadores en los diferentes EPC evidenció lo que es de conocimiento público y que comenzó con una prueba piloto en el establecimiento penitenciario La Modelo (grupo focal, EPMSC, La Modelo, mayo de 2013), aspecto que los mismos medios de comunicación han documentado (El Tiempo, 2013), y que se refiere a una nueva declaratoria de emergencia carcelaria decretada a finales del mes de mayo de 2013 por el gobierno Santos.

El primer factor analizado en los aspectos relacionados con el capital físico de los EPC tiene que ver con la capacidad de infraestructura que tiene el Inpec para atender a los internos que se encuentran a su cargo. A julio de 2013, los EPC tenían una capacidad para cubrir a 75.726 internos, la cual, frente al total de la población existente, conduce a un permanente desbordamiento. El SPCC cuenta con más internos que los cupos que físicamente posee (tabla 14).

Tabla 14. Capacidad de infraestructura en las direcciones regionales del Inpec

\begin{tabular}{|l|c|c|c|c|}
\hline \multicolumn{1}{|c|}{ Regional } & Departamentos & $\begin{array}{c}\text { Municipios que } \\
\text { agrupa }\end{array}$ & Cantidad ERON & $\begin{array}{c}\text { Capacidad } \\
\text { ERON }\end{array}$ \\
\hline Central & 8 & 39 & 42 & 28.481 \\
\hline Occidente & 4 & 23 & 24 & 14.414 \\
\hline Norte & 8 & 14 & 16 & 7180 \\
\hline Oriente & 4 & 13 & 14 & 7142 \\
\hline Noreste $^{*}$ & 2 & 21 & 21 & 8414 \\
\hline Viejo Caldas $^{* *}$ & 5 & 18 & 21 & 10.095 \\
\hline \multicolumn{2}{|r|}{ Total } & 128 & 138 & 75.726 \\
\hline
\end{tabular}

*Administrativamente, el establecimiento penitenciario de mediana seguridad y carcelario de Aguachica corresponde a la regional Oriente.

** Administrativamente, los establecimientos penitenciarios de mediana seguridad y carcelario de Puerto Boyacá (Boyacá), Armero-Guayabal, Fresno, Líbano y el Complejo de Picaleña (Tolima) están adscritos a la regional Viejo Caldas.

Fuente: Sisipec Web, julio de 2013.

Actualmente, existen 118.201 internos en el país, por lo que, frente a la capacidad física de los EPC, hay un hacinamiento del 56,1\%. El Observatorio de Seguridad Ciudadana de la Organización de los Estados Americanos (OEA) (2013) muestra que Colombia no ha logrado superar 
el número de espacios disponibles para atender a los internos recluidos en sus EPC, superando la capacidad en más de la mitad; la relación muestra que por cada 100 cupos que existen, hay en promedio 156 internos (figura 13). Una información preocupante que permite evidenciar la imposibilidad institucional por atender el exceso de demanda que prevalece, lo que hace que la situación sea estructural, sin tener novedades ni perspectivas de mejoramiento real.

Figura 13. Comportamiento del número de internos por cada 100 cupos

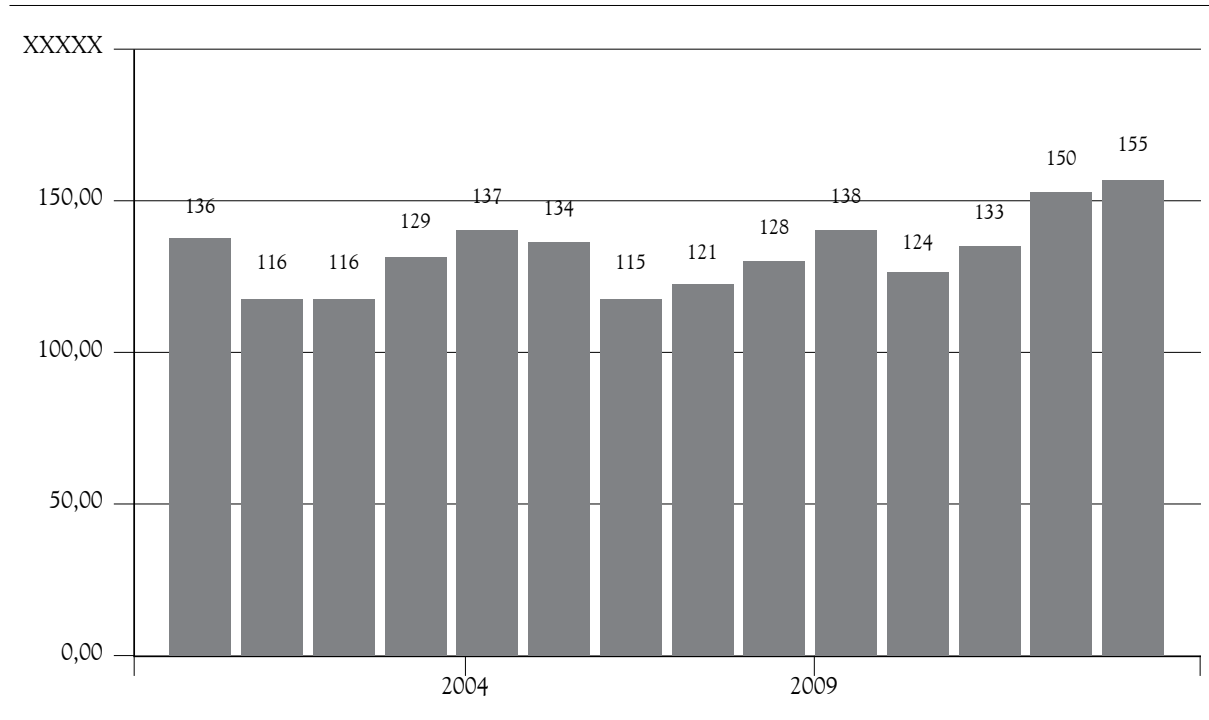

Fuente: Ministerio de Justicia y Derecho Instituto Nacional Penitenciario y Carcelario (Inpec). Departamento para la Prosperidad Social, Instituto Colombiano de Bienestar Familiar Cecilia de la Fuente de Lleras.

Cifras analizadas con anterioridad (Abaunza et al., 2011) evidencian la imposibilidad del Estado por otorgar una capacidad adecuada para la población existente en los EPC, lo que se suma a la precaria aplicación de justicia que existe en Colombia. El actual ministro de Justicia, Alfonso Gómez Méndez, ha mencionado la incapacidad estatal por hacer cumplir las propias normas que crea: "Como no cumplimos la ley entonces cambiémosla [...] Hemos caído no solo en el populismo punitivo si no que hemos padecido de otro mal que es el fetichismo normativo: creer que cambiando las normas se cambia la realidad" (Revista Semana, 2014). 
En el caso de los AMPL, la situación es aún más crítica porque dependiendo de los niveles de hacinamiento en cada EPC, deben ocupar el mismo espacio que los demás internos, sin tener ninguna diferencia por ser población en condiciones excepcionales, no porque el Inpec lo desee, sino porque la capacidad del establecimiento no lo permite. Uno de esos casos donde la situación es crítica es en el EPC de Medellín Bellavista, donde sus instalaciones fueron diseñadas con una capacidad para atender a 2424 personas y se encontraron 7500 internos, por lo que las cifras de hacinamiento son superiores al 200\%, lo cual se refleja en lo que los mismos AMPL manifiestan: "Dormimos en el suelo, imagínese doctor, unos durmiendo en los baños. Varias noches así, 80 y pico en un calabozo, es el colmo. Un día 9 nos tuvimos que tirar al baño", "iUstedes creen que es justo que haya un solo sanitario para todos los que aquí estamos?" (Grupo focal, EPMSC Medellín, Bellavista, julio de 2013). En este establecimiento no existe un pabellón exclusivo para los AMPL debido al mismo hacinamiento que se presenta; sería un ideal, pero físicamente es imposible.

Otros EPC que sufren problemas de hacinamiento han flexibilizado el uso de las instalaciones, dándoles cierta libertad a los internos, facilitando la movilidad en sus lugares de reclusión, haciendo que se perciban, por parte de los AMPL, condiciones diferentes, especialmente en los pabellones de mujeres: "Aquí nosotras tenemos las habitaciones, las celdas abiertas [...] Yo lo digo, tenemos muchos privilegios que en otras cárceles, porque yo estuve en el patio 12 y es muy bueno todo, lo que pasa es que como todo tiene sus cosas [...] hay internas de demasiada mala convivencia, como todo. Pero como le explicaba ahorita tenemos desayuno, almuerzo y comida gratis [...] aquí nos lavan la ropa, hasta lavandería nos tienen" (grupo focal de mujeres, Coped, Pedregral de Medellín, julio de 2013).

La situación de hacinamiento es más grave en la reclusión de hombres que en la de mujeres; en Coped se evidencia que aún no existe, de forma marcada, el problema de hacinamiento, pero no hay planes de contingencia para cuando esto ocurra. Independientemente del grado de hacinamiento que exista entre un establecimiento y otro, la situación real que sufren los EPC y la dotación con la que ellos cuentan, la gestión administrativa que se realiza es vital, y esta hace que pueda aumentar o disminuir la percepción de 
condiciones físicas del establecimiento. Así, por ejemplo, en Villahermosa la sensación del pabellón de AMPL es de estar en un hogar geriátrico, donde incluso no existen las celdas, sino que son puertas de madera donde se coloca el número de habitación y residen los internos; existe autorregulación en el uso de las instalaciones y la administración del mismo pabellón. Los mismos internos hablan de sus condiciones de vida en este sitio y describen un día allá así:

A las $5 \mathrm{a} . \mathrm{m}$. algunos se levantan a hacer ejercicios, a bañarnos, a esperar el desayuno a las 6:30 a. m. o 7:00 a. m. Otros se la pasan jugando billar, jugando parqués, dominó, otros se la pasan viendo televisión todo el día y no los levantan ni con una grúa jejeje... Pero hay algo mucho más importante y es que eso que quede registrado allí, en este patio, aquí no se cobra ni un peso al preso por nada, aquí llega el preso y tiene que hacer carrera para ocupar una celda, todos tienen esa opción así no tengo cinco centavos porque la gran mayoría es gente demasiado pobre, no es como otros patios donde son exclusivos de la gente de dinero, aquí la mayoría de gente no tienen recursos, pero viven en condiciones un poquito digámoslo entre comillas, un poquito más dignas, debido a que aquí no se les cobra cinco centavos, los que entre comillas administran el patio o internos de este patio donde está el presidente y estoy yo, no se les cobra cinco centavos a nadie por ni siquiera por hacerle un memorial, aquí la solidaridad es absoluta. (Grupo focal, EPAMSC Cali-ERE-, Villahermosa, julio de 2013)

Al tener en cuenta lo anterior, la percepción de las personas sobre la situación que afrontan en su diario vivir, frente a las condiciones físicas reales, está sujeta a tres factores que potencializan unas mejores o peores condiciones de vida de los AMPL. El primero de ellos consiste en tener un espacio físico exclusivo para este tipo de población. En los EPC donde esto ocurre, el trato entre iguales hace que se genere una dinámica homogénea, que difiere de donde deben estar compartiendo con personas de otras edades, sobre todo en el caso de los hombres. 
El segundo tiene que ver con la dotación de los EPC; al respecto, no hay diferencia alguna frente a otros pabellones; los AMPL, por sus condiciones físicas, requieren que las instalaciones se encuentren adecuadas a nivel de espacios, baños y demás, para que su salud no se deteriore aún más; sin embargo, en los EPC visitados, desafortunadamente, esto no ocurre, y mucho menos en los que carecen de pabellones especiales para esta población.

El tercer factor que involucra el capital físico del establecimiento es tener presente el padecimiento de alguna enfermedad (física o psicológica), lo que es fundamental para evaluar el estándar de vida de los AMPL; en la medida en que se presente una enfermedad, la infraestructura debe ser la adecuada para su atención, por el bienestar de quien la padece, pero también por los demás que pueden ser afectados directa o indirectamente.

Por todo lo mencionado, se puede concluir que el capital físico, como una condición de medición del estándar de vida, actualmente es un factor crítico que no solamente afecta a los AMPL -donde se agrava aún más-, sino que sigue siendo una falencia del SPCC, cuya solución no se observa en el corto ni en el mediano plazo, mientras este aspecto se continúe manejando con anuncios gubernamentales, cuya única visual sea la ampliación de cupos -algo necesario, pero nunca suficiente-, y se pierda la perspectiva humana; si no se reconoce con hechos que allí hay personas que, independientemente de la situación por la que están sindicadas o condenadas, deben mantener una mínimas condiciones físicas que les garanticen un estándar de vida, la privación de la libertad puede constituir una forma de tortura o un trato inhumano y degradante, ${ }^{7}$ como actualmente ocurre (Oficina del Alto Comisionado de las Naciones Unidas para los Derechos Humanos, 1996), y esta es aún más grave si se tiene presente que las deficientes condiciones físicas de los establecimientos con sobrepoblación en

7 La Declaración sobre Protección de Todas las Personas contra la Tortura y Otros Tratos o Penas Crueles, Inhumanos o Degradantes, adaptada por la Asamblea General de las Naciones Unidas en su resolución 3452 del 9 de diciembre de 1975, menciona en su artículo 2: "Todo acto de tortura u otro trato o pena cruel, inhumano o degradante constituye una ofensa a la dignidad humana y será condenado como violación de los propósitos de la Carta de las Naciones Unidas y de los derechos humanos y libertades fundamentales proclamados en la Declaración Universal de Derechos Humanos". 
lugar de disminuir, aumentan, ${ }^{8}$ a un ritmo mayor que lo hace la capacidad de los EPC; un ejemplo de ello se evidencia al observar el segundo semestre del 2013 (Inpec, 2014) (tabla 15).

Tabla 15. Capacidad, población, sobrepoblación y hacinamiento, segundo semestre de 2013

\begin{tabular}{|l|r|r|r|r|r|r|r|}
\hline \multicolumn{1}{|c|}{ Concepto } & \multicolumn{1}{c|}{ Julio } & \multicolumn{1}{c|}{ Agosto } & Septiembre & Octubre & Noviembre & Diciembre & $\begin{array}{r}\text { Promedio } \\
\text { mensual }\end{array}$ \\
\hline Capacidad & 75.726 & 75.726 & 75.895 & 75.895 & 75.895 & 76.066 & 75.867 \\
\hline Población & 118.201 & 118.478 & 119.350 & 120.038 & 120.310 & 120.032 & 119.402 \\
\hline Soprepoblación & 42.475 & 42.752 & 43.455 & 44.143 & 44.415 & 43.966 & 43.534 \\
\hline Hacinamiento & $56,1 \%$ & $56,5 \%$ & $57,3 \%$ & $58,2 \%$ & $58,5 \%$ & $57,8 \%$ & $57,4 \%$ \\
\hline
\end{tabular}

Fuente: Sisipec Web, diciembre de 2013.

Esta situación hace que las medidas que se toman ${ }^{9}$ reiteren el incumplimiento repetitivo de lo que internacionalmente se definió hace años en cuanto a los "locales destinados a los reclusos" (Oficina del Alto Comisionado de las Naciones Unidas para los Derechos Humanos, 1996-2012) en el Primer Congreso de las Naciones Unidas sobre Prevención del Delito y Tratamiento del Delincuente, celebrado en Ginebra en 1955, y aprobado por el Consejo Económico y Social en sus resoluciones 663C (XXIV) del 31 de julio de 1957 y 2076 (LXII) del 13 de mayo de 1977, donde se establecieron las reglas de aplicación general sobre las instalaciones:

1. Las celdas o cuartos destinados al aislamiento nocturno no deberán ser ocupados más que por un solo recluso. ${ }^{10} \mathrm{Si}$ por razones especiales,

8 En los EPC están ingresando en promedio 92 nuevos internos diariamente, 2760 internos mensuales, mientras que se le otorga libertad a 1000 cada mes; ese desbalance ayuda a que los niveles de hacinamiento sigan en aumento y comiencen a llegar al 60\% (El Tiempo, 2013).

9 La última medida tomada recientemente por el Gobierno fue la aprobación de la Ley 1709 de 201; al respecto: "La suspensión de la pena es una de las medidas contra el hacinamiento, prevista en el nuevo Código Penitenciario [...] Los presos están hacinados en las cárceles de Colombia y la solución que el gobierno le quiere dar a ese problema es dejar libres a 9000 reclusos que cumplen con ciertas condiciones" (Revista Semana, 2014).

10 Corroborando el trabajo de campo realizado en los EPC visitados, lo mencionado por el juez 
como el exceso temporal de población carcelaria, resultara indispensable que la administración penitenciaria central hiciera excepciones a esta regla, se deberá evitar que se alojen dos reclusos en cada celda o cuarto individual. Cuando se recurra a dormitorios, estos deberán ser ocupados por reclusos cuidadosamente seleccionados y reconocidos como aptos para ser alojados en estas condiciones. Por la noche, estarán sometidos a una vigilancia regular, adaptada al tipo de establecimiento de que se trate.

2. Los locales destinados a los reclusos y especialmente a aquellos que se destinan al alojamiento de los reclusos durante la noche, deberán satisfacer las exigencias de la higiene, habida cuenta del clima, particularmente en lo que concierne al volumen de aire, superficie mínima, alumbrado, calefacción y ventilación.

3. En todo local donde los reclusos tengan que vivir o trabajar: a) Las ventanas tendrán que ser suficientemente grandes para que el recluso pueda leer y trabajar con luz natural; y deberán estar dispuestas de manera que pueda entrar aire fresco, haya o no ventilación artificial; b) La luz artificial tendrá que ser suficiente para que el recluso pueda leer y trabajar sin perjuicio de su vista.

4. Las instalaciones sanitarias deberán ser adecuadas para que el recluso pueda satisfacer sus necesidades naturales en el momento oportuno, en forma aseada y decente.

5. Las instalaciones de baño y de ducha deberán ser adecuadas para que cada recluso pueda y sea requerido a tomar un baño o ducha a una temperatura adaptada al clima y con la frecuencia que requiera la higiene general según la estación y la región geográfica, pero por lo menos una vez por semana en clima templado.

Pedro Uribe Pérez, quien realizó una inspección judicial el 5 de agosto de 2013, en una pequeña cárcel en Facatativá, apoya lo encontrado en la investigación y refleja que la situación de las instalaciones no tiene lugar excluyente. "Duermen en el piso, pegados los unos a los otros, debajo de los camarotes, en rincones de 40 centímetros y en los techos hay cobijas colgadas a manera de hamacas. Incluso, en uno de los dormitorios existe un solo baño que comparten casi cien personas" (El Tiempo, 2013). 
6. Todos los locales frecuentados regularmente por los reclusos deberán ser mantenidos en debido estado y limpios. (Oficina del Alto Comisionado de las Naciones Unidas para los Derechos Humanos, 1996-2012, cursivas de los autores)

La comparación del capital físico actual como uno de los factores del estándar de vida para los AMPL en los EPC permite determinar que las variables de espacios disponibles, baños, hacinamiento, etc., presentan un estado deficitario en cuanto a las condiciones de detención; violan las normas de derecho internacional humanitario (DIH) y otros estándares del mínimo vital establecidos a nivel internacional, lo cual necesariamente termina afectando e incidiendo en la salud, la higiene y el acceso al agua, y los más afectados son los internos más vulnerables, como los AMPL, más aún si tienen enfermedades crónicas.

\section{Capital humano}

Si solo se tuviera en cuenta el capital físico en las condiciones de vida, se trataría de un enfoque utilitarista, omitiendo el valioso aporte teórico de Amartya Sen (1998), que incluye las potencialidades, las capacidades y las aptitudes de las personas, y que están relacionadas al capital humano.

El capital humano presente y potencial en los EPC está relacionado, directamente, con la población objeto de estudio, los internos; en este caso, los AMPL. Este aspecto es esencial en el momento de evaluar los logros actuales y futuros de un establecimiento o de forma conjunta del SPCC frente a la gestión que se realiza con esta población en particular. Dentro del análisis a los AMPL, se incluyeron variables de acuerdo con el enfoque básico de necesidades que los AM presentan (Pérez Ortiz, 1997), y que se adaptan a lo que existe en el interior de los EPC.

La visual económica de las sociedades capitalistas muestra la existencia de los AM como un grupo inferior a los demás debido a su dependencia y el marginamiento al que se ven sometidos, por lo que se trata de un capital humano en una condición "subsidiaria" al resto de la sociedad, 
que demanda beneficios en forma de salud, servicios sociales, educativos y, a cambio, no compensa con nada. Para determinar esas características del capital humano en los AM, se tienen en cuenta algunas posiciones en las que se coincide desde diversas perspectivas teóricas que agrupa la División de Población de la Cepal, como:

a) La pobreza, la dependencia, la enfermedad o la incapacidad no se deben considerar inherentes a la vejez, sino que son condiciones que pueden ser explicadas por variables sociales, económicas y/o culturales diferentes a la edad.

b) $\mathrm{Al}$ igual que cualquier persona, los Am pueden lograr un estado de bienestar y aspirar a uno superior, aunque existen unos riesgos, no se puede suponer la imposibilidad del bienestar en esta población.

c) Los AM, al igual que cualquier persona, pueden mantener y desarrollar actividades sociales determinadas por tres factores o variables: Condiciones de salud, situación económica y apoyo social recibido. Así, la edad por sí sola no debería impedir el desarrollo social, exceptuando que por circunstancias puntuales las variables mencionadas presenten un deterioro.

d) Se debe tener presente que existen parámetros sociales sobre las edades, y que marcan pautas para los AM en cuanto a comportamientos, expectativas, roles, etc., y van marcado la última etapa del ciclo de vida que se encuentra definido histórica y socialmente. (Celade, 2001)

Esas perspectivas fundamentan un desarrollo conceptual más profundo del sentido que se le da a las condiciones de vida o la calidad de vida que se relacionan directamente con el concepto de bienestar, cuyo significado aún es tema de debate según el pensamiento económico que se utilice y el alcance que desde allí se le dé (Schumpeter, 1994).

Para poder operacionalizar los diversos conceptos, y aunque las características de condiciones de vida dependen del contexto en el que se manejen -incluso pueden diferir entre EPC-, en el caso de los AMPL, para 
analizar el capital humano, se agruparon diversas categorías que caracterizan las condiciones de vida con las que se analizan los AMPL (tabla 16).

Tabla 16. Categorías para el análisis de las condiciones de vida

\begin{tabular}{|c|c|}
\hline Condiciones de vida & Caracterizaciones o categorías \\
\hline \multirow{3}{*}{ Condiciones de salud } & Esperanza de vida. \\
\hline & Salud física. \\
\hline & Psicológicas. \\
\hline \multirow{12}{*}{ Condiciones sociales } & Autopercepción. \\
\hline & Estigmatización. \\
\hline & Expectativa de vida. \\
\hline & Imaginarios sociales del delincuente. \\
\hline & Red de apoyo. \\
\hline & Solidaridad. \\
\hline & Asistencia social. \\
\hline & Aprendizaje en prisión. \\
\hline & Aspectos sociales de los delitos sexuales. \\
\hline & Espiritualidad. \\
\hline & Familia. \\
\hline & Significado otorgado a prisión. \\
\hline Condiciones económicas & Disponibilidad de ingresos. \\
\hline \multirow{2}{*}{ Condiciones jurídicas } & Sindicados e imputados. \\
\hline & Condenados. \\
\hline
\end{tabular}

Fuente: elaboración propia.

\section{Condiciones de salud de los adultos mayores privados de la libertad}

En cuanto a las condiciones de vida mencionadas del capital humano, que permitieron la caracterización de los AMPL, se encuentran, en primera 
instancia, las condiciones de salud que se enmarcan dentro de tres caracterizaciones: esperanza de vida, salud física y psicológica de los internos.

\section{Esperanza de vida (longevidad)}

De acuerdo con el Banco Mundial (2013), la esperanza de vida en Colombia es, en promedio, de 74 años, con una tendencia a que se alargue aún más en la próxima década, según las mismas estadísticas que maneja el Departamento Administrativo Nacional de Estadística (DANE); esta es más larga en las mujeres, quienes, se estima, viven en promedio 77 años frente a los hombres, quienes viven, aproximadamente, 73 años (figura 14).

Figura 14. Esperanza de vida

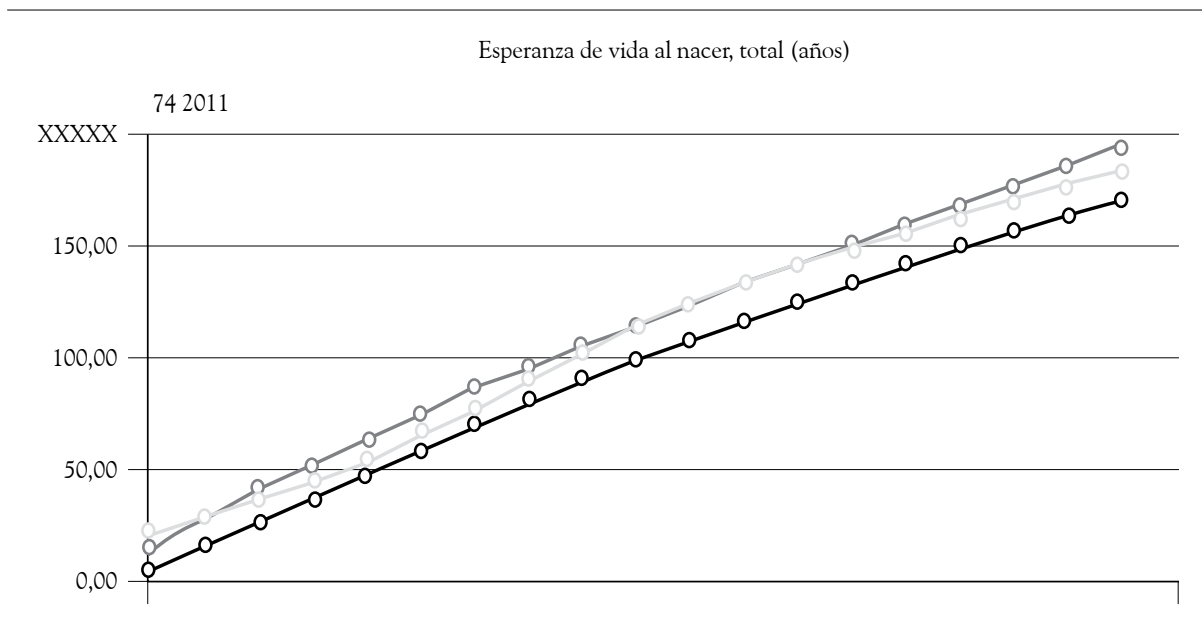

Fuente: datos del Banco Mundial.

Frente a la esperanza de vida en Colombia, y observando la edad actual de los AMPL, se encuentra que la mayoría de ellos cuentan con una edad 12 años por debajo de ese indicador; 62 años es la edad más frecuente, tanto en hombres como en mujeres. De ellos, la edad de las mujeres oscila entre los 62 y los 82 años, y la de los hombres entre los 62 y los 94 años (figura 15). 
Figura 15. Longevidad de los adultos mayores privados de la libertad

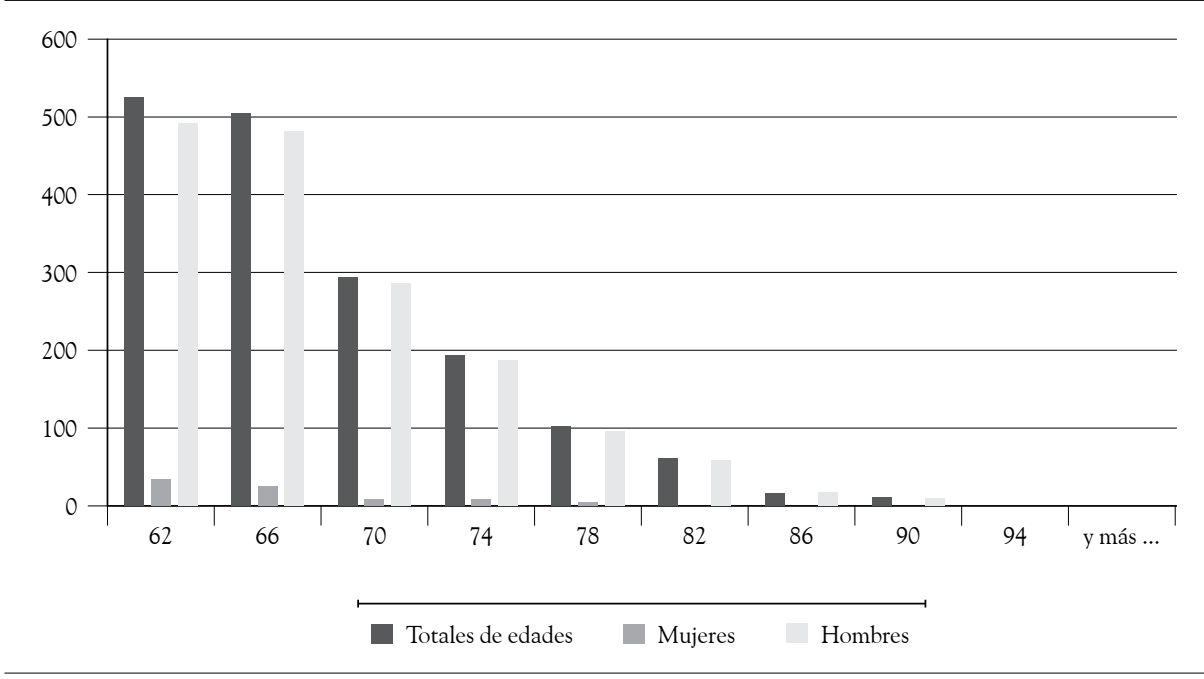

Fuente: Sisipec Web, 31 de julio de 2013. Cálculos de los autores.

Esta condición de longevidad de los AMPL frente a la esperanza de vida invita a reflexionar hasta qué punto una persona que está por debajo de la línea de esperanza de vida en Colombia podría cumplir condenas hasta ese límite, o qué sentido tiene tener a un AM que ha sobrepasado los límites de esperanza de vida en un EPC. Asimismo, invita a reflexionar sobre la funcionalidad de los programas dirigidos a esta población para una eventual resocialización debido al estado de salud que a esa edad presenta.

\section{Estado de salud física}

Al buscar cifras oficiales sobre la salud física o mental de los AMPL, para sorpresa, el Inpec no cuenta con esos datos correlacionados con la edad, lo que ratifica la percepción de los internos frente a la vulneración de su derecho a la salud. Sin embargo, al observar las discapacidades, se tiene que el $96 \%$ carecen de cualquier tipo de ellas, el $4 \%$ tienen discapacidad en sus funciones y solo el $2 \%$ presentan discapacidad en estructuras (figura 16). 
Figura 16. Discapacidades en adultos mayores privados de libertad

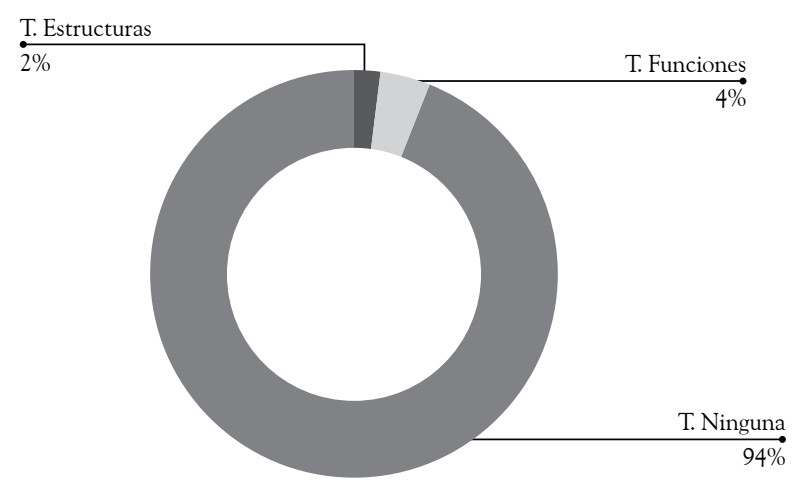

Fuente: Sisipec Web, 31 de julio de 2013. Cálculos de los autores.

Frente a esto, al indagar sobre las enfermedades físicas que los AMPL asocian a su estadía en prisión, se pudo evidenciar que este tema es de interés en la población; de hecho, fue uno de los temas que mayor espacio generó para discusión dentro de los grupos focales. De esta forma, se logró agrupar el cúmulo de enfermedades descritas en sus narraciones (tabla 17).

Tabla 17. Enfermedades físicas asociadas a la prisión según los adultos mayores privados de la libertad

\begin{tabular}{|l|l|}
\hline \multicolumn{1}{|c|}{ Enfermedad } & \multicolumn{1}{c|}{ Referencia de los internos } \\
\hline Cardiovascular & $\begin{array}{l}\text { Hipertensión, tensión alta, sufrir del corazón, problemas } \\
\text { cardiacos. }\end{array}$ \\
\hline Viral & Gripa, viH. \\
\hline Bacteriana & Tuberculosis, sífilis. \\
\hline Úlceras & Úlcera gástrica, úlceras en la piel. \\
\hline Trastornos metabólicos & Diabetes. \\
\hline Alergias & Granos, enfermedades de la piel. \\
\hline Cáncer & De colon, de próstata. \\
\hline Pulmonar & Afecciones pulmonares, neumonía. \\
\hline Reumatológica & Artritis. \\
\hline Sistema óseo & $\begin{array}{l}\text { Osteoporosis, problemas de columna vertebral, dolor en los } \\
\text { huesos. }\end{array}$ \\
\hline
\end{tabular}




\begin{tabular}{|l|l|}
\hline \multicolumn{1}{|c|}{ Enfermedad } & \multicolumn{1}{c|}{ Referencia de los internos } \\
\hline Visión & Disminución de la visión. \\
\hline Auditiva & Por ruidos, escándalo, mucha bulla. \\
\hline Otras & $\begin{array}{l}\text { Colesterol, próstata, triglicéridos, la vesícula, migraña, diálisis, } \\
\text { gastritis, dermatitis. }\end{array}$ \\
\hline
\end{tabular}

Fuente: grupos focales en los EPC visitados.

$\mathrm{Al}$ analizar estos resultados, es claro que se encuentran diversos síntomas y enfermedades, que aunque son atribuidos al estar "encarcelados", son comunes en este grupo etario a nivel general en el país, según la Encuesta Nacional de Demografía y Salud (Profamilia, 2010). Esto puede responder a lo planteado por Arango y Ruiz (2008), en cuanto a que la vejez se ha equiparado con la enfermedad, y a partir de ahí resulta que la mayoría de los AM interpretan su salud como mala.

Sin embargo, vale la pena decir que la gravedad de la enfermedad puede aumentar a causa de las condiciones en prisión. Al respecto, una de las atribuciones a la generación de enfermedad está relacionada con la habitabilidad, la cual está dada por las características físicas del establecimiento: "Aquí se enferman de este baldosín frío, de acostarse ahí uno se llena los calambres" (grupo focal, EPMSC ERE Bucaramanga, julio de 2013), "De frío le da a uno dolor de huesos y la gripa" (grupo focal, EPMSC Medellín, julio de 2013), "La parte auditiva se pierde muchísimo, los ruidos son un escándalo y una bulla que los señores que están en reclusión es mucho el escándalo" (grupo focal Comeb, Cúcuta, julio de 2013). De otro lado, estas enfermedades se encuentran relacionadas con las de visión, las gastrointestinales o crónicas, que fueron asociadas a la dinámica carcelaria e ilustradas en el capítulo de la fundamentación del concepto.

El acceso limitado al sistema de salud también puede ampliar la percepción de gravedad de la enfermedad, ya que las personas manifiestan dilación en los procesos de atención tanto de urgencias como de tratamientos a las dolencias que padecen, lo que genera ansiedad, incertidumbre y preocupación constante por su estado de salud, al conocer y proyectar un resultado negativo o poco satisfactorio. Al respecto, Koch, Cravero y Farre (citados en Londoño \& Chaparro, 2011) indican que el estado de salud 
puede observarse como unipersonal y multideterminado, y la posibilidad de acceder a los servicios médicos es una de las medidas para establecer satisfacción de necesidades. Desde esta perspectiva, se vería en riesgo la condición de salud física de los AMPL.

\section{Caracterización psicológica}

En este apartado se expondrán las características psicológicas relacionadas con las funciones cognitivas y las condiciones psicopatológicas observadas en los AMPL. La idea es aproximarse a esta realidad para proyectar, en alguna medida y a manera de propuesta, acciones para la atención acordes con la población. Para Bonilla et al. (2009), la caracterización es una fase descriptiva cuyo fin es identificar, entre otros aspectos, los componentes, los acontecimientos, los actores, los procesos y el contexto de una experiencia, un hecho o un proceso. Partiendo de esta afirmación, se realizó un análisis psicológico de la información recolectada mediante la aplicación de los instrumentos Neuropsi, SCL 90R y grupos focales, en los que se preguntó a los AMPL acerca de las enfermedades psicológicas o los cambios experimentados en prisión. La aplicación de instrumentos se describe en las siguientes fases y se explica a profundidad en el desarrollo del texto.

Se presenta la descripción de las funciones cognitivas de 21 participantes con quienes se llevó a cabo la aplicación de 2 instrumentos de screening con el fin de observar el funcionamiento mental y psicológico en relación con el tiempo de internamiento. Este ejercicio se desarrolló en paralelo con la ejecución de los grupos focales. Los primeros instrumentos aplicados a estos 21 internos fueron el Neuropsi, que permite indagar un amplio espectro de funciones cognoscitivas, y el SCL-90, el cual establece 9 dimensiones psicopatológicas; asimismo, se recolectaron datos sociodemográficos exclusivos a los 21 participantes.

Los criterios para la selección de los participantes en el estudio fueron: ser mayor de 60 años, estar condenado, participar voluntariamente, y haber diligenciado el consentimiento informado y en tiempos específicos de internamiento (el internamiento menor para un periodo de reclusión 
entre 9 y 49 meses, el internamiento intermedio comprendido entre 50 y 90 meses y el internamiento prolongado a partir de 91 y hasta 132 meses). Inicialmente, se proyectaron 3 internos por cada intervalo de tiempo, pero se observó que el desarrollo de las pruebas era complejo para algunos de ellos, situación que contrastó con el poco tiempo disponible asignado. De esta forma, se tomó 1 interno por cada lapso de tiempo; es decir, 3 por establecimiento o ciudad. El tipo de estudio elegido para el desarrollo de la investigación no permite interpretar que los resultados obtenidos sean generalizables a toda la población, por cuanto se tomó solo como indicador de lo que ocurre a los internos participantes, específicamente. Sin embargo, puede interpretarse como una primera aproximación al funcionamiento cognitivo y psicopatológico de los AMPL (tabla 18).

Tabla 18. Participantes por establecimiento en la descripción de funciones cognitivas

\begin{tabular}{|l|l|c|}
\hline \multicolumn{1}{|c|}{ Establecimiento } & \multicolumn{1}{c|}{ Ciudad } & Participantes \\
\hline EPMSC & Acacias & 3 \\
\hline Coiba & Ibagué & 3 \\
\hline EPMSC & Medellín & 3 \\
\hline EPMSCERE & Bucaramanga & 3 \\
\hline EPMSCERE & Cúcuta & 2 \\
\hline Comeb & Bogotá & 2 \\
\hline EPMSCERE & Cali & 3 \\
\hline EPC Cojam & Jamundí & 2 \\
\hline \multicolumn{2}{|c|}{} \\
\hline
\end{tabular}

Fuente: grupos focales en los EPC visitados.

Respecto a las condiciones sociodemográficas, se encontró que la edad mínima de los participantes era de 60 años y la edad máxima, de 74 años, con una media en edad de 65 años. En cuanto al nivel de escolaridad, se encontró que el 14,3\% (3 sujetos) no cuentan con un nivel de educación. De los que cuentan con educación, se halló que el mayor número de participantes (el 33,3\%) (7 sujetos) se encuentran en el nivel de 
básica incompleta, seguidos de los que se encuentran en la media incompleta, con el 19\% (4 sujetos), y el 14,3\% (3 sujetos) han terminado alguna profesión.

Desde la perspectiva jurídica, los participantes manifestaron estar privados de la libertad por haber cometido delitos de homicidio (con el 42,9\%, 9 sujetos), seguidos de delitos sexuales (con el 33,3\%, 7 sujetos). Vale la pena mencionar que estos datos son subjetivos en la medida en que no fueron contrastados con el expediente para su verificación, de hecho se cree que pudieron ser más delitos sexuales ya que la estigmatización sobre estos impide que sean revelados.

Respecto a los tiempos de condena, se encontró que la más baja fue de 41 meses y la máxima de 420 meses, la media para esta condición fue de 211,42 meses. El tiempo que llevaban privados de la libertad en el momento de la evaluación estuvo en un mínimo de 9 meses y un máximo de 132 meses, con una condena media de 68,62 meses.

Dentro de las actividades que actualmente desempeñan en prisión, se encontró que, a excepción de 2 participantes, realizaban alguna actividad al interior de los EPC; las que más se presentaron fueron las relacionadas con los trabajos manuales o artesanías, seguidas de las actividades de aseo; no obstante, manifestaron desempeñar múltiples actividades que no están dentro de las válidas como redención de pena, como lavar ropa.

\section{Funciones cognitivas}

Las funciones cognitivas, como se mencionó anteriormente, fueron evaluadas a los 21 participantes seleccionados para la aplicación del instrumento Neuropsi, que los autores describen como breve, confiable y objetivo, y funciona adecuadamente en pacientes psiquiátricos, geriátricos, neurológicos y con diversos problemas médicos (Ostrosky et al., 2010). A continuación, en la tabla 19, se dan a conocer las características esenciales del instrumento. 
Tabla 19. Características esenciales del instrumento Neuropsi

\begin{tabular}{|c|c|}
\hline $\begin{array}{l}\text { Áreas cognitivas } \\
\text { evaluadas/subáreas }\end{array}$ & $\begin{array}{l}\text { Orientación: tiempo, lugar y persona. } \\
\text { Atención y concentración: dígitos, 20-3. } \\
\text { Memoria: palabras, evocación espontánea, por categorías, reco- } \\
\text { nocimiento. } \\
\text { Lenguaje: denominación, repetición, comprensión. } \\
\text { Procesos visoconstructivos: figura semicompleja. } \\
\text { Funciones ejecutivas: semejanzas, cálculo, secuencias, mano dere- } \\
\text { cha, mano izquierda, movimientos alternos, reacciones opuestas. } \\
\text { Lectura, escritura y cálculo: dictado, copia, lectura. }\end{array}$ \\
\hline Normas & $\begin{array}{l}\text { Estandarizada en una muestra de } 800 \text { sujetos normales hispano- } \\
\text { hablantes entre los } 16 \text { y los } 85 \text { años, la muestra se estratificó de } \\
\text { acuerdo con edades agrupadas en: } 16 \text { a } 30,31 \text { a } 50,51 \text { a } 65 \text { y } 66 \\
\text { a } 85 \text { años; y en cada rango de edad se incluyeron cuatro niveles } \\
\text { educativos: 0; } 1 \text { a 4; } 5 \text { a } 9 \text { y más de } 10 \text { años de estudio. }\end{array}$ \\
\hline Calificación & $\begin{array}{l}\text { Con los datos independientes de cada habilidad cognoscitiva, se } \\
\text { obtiene un perfil individual que señala las habilidades e inhabilida- } \\
\text { des del sujeto en cada una de las áreas evaluadas. Los parámetros } \\
\text { de estandarización permiten obtener un grado o nivel de alteración } \\
\text { que clasifica en: normal, alteraciones moderadas y alteraciones severas. }\end{array}$ \\
\hline Áreas de aplicación & $\begin{array}{l}\text { Útil como instrumento de tamizaje o para ayudar a determinar si } \\
\text { se necesita una evaluación neuropsicológica completa. }\end{array}$ \\
\hline
\end{tabular}

Fuente: elaboración propia.

Los resultados que muestran de manera general el funcionamiento cognitivo de los AMPL se exponen de acuerdo con el orden de las áreas y subáreas del instrumento. En el análisis de los resultados, se centró la atención en las puntuaciones que dejaron ver algún nivel de afectación, por cuanto la mayoría de evaluados se ubicaron dentro de lo normal o esperado para el nivel educativo y la edad.

\section{Orientación}

En esta área, se observó que todos los participantes demostraron ubicación global en tiempo, espacio y estado de activación óptimo, en el momento de 
la aplicación del instrumento, por lo que se puede afirmar que esta área se conserva, contrariamente a la edad y el tiempo de internamiento.

\section{Atención y concentración}

La atención permite la integración de estímulos, agrupándolos o alternándolos, seleccionando y activando los procesos cognitivos en actividades de interés. En los AM puede aparecer disminución en la atención sostenida debido a que las señales recibidas mediante los sentidos están siendo filtradas de manera irregular. En este sentido, en la compilación realizada por Losadas (2003) y López et al. (2001) (citados en Sánchez \& Pérez, 2008) se afirma que como producto del envejecimiento se presenta la disminución progresiva en el grado de vigilancia, que se manifiesta en tareas para mantener la atención (figura 17).

Figura 17. Atención y concentración

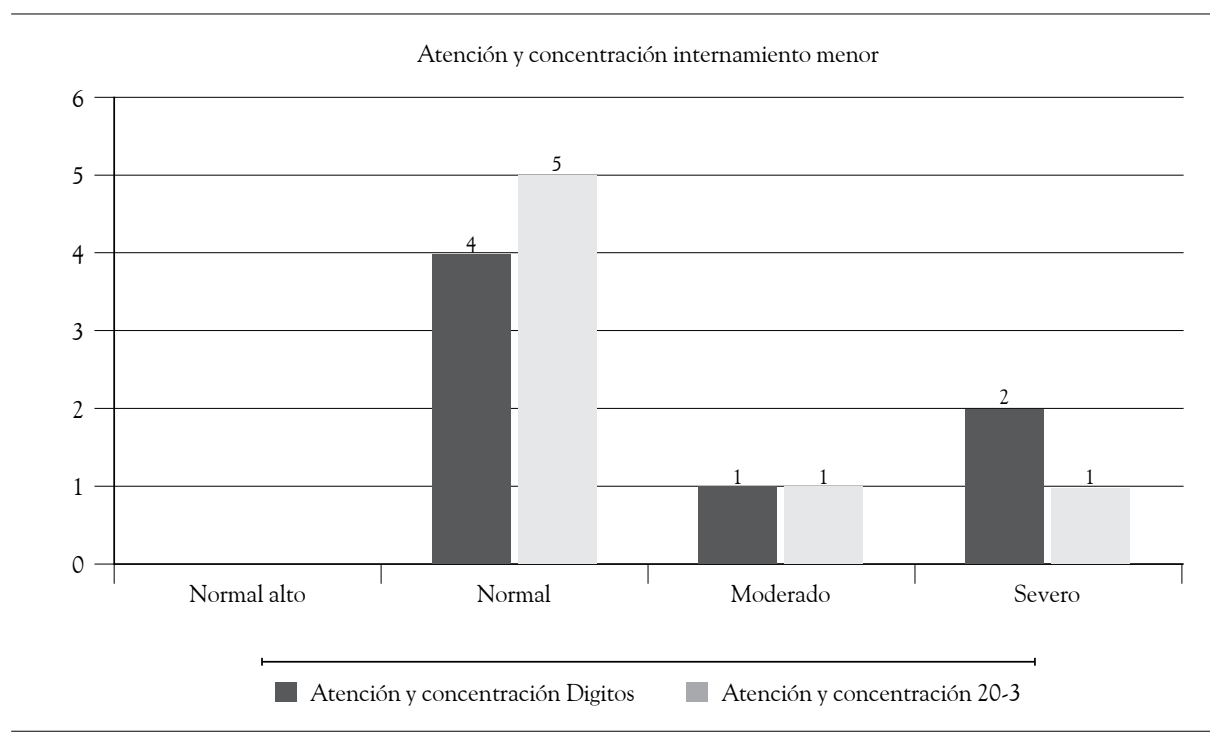


Atención y concentración internamiento intermedio
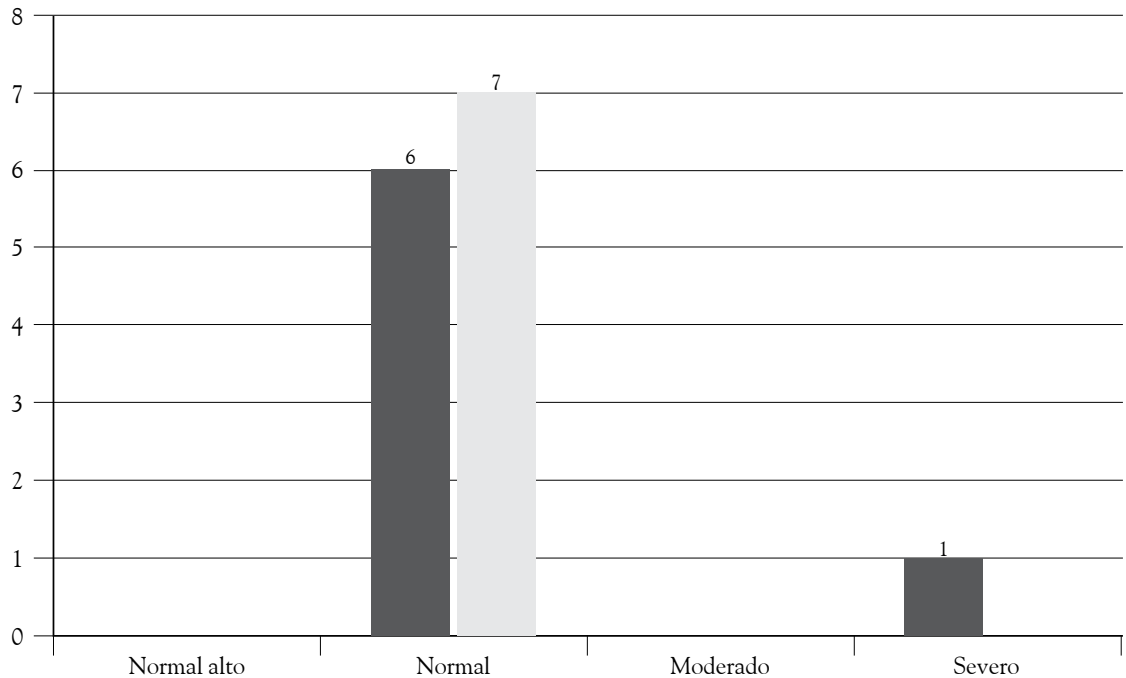

Atención y concentración Digitos

Atención y concentración 20-3

Atención y concentración internamiento prolongado

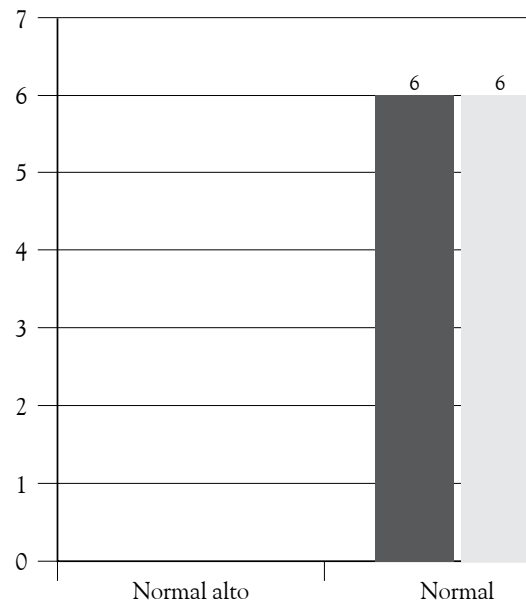

6

Atención y concentración Digitos

Atención y concentración 20-3

Fuente: elaboración propia.

En los AMPL evaluados, las tareas señaladas por el instrumento que implicaban la repetición o regresión numérica sucesiva enmarcaron las funciones de atención y concentración. De esta manera, la mayoría de ellos se ubicaron en el margen de la normalidad, en los 3 intervalos de tiempo, es 
decir que lograron realizar la actividad adecuadamente. No obstante, en el internamiento menor, 3 de 7 evaluados presentaron alteración severa en esta área, mientras que con afectación moderada se encontraron solo 2 internos. Entre tanto, en los AMPL del grupo de evaluados, con un periodo de internamiento intermedio, solo aparece un participante con indicador de daño severo. Finalmente, en un interno se presentan los niveles de alteración moderado y severo, en este proceso, en el internamiento prologado.

$\mathrm{Al}$ analizar los resultados, se infiere que la capacidad de mantener la atención para realizar tareas que implican secuencias de actividades en orden progresivo de selección de estímulos en los procesos cognitivos se vio más alterada en los sujetos participantes con menor tiempo de internamiento. Este hallazgo es consistente con los resultados de López, Calero y Navarro (2013), en cuanto que la atención sostenida y la capacidad de aprendizaje o plasticidad cognitiva son, por este orden, las variables que mejor explican los cambios experimentados por las personas mayores. Ahora, si se analiza esta función en relación con las consecuencias y las exigencias de adaptación al contexto carcelario, es claro que la cantidad de estímulos percibidos como nuevos en prisión altera la selección y la discriminación de los procesos de atención por un tiempo. Por la reiteración, estos estímulos se convierten en los únicos percibidos, lo que genera baja en esta función y tiene como consecuencia una mayor atención para estímulos nuevos o novedosos.

De ser así, podría decidirse que para los internos seleccionados en el nivel de internamiento inicial, será necesario establecer actividades con instrucciones que se desarrollen progresivamente y sin mayor exigencia de atención por largos periodos de tiempo. Y para los que participaron en el grupo de mayor tiempo de internamiento, sería la oportunidad de brindar nuevos y varios estímulos dentro del proceso de atención y tratamiento, ya que esta función estaría conservada.

\section{Memoria}

Se hará especial énfasis en esta área por ser una de las más evaluadas en el instrumento y porque está fuertemente asociada al proceso de enveje- 
cimiento. En la comprensión de este concepto, Schacter y Tulving (1994) (citados en Dixon et al., 2013) indican que la memoria es un conjunto de procesos que relacionan mecanismos cerebrales, el procesamiento de la información y los principios operacionales. Este proceso se puede ver afectado por los cambios que se dan en el curso de la vida, especialmente cuando se está en la etapa de la vejez. Al respecto, Dixon et al. (2012) plantean que la memoria es una herramienta esencial que indica que el proceso del desarrollo en la persona es exitoso, es decir, gozar de "buena memoria" se ha convertido en el imaginario común, en indicador que no se está presentando deterioro producto del envejecimiento. Esta tendencia se puede ver reforzada por lo habitual, que es escuchar lamentaciones acerca de los olvidos que muchos AM permanentemente manifiestan, y basta con pensar en la posibilidad de perderla para comprender que una de las implicaciones del envejecimiento más temida es que aparezcan signos que indiquen la pérdida de la memoria (Dixon et al., 2012).

Dos procesos asociados al adecuado y normal funcionamiento de la memoria son las funciones de codificación y evocación; en cuanto a la primera, Etchepareborda y Abad-Mas (2005) expresan que la información puede codificarse en imágenes, sonidos, experiencias, acontecimientos o ideas significativas, y que el entorno o las situaciones son determinantes para que el estímulo se procese adecuada o inadecuadamente. Esto resalta la importancia de la atención, la concentración y las condiciones emocionales de la persona en el ordenamiento de la información para su posterior recuperación. La segunda función, la de evocación, hace referencia al proceso de recuperación de la información previamente almacenada y codificada; es decir, ofrece la posibilidad de recordar.

Existen investigaciones centradas en los procesos de recordar eventos o información experimentados o adquiridos con anterioridad, y en los cambios que este proceso tiene con la edad o las condiciones en que se presentan. Al respecto, las investigaciones de Baltes y Strunder (1996), Dixon et al. (2012), Moulin et al. (2010), Herlitz y Rehnman (2008) mostraron que factores como la vulnerabilidad neuronal, el estado de salud, la vitalidad, el estilo de vida, la educación, el género y el medio ambiente pueden agravar o modular estos cambios; los resultados mostraron bajos puntajes en 
la población AM en comparación con los más jóvenes, y gradualidad en el deterioro, es decir, a pesar de las condiciones del entorno, este no sucederá de manera espontánea.

Respecto a esta área, el presente estudio evidenció diferencias de los evaluados en función del tiempo. En el internamiento menor, se observó afectación moderada en 2 de 7 internos, en las subáreas de seriación de palabras y memoria por claves (recordar palabras retenidas según categorías previamente establecidas). Asimismo, en las áreas de codificación mediante memoria verbal espontánea (recordar sin un orden previamente establecido), procesos visoespaciales y memoria por reconocimiento, se encontró solo 1 de los internos por cada área valorada. En cuanto a las subescalas que mostraron afectación severa, se encontraron 2 internos afectados en los procesos de evocación por claves, y en memoria verbal espontánea, un interno (figura 18).

Figura 18. Memoria internamiento menor

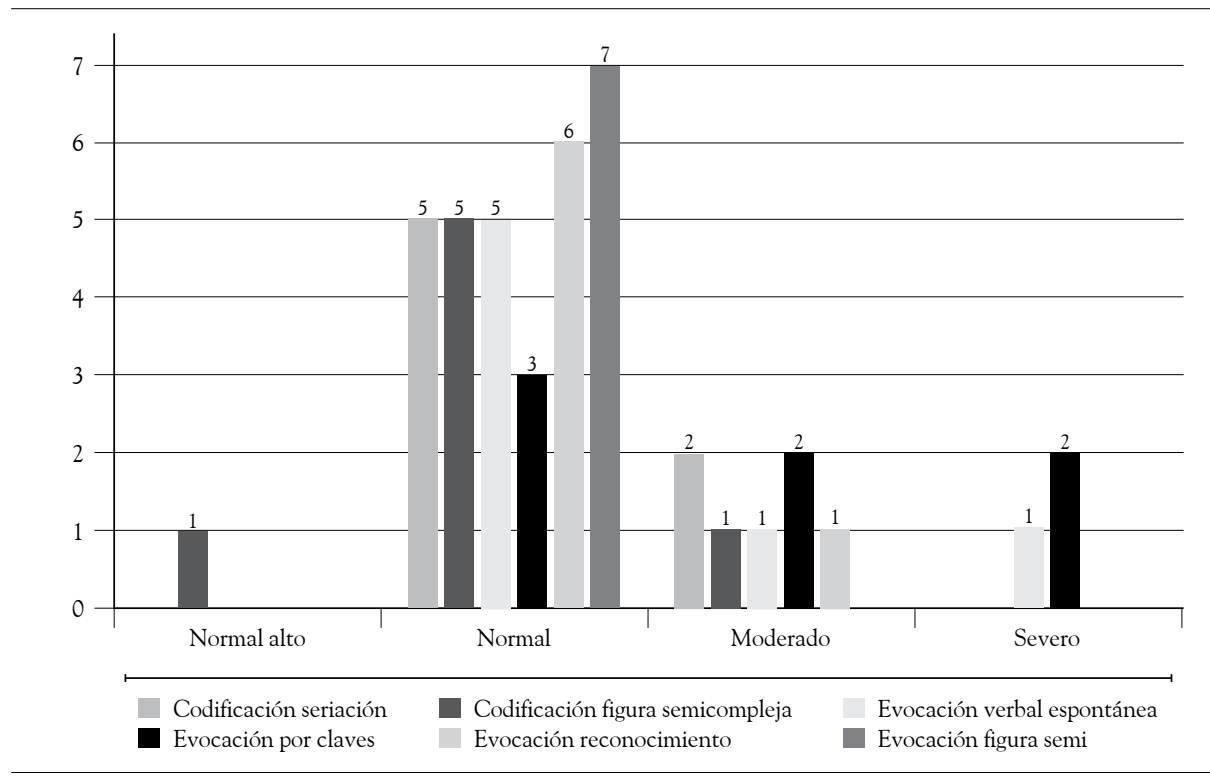

Fuente: elaboración propia.

Respecto al internamiento intermedio, se observó, en relación con el internamiento menor, aumento en cuatro internos con afectación moderada en la función de evocación por claves. Y con posible deterioro severo, apare- 
cen las funciones de codificación mediante proceso visoespacial, evocación verbal espontánea, por claves y por reconocimiento en 2 internos para cada una y un interno con deterioro con evocación por memoria visoespacial.

Figura 19. Memoria internamiento intermedio

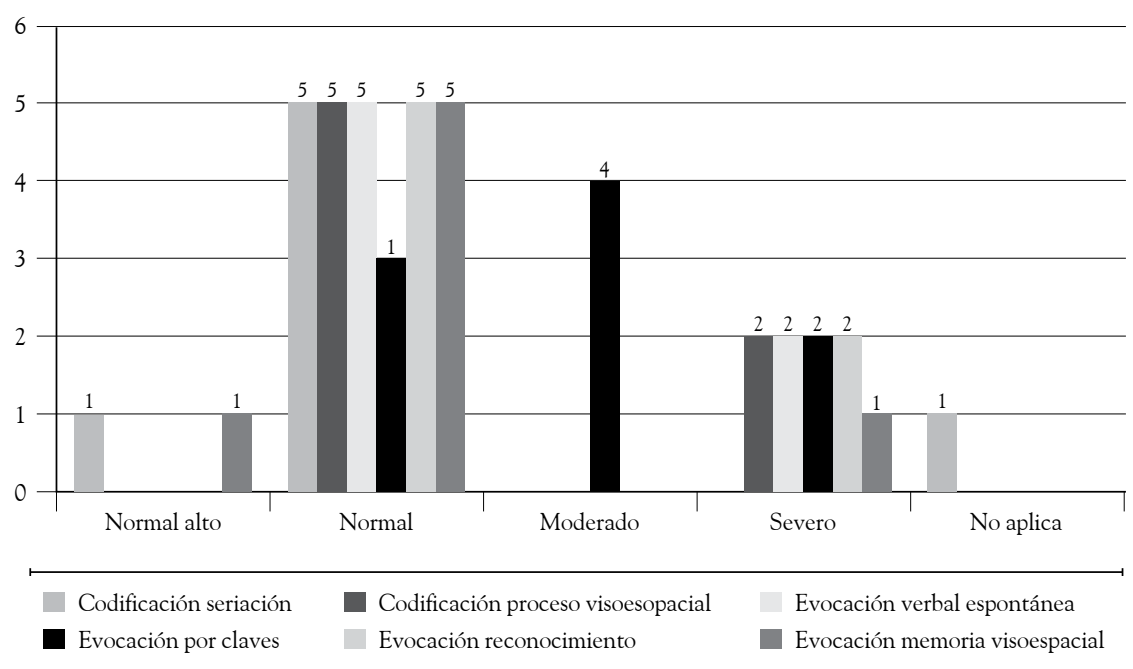

Fuente: elaboración propia.

Finalmente, para el grupo de internos evaluados con periodo prolongado de encarcelamiento, aparecen alteradas con intensidad moderada las funciones de evocación por reconocimiento y verbal espontánea en 2 internos, y nuevamente la evocación por claves en 1 de los participantes. Se destaca para deterioro severo la función de evocación por claves en 5 de los 7 participantes.

En resumen, se tiene que los resultados expuestos dan cuenta de que los AMPL afectados presentan dificultades para evocar a partir de datos organizados de manera metódica como la categorización que aparentemente se acentúa con el internamiento prolongado. Esto tiene relación con los estudios de Park y Reuter-Lorenz (2009) que demuestran que la velocidad con que se procesa la información en los sistemas de memoria operativa o de trabajo y memoria a largo plazo en el subsistema de memoria episódica disminuye de manera vertiginosa con la edad. Por otra parte, al parecer, en compensación con las limitaciones que implican los deterioros menciona- 
Figura 20. Memoria internamiento prologando

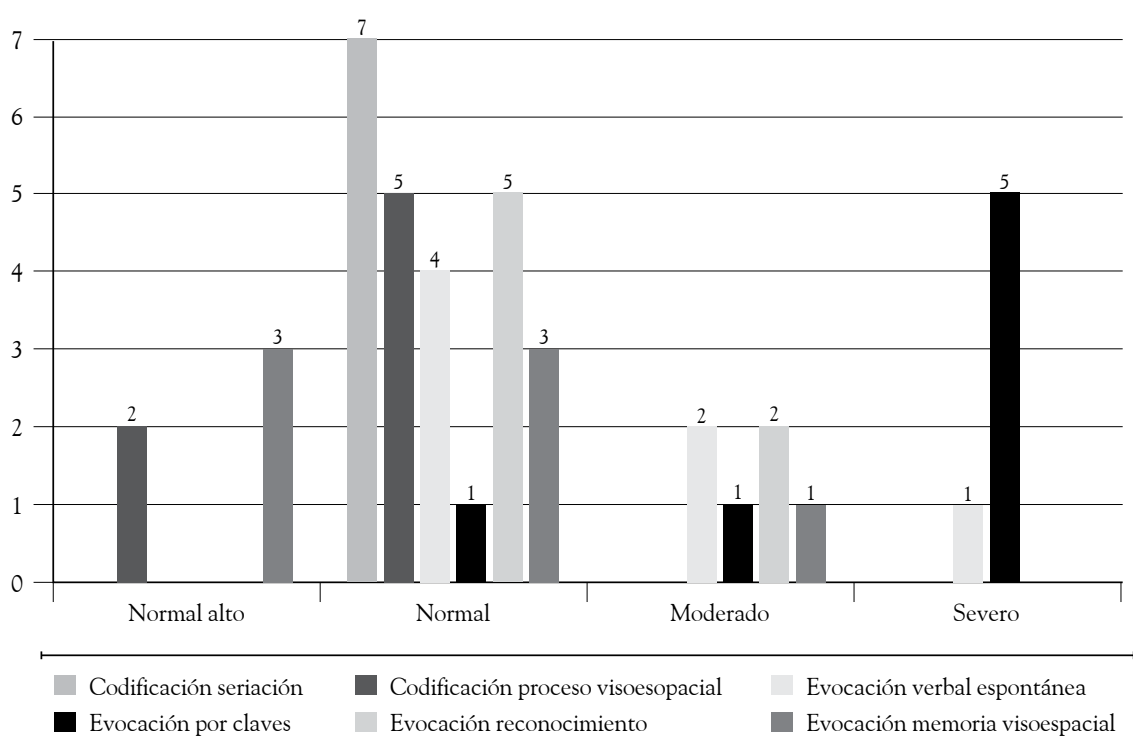

Fuente: elaboración propia.

dos, los AMPL evaluados tienen facilidades en la función de codificación de la información mediante registros visuales y, de igual manera, la evocación mediante la memoria visoespacial; esto es coherente con Etchepareborda y Abad-Mas (2005), para quienes si la experiencia ha sido bien almacenada y clasificada, será más fácil localizarla y utilizarla en el momento en que se solicita.

\section{Lenguaje}

Este es definido por Portellano (2005) como un sistema de comunicación simbólico que se manifiesta a través de las palabras y la escritura; implica la complejización de todos los procesos cognitivos, incluido el de pensamiento, mediante la utilización de las manos, los pies y el aparato fonatorio para la producción de elementos simbólicos que representan o reproducen ideas, deseos, estados anímicos y demás; permite establecer un contacto entre la mente y el mundo. 
Para que se produzca el lenguaje, es necesaria la articulación de los sentidos y, para ilustrarlo, se hace un recorrido muy elemental del curso que sigue en su producción. En el caso de la escucha, los estímulos son captados por los órganos del sistema auditivo y son trasmitidos al cerebro, donde entran en juego los sistemas de memoria, aprendizaje y pensamiento para dar sentido o interpretar lo percibido; mientras que para la lectura, la información estimula el área visual primaria para ser integrada con los estímulos auditivos, trasmitiéndola al área de Wernicke, que es la responsable de la comprensión de lo que significan las palabras. Para el habla, se hace necesario que la información procesada con anterioridad en los sistemas de memoria sea conducida hasta las áreas del cerebro donde están ubicados los componentes que estimulan las formas como se deben producir los sonidos de manera comprensible, para finalmente articular las palabras mediante los movimientos correctos de los músculos bucofonatorios. De acuerdo con el Neuropsi, esta área observa el funcionamiento del lenguaje a partir de 6 subáreas, las cuales serán descritas en función del comportamiento de la escala en los AMPL y la observancia de necesidades de atención o intervención específica para los afectados (figura 21).

En general, los resultados de las subpruebas de lenguaje se ubicaron en la categoría de la normalidad; se descartó en los evaluados trastornos relacionados con afasias, entendidas como la afectación en el procesamiento simbólico del lenguaje, y caracterizadas por la presencia, en un grado variable, de trastornos de comprensión, expresión, denominación, fluidez y repetición (Portellano, 2005). Pero algunos afectados mostraron inhabilidad en la función de comprensión en los 3 niveles de internamiento; en el internamiento prolongado, se detectó el mayor número de internos (3 de 7) con afectación moderada en comprensión de instrucciones. Lo que se detalla en este apartado del estudio tiene relación con investigaciones citadas por Lopuzzo (2002), en las que se encontró la ocurrencia de 3 fenómenos en que se pueden agrupar las conclusiones acerca de lo que sucede con el lenguaje en AM. 
Figura 21. Lenguaje internamiento menor, intermedio y prologando

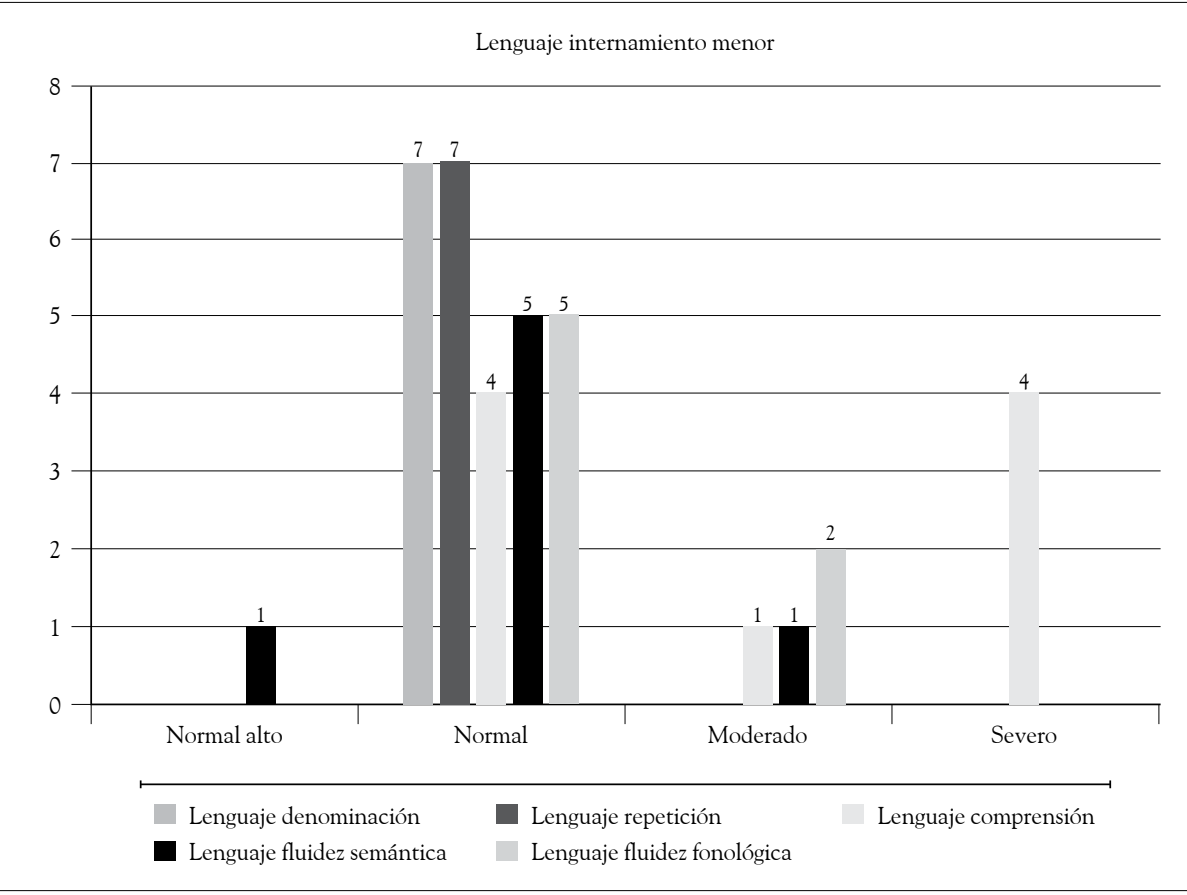

Lenguaje internamiento intermedio

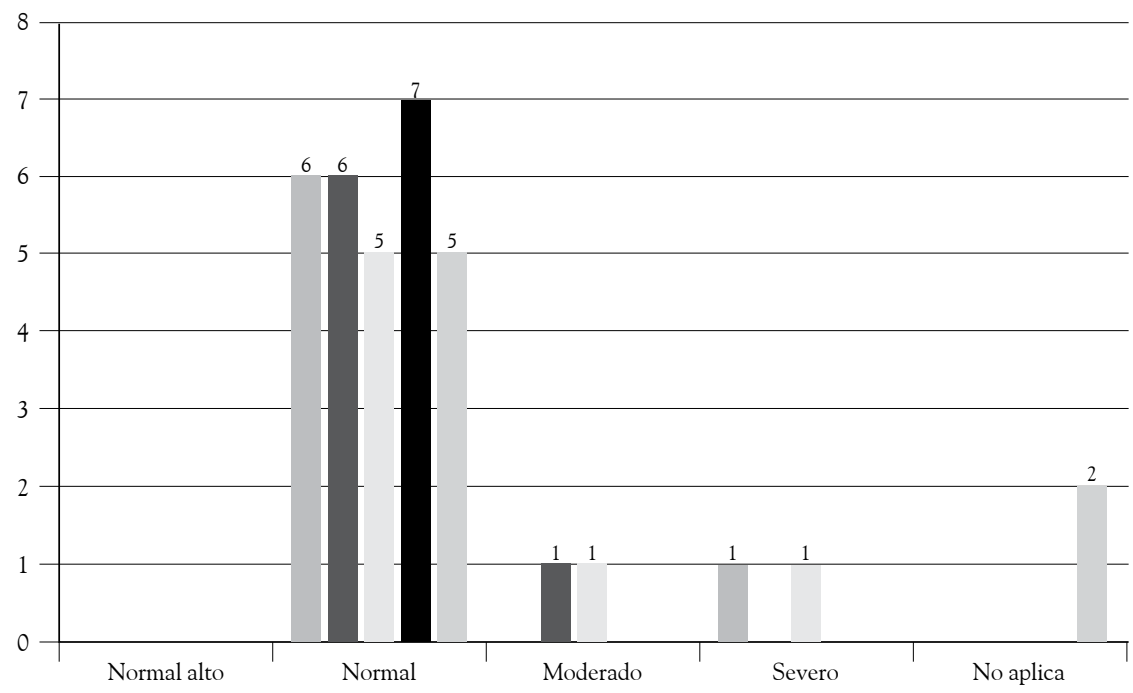

Lenguaje denominación

Lenguaje repetición

Lenguaje comprensión

Lenguaje fluidez semántica

Lenguaje fluidez fonológica 


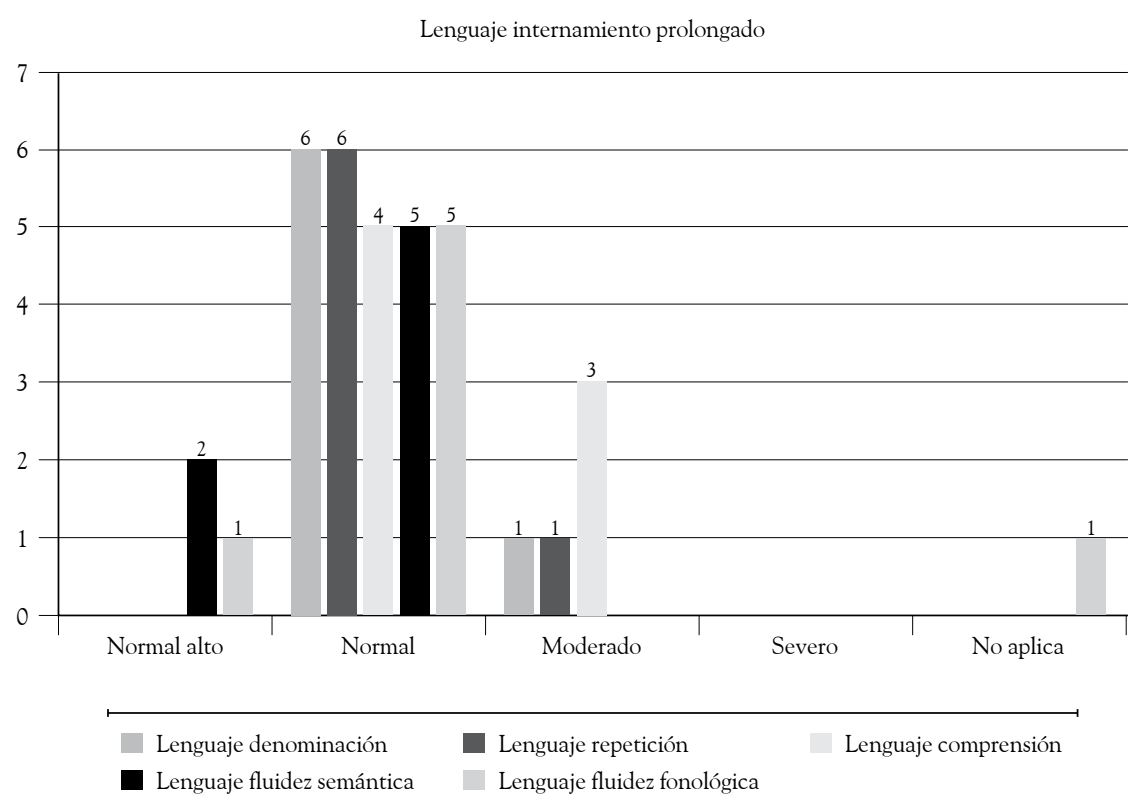

Fuente: elaboración propia.

1. El vocabulario pasivo (denominación) se mantiene.

2. Dificultades importantes en el acceso al léxico (comprensión).

3. El conocimiento conceptual no se deteriora, al parecer aumenta (fluidez fonológica, fluidez semántica).

Como conclusión, se puede decir que el lenguaje es una facultad del ser humano cuya emergencia depende de la unión de 2 componentes, descritos por Destéfano (2012): el sistema cognitivo y el sistema de ejecución (biológico). El funcionamiento de los órganos que componen el sistema de ejecución puede llegar a afectar el lenguaje no en su contenido, sino en la producción, pero una afectación en el sistema cognitivo sí perturba el lenguaje en su contenido. Es el caso de este estudio, en el que se observó que en los valorados, el lenguaje sigue funcionando, pero el nivel de comprensión de los internos que mostraron afectación no encaja en lo esperado, por cuanto se hace necesario conocer antecedentes clínicos de los AMPL que mostraron alteración moderada o severa. 


\section{Lectoescritura}

Antes de presentar el análisis de estas funciones, es necesario aclarar que 8 de los 21 participantes no presentaron una calificación de estas subescalas ya que no cumplían con el nivel académico requerido (figura 22).

Figura 22. Lectoescritura; internamiento menor, intermedio y prolongado

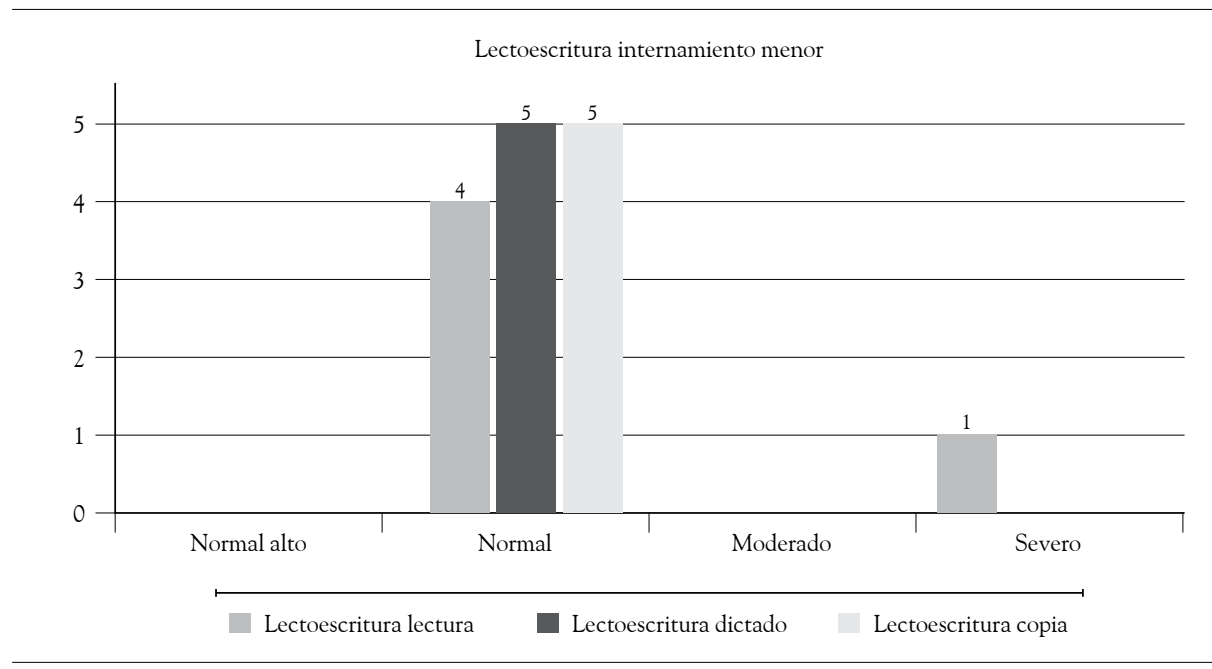

Lectoescritura internamiento intermedio

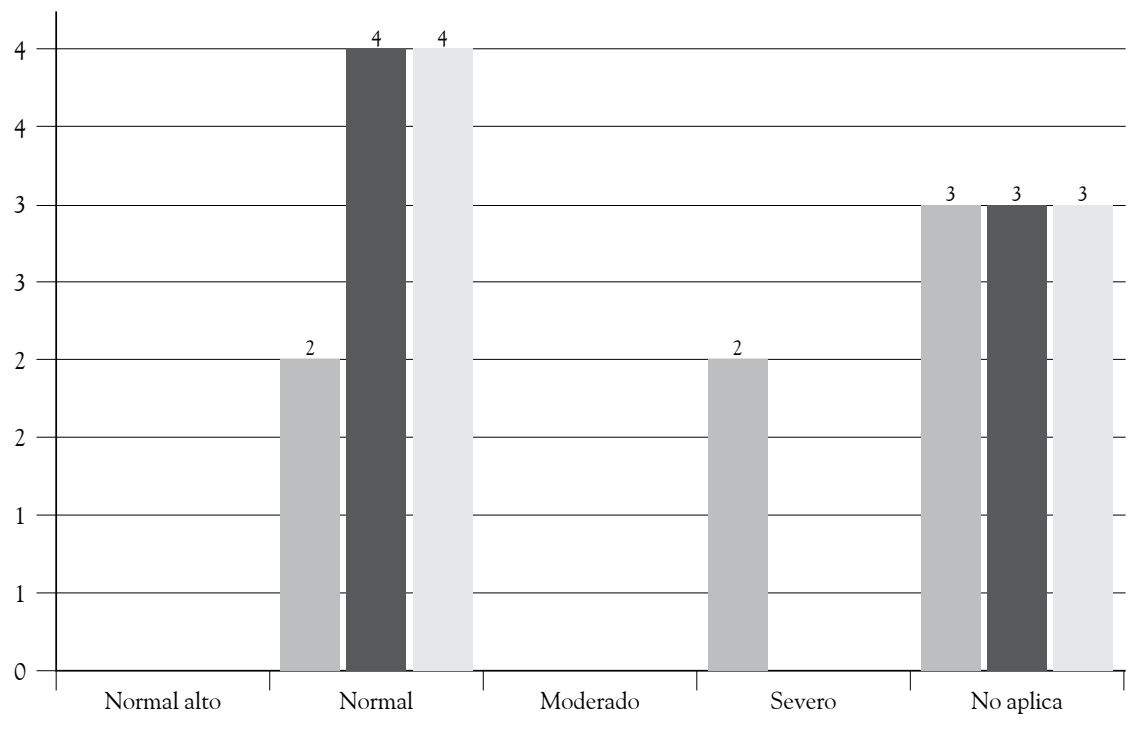




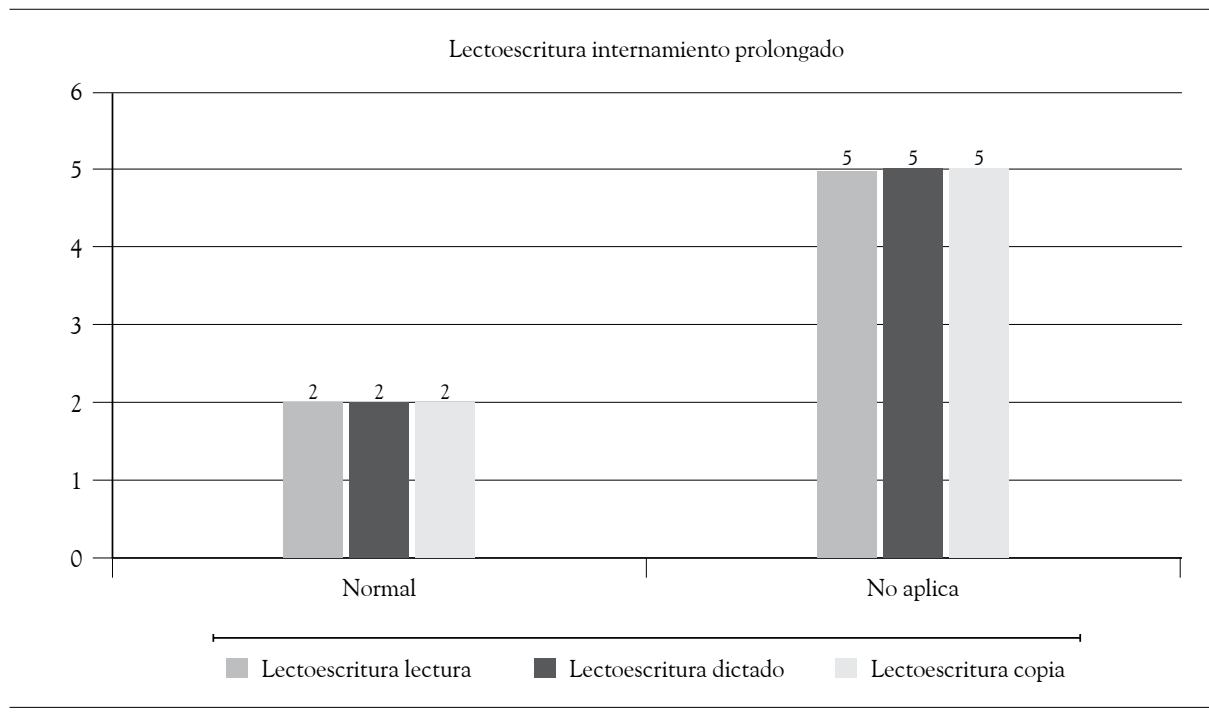

Fuente: elaboración propia.

Se registró un participante con alteración severa en lectura del grupo de internamiento menor y 2 del grupo intermedio. Estos resultados no indican que haya un déficit cognitivo en los afectados, debido a que algunos manifestaron que el deterioro de la visión les impedía leer correctamente.

\section{Función ejecutiva}

Para Verdejo y Bechara (2010), las funciones ejecutivas constituyen mecanismos de integración intermodal e intertemporal que permiten proyectar cogniciones y emociones desde el pasado hacia el futuro con el objeto de resolver situaciones novedosas y complejas. Esto implica observar cómo los participantes establecen semejanzas, hacen cálculos u observan secuencias lógicas de los acontecimientos con el fin de llevar a cabo el cumplimiento de objetivos. En el instrumento, este apartado está dividido en dos grandes grupos: las funciones conceptuales y las motoras (figura 23). 
Figura 23. Funciones ejecutivas conceptuales

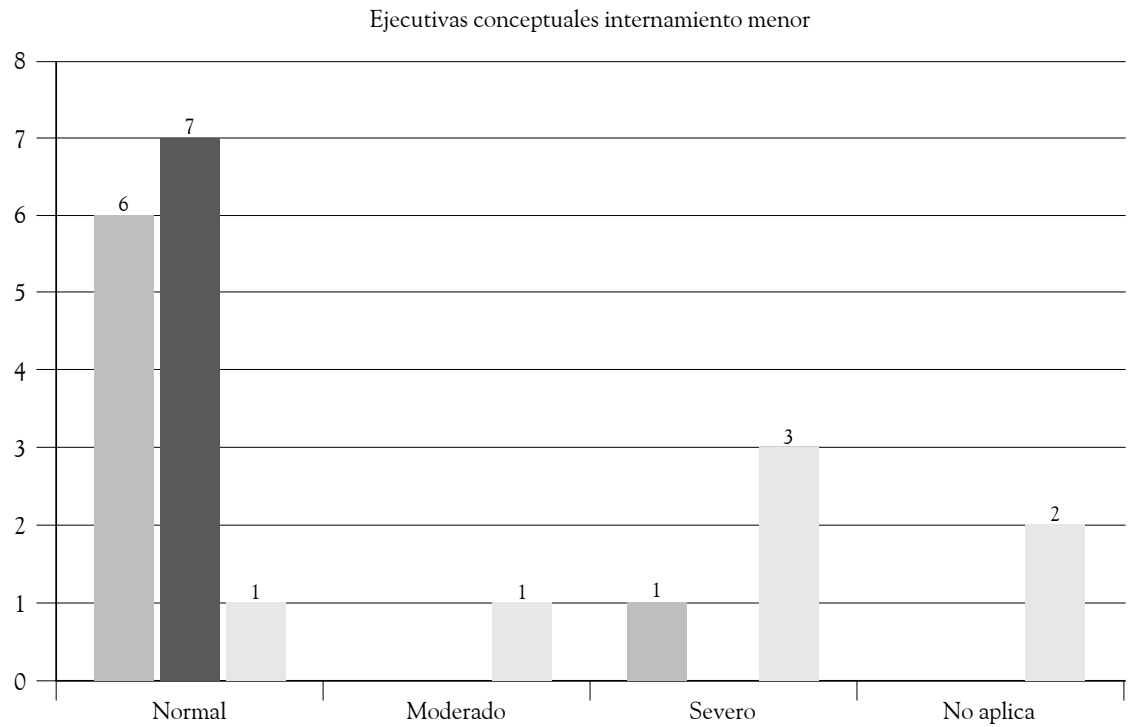

Funciones ejecutivas conceptuales semejanza

Funciones ejecutivas conceptuales cálculo

Funciones ejecutivas conceptuales secuencial

Ejecutivas conceptuales internamiento intermedio

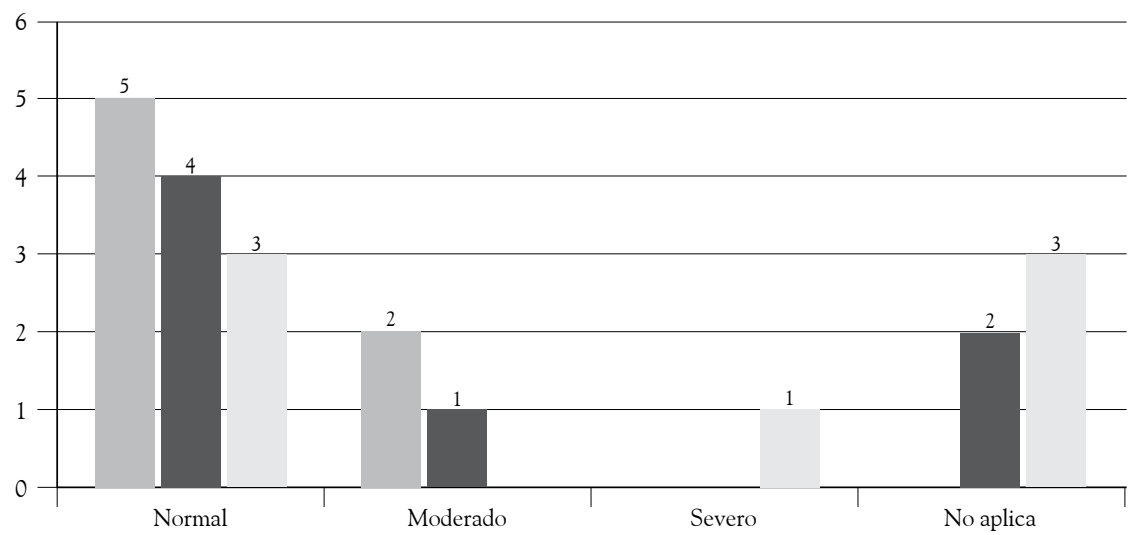

Funciones ejecutivas conceptuales semejanza

Funciones ejecutivas conceptuales cálculo

Funciones ejecutivas conceptuales secuencial 


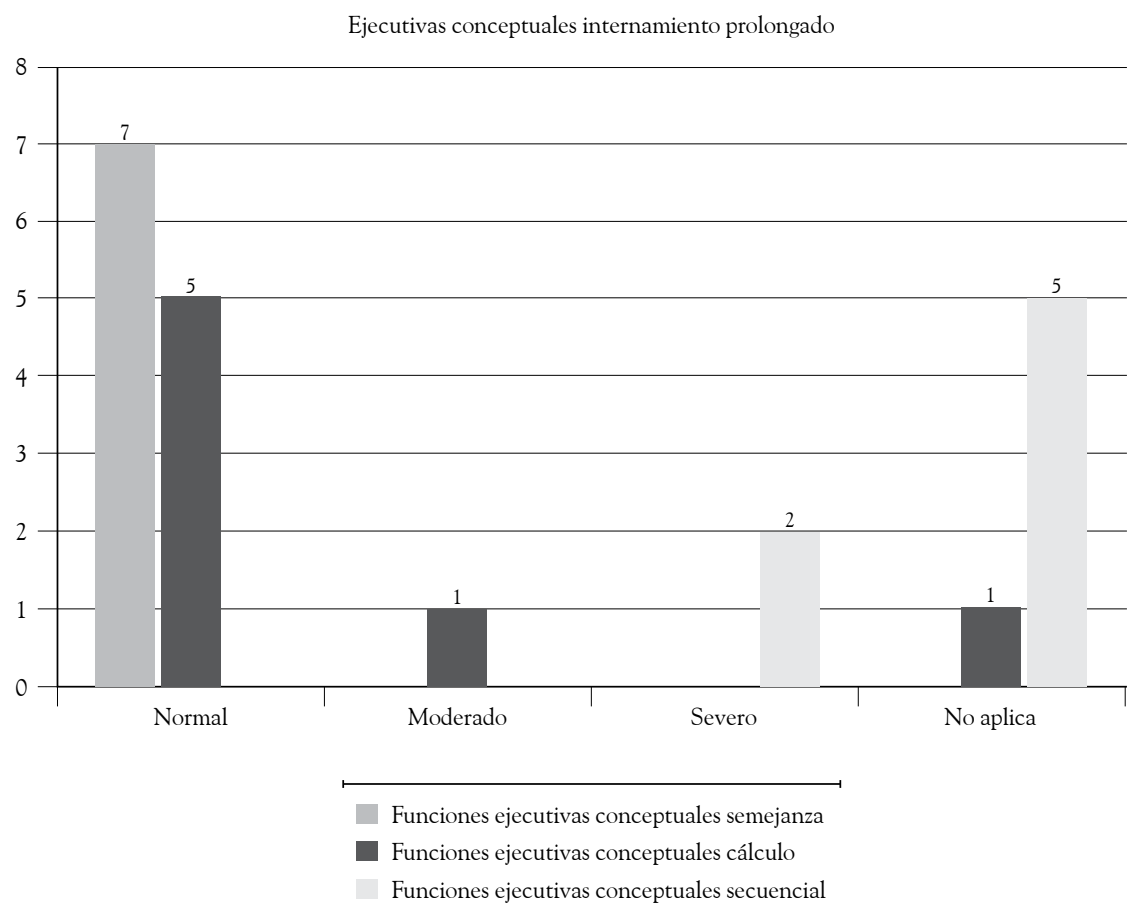

Fuente: elaboración propia.

En el internamiento menor se observó una alteración moderada en la función de secuenciación en un interno, y severa en 3 internos. Tanto en el grupo intermedio como en el prolongado la afectación severa de esta función apareció solo en un interno. En los internamientos intermedio y prolongado aparece solo un participante con alteración moderada en la función de cálculo.

La función semejanzas se encuentra asociada con el razonamiento analógico, que tiene que ver con la capacidad de entendimiento y explicación, de justificar las relaciones de semejanza, de encontrar conexiones entre los objetos y las situaciones, de poder hallar los esquemas de inferencia según la naturaleza del problema (Abregú, 2009); en otras palabras, se refiere a la capacidad de discriminar entre diferentes posibilidades que son adecuadas para cumplir un fin. En el grupo de internamiento menor, esta capacidad aparece con afectación severa en un sujeto, mientras que en el grupo intermedio, aparecieron 2 internos con alteración moderada. 
Consecuentemente con lo expuesto, se estableció que la función con mayor frecuencia de alteración fue la de secuenciación, que se encuentra directamente relacionada con la habilidad para anticipar, ensayar y ejecutar secuencias complejas de conducta en un plano prospectivo (Verdejo \& Bechara, 2010). En este sentido, los resultados mostraron que los participantes con esta afectación y menor tiempo de internamiento pueden llegar a experimentar dificultades en la planificación y la anticipación de actividades. Esta característica, en los AMPL, disminuyó en el grupo con internamiento intermedio y se elevó nuevamente en el grupo de internos detenidos por largo tiempo. Finalmente, es necesario mencionar que no se incluyeron resultados en funciones como secuenciación y cálculo, en algunos de los internos evaluados, como sucedió con la función lectoescritura (figura 24).

Figura 24. Funciones ejecutivas motoras

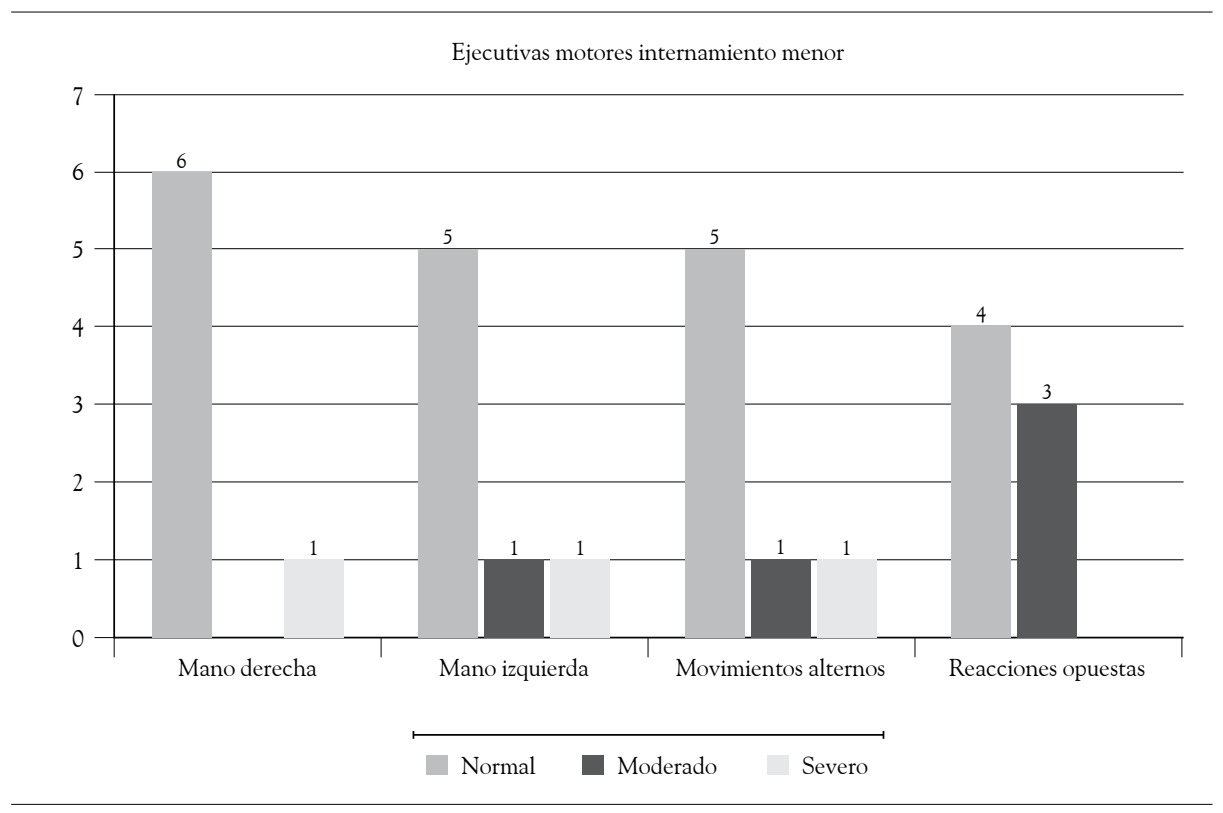




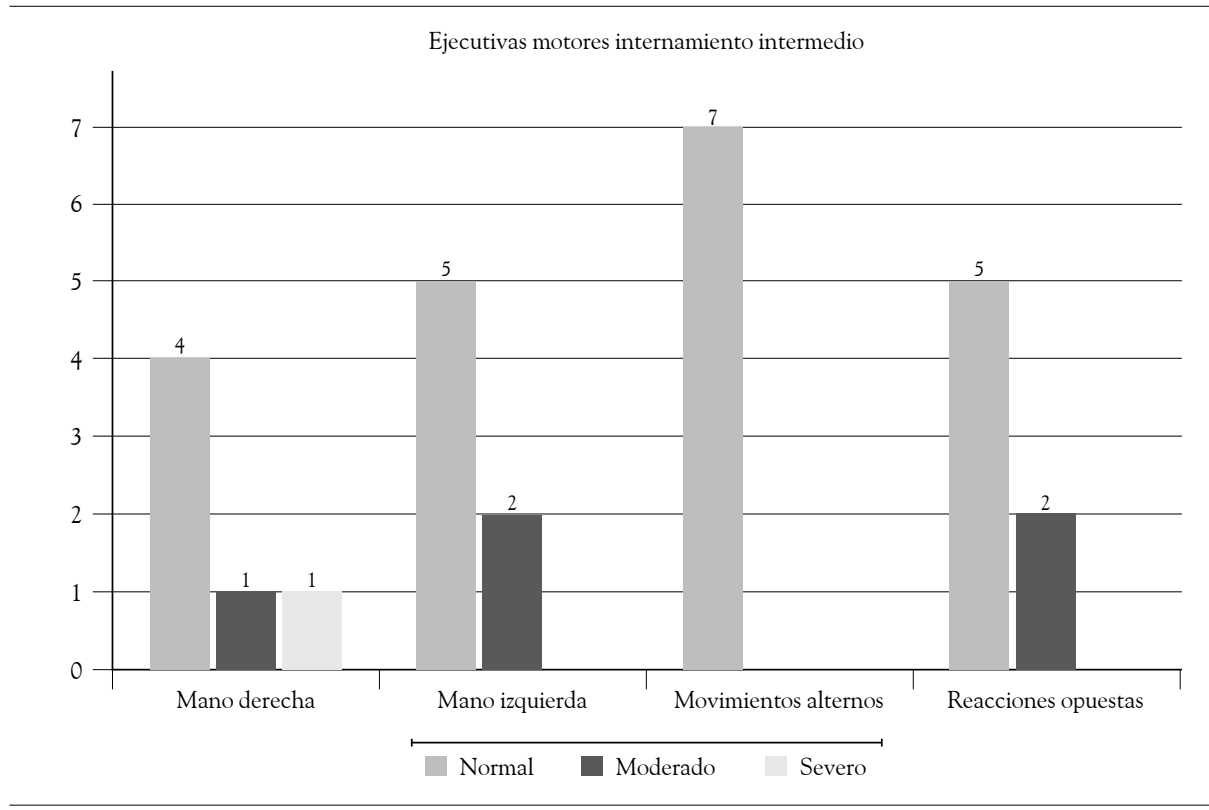

Ejecutivas motores internamiento prolongado

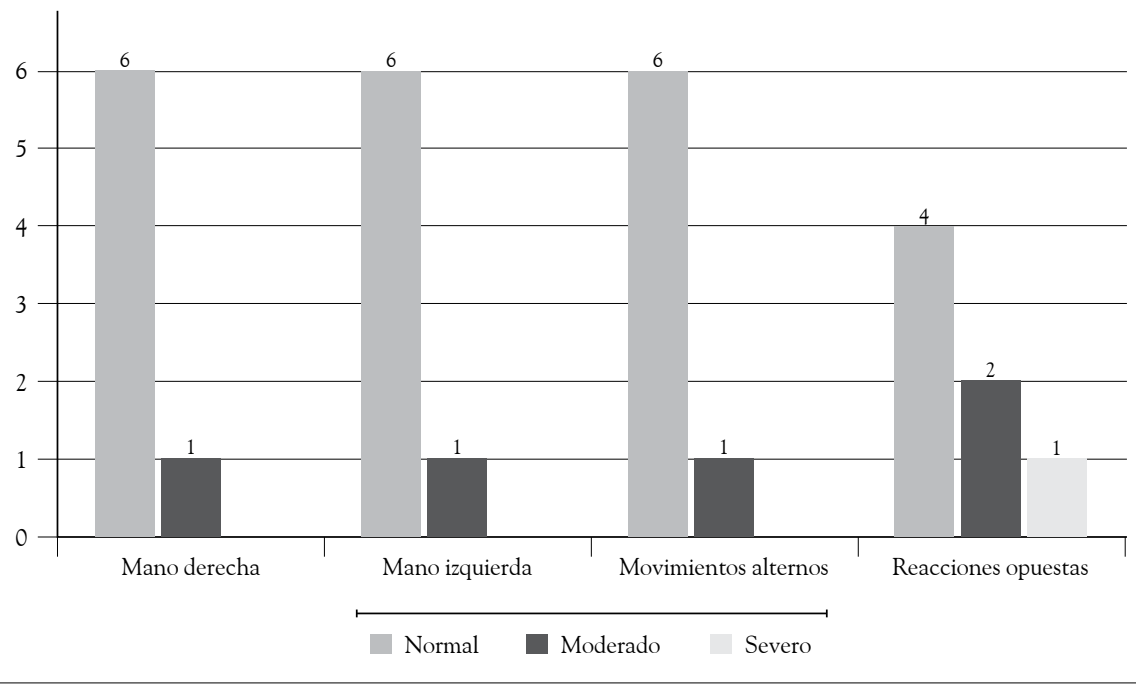

Fuente: elaboración propia.

Los resultados indicaron, en su gran mayoría, una actividad normal de los evaluados para las funciones ejecutivas motoras en todos los niveles de internamiento. Como quiera que estas se encargan de organizar y administrar la acción de todas las funciones cognitivas que se evaluaron, se puede decir que estos internos poseen la capacidad de administrar adecuadamente 
las habilidades. Sin embargo, estos resultados también mostraron que por cada 1 de los 2 primeros niveles de internamiento, se presentó un sujeto con alteración severa en la mano derecha, y un sujeto del primer momento de internamiento mostró alteración severa en el uso de la mano izquierda.

Cuando la tarea implicó el uso de las dos manos de manera alterna, se observó alteración severa en uno de los internos iniciales en prisión. En cuanto a la tarea que implicaba movimientos opuestos para cada una de las manos, se percibió una alteración moderada en 3 internos iniciales, 2 intermedios, y una alteración severa en 1 de los internos con estancia prolongada en la cárcel.

En estos sujetos en los que se presentó algún nivel de alteración se hace necesario descartar o corroborar la presencia de una lesión en la corteza premotora, que es la que permite la planeación, la organización y la ejecución secuencial de movimientos y acciones complejas (Flores \& Ostrosky, 2008).

En suma, a partir de cada una de las pruebas que componen la batería Neuropsi, y que calificaron el desempeño de los AMPL, se pudo establecer que estos se encontraban ubicados en tiempo, espacio y persona en el momento de realizar la prueba. Los internos con menor tiempo de internamiento presentaron disminución en la velocidad con que procesan, retienen y evocan la información, posiblemente porque están influenciados por las situaciones de adaptación al entorno y demás que se presentan durante el inicio del internamiento.

Por otra parte, la función memoria de los sujetos afectados presenta alteración principalmente en la evocación por categorías, en especial en el grupo con internamiento prolongado. Por contraste, la evocación por procesos visoespaciales se convierte en el recurso mediante el cual algunos de los evaluados traen al presente de nuevo lo aprendido. Además, no se observa alteración en la función lenguaje en los evaluados, que permita inferir la presencia de daños neurológicos producto del envejecimiento o lesión cerebral, y la principal alteración apareció en la dificultad para comprender instrucciones.

Las condiciones de aplicación del instrumento conllevaron la exclusión de un grupo de internos por su nivel educativo, cuando se llevó a cabo 
el apartado de lectoescritura. Es necesario aplicar instrumentos que faciliten la evaluación de estas funciones y su relación con el deterioro cognitivo y el paso del tiempo.

Existe normalidad en el ejercicio de las funciones ejecutivas de los evaluados, por cuanto los internos que obtuvieron esos resultados están en la capacidad de adaptarse a situaciones nuevas con respuestas adecuadas a las exigencias del contexto. Esto resalta la importancia de tener en cuenta a los sujetos con algún nivel de alteración en funciones motoras para valoraciones más precisas.

\section{Condiciones psicopatológicas}

Los resultados de la primera parte hacen referencia a la descripción de los datos de la muestra en general (21 participantes), de acuerdo con las dimensiones sintomáticas, la percepción de gravedad de los síntomas y la referencia de los ítems críticos que más fueron seleccionados por los participantes. En la segunda parte, se discriminan los datos por tiempo de internamiento, específicamente de las dimensiones sintomáticas.

Para la extracción de los datos, se calificaron las pruebas de acuerdo con las plantillas, y los puntajes directos se convirtieron a puntuaciones $\mathrm{T}$, de acuerdo con los baremos de población no clínica expuestos por el instrumento. De este modo, se tomaron como significativos aquellos que se encontraron por encima del T 58, donde se considera como positiva o presente la dimensión psicopatológica que se está comparando; del mismo modo ocurrió para los índices globales y para los ítems críticos.

Respecto a los resultados del total de la población, se obtuvo, dentro de las dimensiones psicopatológicas a nivel general, que la depresión fue positiva en mayor frecuencia, en este caso, en 12 participantes; seguida, en igual cantidad, por las condiciones de somatización y obsesión compulsiva, en 11 participantes. Finalmente, la ideación paranoide se registró en 10 participantes (figura 25). 
Figura 25. Dimensiones psicopatológicas generales

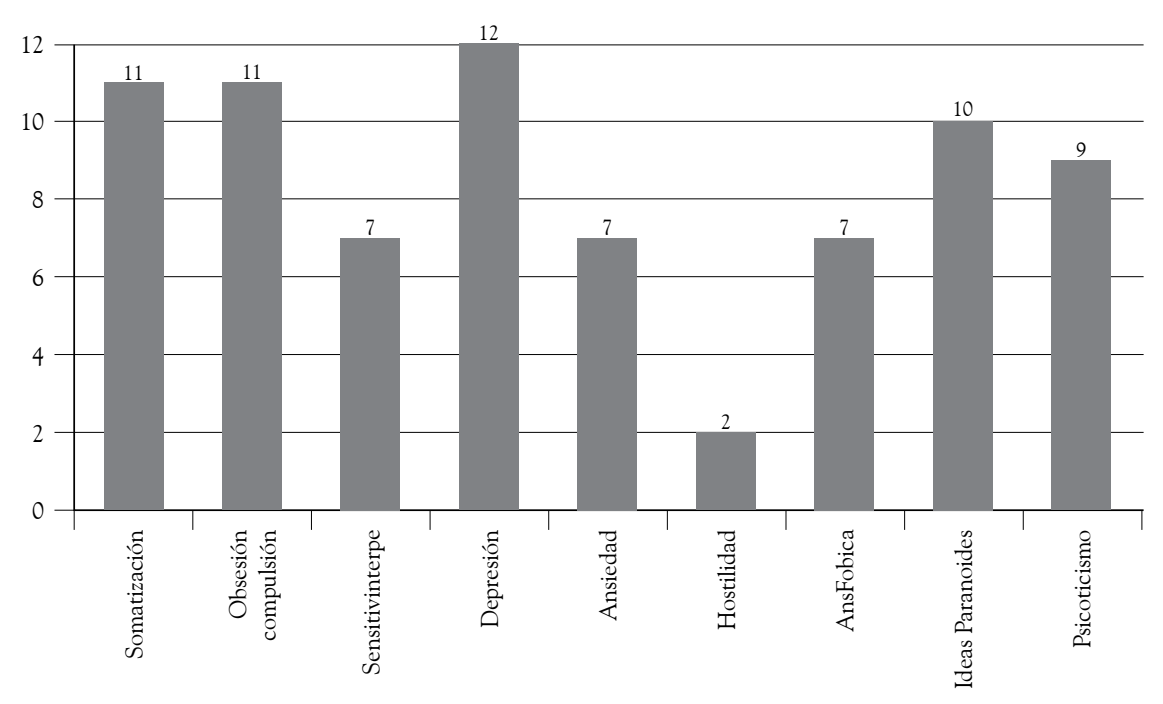

Fuente: elaboración propia.

A partir de este primer análisis de los resultados, se concluye que los internos que mostraron síntomas positivos para la depresión corresponden al $57 \%$ del total de los evaluados. Este elevado número deber ser tenido en cuenta pues si bien la muestra es pequeña, encontrar 12 personas con poco interés por las cosas, pensamientos fatalistas, sentimientos de desesperanza hacia el futuro o con la sensación de ser inútiles o no valer nada - que son algunos de los ítems que respondieron positivamente- definitivamente amerita intervención con el fin de prevenir consecuencias como el suicidio, fenómeno latente en prisión; lo cual se puede contrastar con el estudio de Mojica et al. (2009), llevado a cabo en un EPC colombiano, donde se concluyó que los reclusos que presentan riesgo suicida tienen mayores grados y niveles moderados y altos de desesperanza y de depresión, y existe una correlación positiva entre el riesgo suicida y estas 2 variables. Además, este aspecto también se corresponde con la afectación que apareció con mayor frecuencia en las participaciones de los AMPL en los grupos focales, cuando se habló acerca de la percepción de enfermedad mental o psicológica. 
En cuanto a los internos que observan síntomas positivos en somatización, se hace necesario descartar que estos indicadores no estén relacionados con una patología médica, toda vez que las preguntas indagan sobre enfermedades en los sistemas cardiovascular, respiratorio, gastrointestinal y muscular, que son percibidos, según los AMPL, como los más afectados en la cárcel, como se estableció en el apartado "Percepción de enfermedades físicas en prisión".

La obsesión-compulsión que aparece con síntomas positivos en 11 de los participantes muestra que en ellos pueden estar presentes los siguientes aspectos: la preocupación acerca del desaseo, el descuido o la desorganización; sentirse incapaces de hacer las cosas o terminar las tareas; la dificultad para tomar decisiones; entre otros. Esto es concordante con las condiciones ambientales que pueden conllevar consecuencias no deseables del envejecimiento vinculadas a estilos de vida y condiciones del entorno en la cárcel, frente a las cuales no pueden hacer nada, y que fueron expuestas por los AMPL en los grupos focales. Además, esto tiene relación con lo encontrado por Ruiz (2007), en cuanto que un mayor nivel de malestar emocional se asoció con una evaluación más negativa del clima emocional y una percepción más elevada de no poder disfrutar de las cosas.

Por otra parte, la ideación paranoide, presente en 10 de los internos, incluyó respuestas positivas en ítems como la idea de no poderse fiar de la gente, la sensación de que las otras personas lo miran o hablan mal de él, la percepción de que los otros no reconocen adecuadamente los méritos o la impresión de que los demás son los culpables de los problemas. En este sentido, existe una relación con la subdimensión exclusión y condiciones ambientales, en la que se agruparon las respuestas de los AM participantes en los grupos focales cuando hablaron de la experiencia de la adultez mayor en la cárcel, enmarcada en la sensación de no ocupar un lugar que en determinado momento de la vida tuvieron, el rechazo de otros, la percepción de incomodidad, las amenazas de otros internos, la sensación de no contar con protección ni privilegios.

Vale la pena mencionar que el índice global de severidad, es decir, el indicador del nivel actual de la severidad del malestar (Derogatis, 2002) fue positivo para 8 de los participantes, consecuentemente con los sujetos 
con mayor número de dimensiones positivas; lo que indica, de este modo, un mayor malestar psicológico, como se puede apreciar en la tabla 20.

Tabla 20. Índice global de severidad en los adultos mayores privados de la libertad

\begin{tabular}{|c|c|c|}
\hline N. ${ }^{\circ}$ de dimensiones positivas & N. $^{\circ}$ de Sujetos & Positivo IGS \\
\hline Ninguna & 4 & 0 \\
\hline 1 & 4 & 0 \\
\hline 2 & 2 & 0 \\
\hline 3 & 1 & 0 \\
\hline 4 & 2 & 0 \\
\hline 5 & 1 & 1 \\
\hline 6 & 1 & 1 \\
\hline 7 & 3 & 3 \\
\hline 8 & 2 & 1 \\
\hline 9 & 1 & \\
\hline
\end{tabular}

Fuente: elaboración propia.

Teniendo en cuenta que este índice presenta una medida de la intensidad del sufrimiento psíquico y psicosomático en general, se puede decir que en estos internos está presente la necesidad de realizar evaluaciones puntuales para establecer el nivel actual o la profundidad del trastorno y cuáles son las necesidades de atención específicas con el fin de articular acciones tendientes a la disminución de estos síntomas en los planes de tratamiento penitenciario.

Los resultados analizados en razón del tiempo de internamiento permitieron observar que en el internamiento menor, las 2 dimensiones que más se presentan en 6 sujetos son depresión y obsesivo-compulsión; en la primera se consideran signos y síntomas clínicos propios de los trastornos depresivos. De acuerdo con el manual, se incluyen aquellos relacionados con vivencias disfóricas, de desánimo, anhedonia, desesperanza, impotencia y falta de energía; así como manifestaciones cognitivas relacionadas con muerte y autodestrucción. Este mismo autor describe la segunda como 
"conductas, pensamientos e impulsos que el sujeto considera como absurdos e indeseados, que generan intensa angustia y que son difíciles de resistir, evitar o eliminar. También se relacionan con los fenómenos cognitivos de trastorno y personalidades obsesivas" (Derogatis, 2002). Asimismo, aparece como positiva, en segundo lugar, la dimensión de somatización en 5 sujetos; esto es indicador de sintomatología relacionada con vivencias desagradables frente al funcionamiento del cuerpo y, como lo describe el autor, es posible que estén mostrando una patología médica.

Figura 26. Resultados en razón del tiempo de internamiento

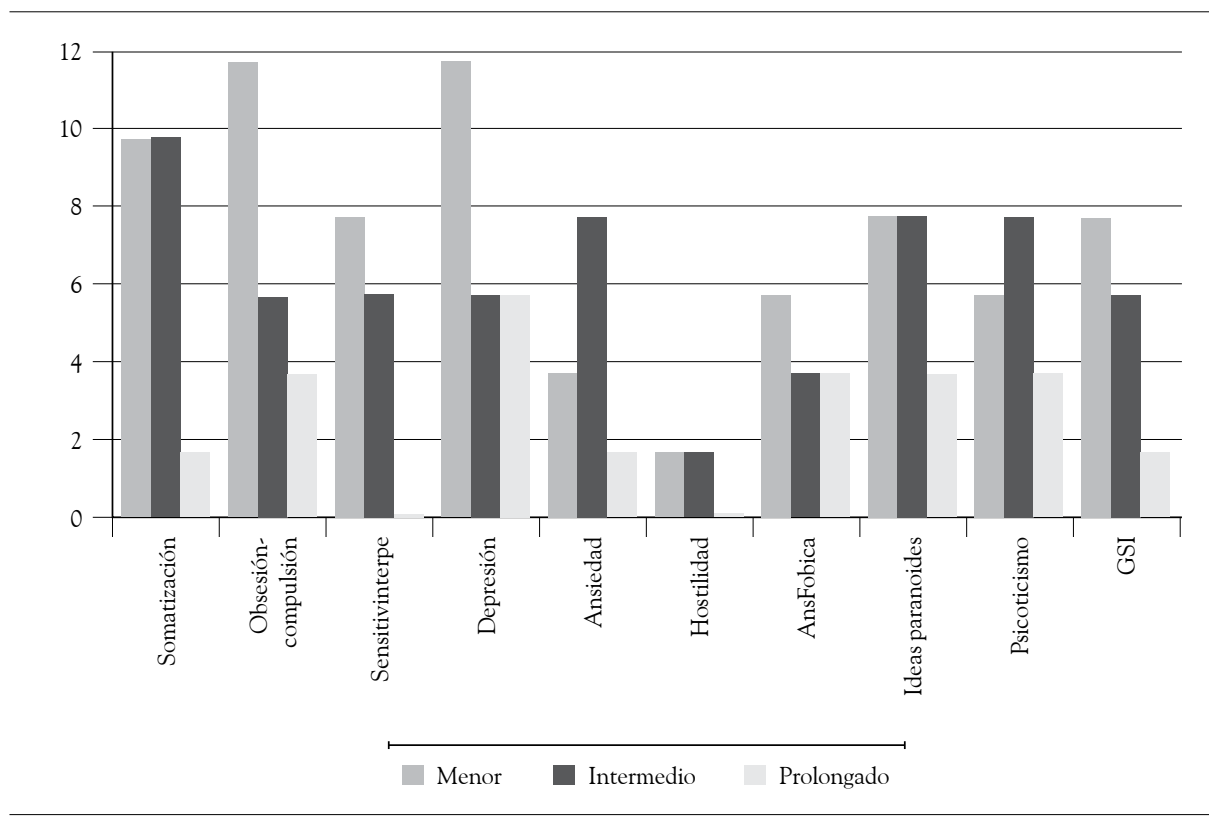

Fuente: elaboración propia.

Frente al internamiento intermedio, se evidenció que la dimensión de somatización es la que más se presenta en 5 participantes. Las dimensiones de ansiedad (signos generales de tensión emocional y manifestaciones psicosomáticas), ideación paranoide (asociada a aspectos de la conducta paranoide en especial a pensamientos proyectivos) y psicoticismo (de acuerdo con Derogatis, esta dimensión se relaciona en población no clínica, en mayor medida con alienación social) se presentan en igual proporción en 4 participantes. En este intervalo de tiempo, se puede observar que, en 
comparación con el internamiento menor, el número de participantes que presentan dimensiones sintomáticas positivas disminuye. Pero la ansiedad es la única dimensión que aumenta en comparación con los que llevan menos tiempo de internamiento. En cuanto al internamiento prolongado, se percibe que el número de dimensiones sintomáticas disminuye en relación con los anteriores intervalos de tiempo; no obstante, la depresión es la dimensión que más se presenta en 3 sujetos.

Al realizar algunas asociaciones entre variables, se observó que a mayor condena impuesta, los participantes reflejaban menores frecuencias positivas en somatización, sensitivismo interpersonal e ideación paranoide y, asimismo percibían menor malestar psicológico (GSI). En relación con la edad, se asoció que a mayor edad, se elevaba la frecuencia positiva de sensitivismo interpersonal y percibían mayor malestar psicológico. De igual manera, se percibió que los participantes que llevaban más tiempo privados de la libertad, presentaban menor frecuencia positiva en las dimensiones de somatización y sensitivismo interpersonal.

En conclusión, se puede afirmar que para los 21 participantes de esta parte del estudio, el mayor número de dimensiones positivas se presenta en el internamiento menor en comparación con los otros 2 tiempos de internamiento. En relación con el aspecto psicopatológico, existe el indicador de que a mayor tiempo de internamiento, menor número de alteraciones psicológicas presentan los AMPL. La somatización es significativa en los 2 primeros intervalos de tiempo de internamiento y la depresión es constante para los 3 intervalos. La ansiedad se presenta en más sujetos en el intervalo de tiempo intermedio. Respecto a la ideación paranoide, se mantiene homogénea en los 2 primeros tiempos de internamiento y disminuye significativamente en el internamiento prolongado.

\section{Percepción de enfermedad mental o psicológica de los adultos mayores privados de la libertad}

Para este apartado de la caracterización, la información se obtuvo a partir de las respuestas de los grupos focales. La pretensión fue observar algunas 
condiciones de enfermedad desde lo psicológico que estuvieran asociadas al internamiento, y conceptualmente se utilizó el término psicopatología para describir trastornos del funcionamiento de la vida mental.

De acuerdo con la naturaleza de los términos empleados para describir de qué se enferman mentalmente o psicológicamente los AMPL, estos se agruparon, teniendo en cuenta la sintomatología, y en ningún caso los diagnósticos, en 3 grandes categorías: estrés, depresión y, desde lo fenomenológico, los síntomas asociados con el malestar psicológico. Para presentar lo anterior, se elaboró la tabla 21 con algunas de las expresiones más representativas.

Tabla 21. Manifestación psicopatológica en los grupos focales de los adultos mayores privados de la libertad

\begin{tabular}{|c|c|c|}
\hline \multicolumn{3}{|c|}{ Manifestación psicopatológica } \\
\hline Estrés & Depresión & $\begin{array}{c}\text { Síntomas de malestar } \\
\text { psicológico }\end{array}$ \\
\hline $\begin{array}{l}\text { "Es el estrés, aquí no sabe- } \\
\text { mos que es el estrés, pero } \\
\text { hay algo que lo enferma a } \\
\text { uno más todavía, que es el } \\
\text { estrés, aquí no sabemos que } \\
\text { es el estrés, pero el estrés lo } \\
\text { mata a uno, lo enferma del } \\
\text { corazón, de muchas cosas, } \\
\text { son enfermedades adqui- } \\
\text { ridas por solo el hecho de } \\
\text { estar encerrado y uno no } \\
\text { adivina con ellas. No es que } \\
\text { tengo gripa, es que me due- } \\
\text { le esto, me duele aquello, } \\
\text { mentiras es que el estrés lo } \\
\text { mata a uno lo pone en difi- } \\
\text { cultades para poder...". }\end{array}$ & $\begin{array}{l}\text { "La depresión hay momen- } \\
\text { tos que hay mucha depre- } \\
\text { sión, de pronto uno de pen- } \\
\text { sar la situación, uno en la } \\
\text { familia". } \\
\end{array}$ & $\begin{array}{l}\text { “... el problema psicológico } \\
\ldots ”\end{array}$ \\
\hline
\end{tabular}




\begin{tabular}{|c|c|c|}
\hline \multicolumn{3}{|c|}{ Manifestación psicopatológica } \\
\hline Estrés & Depresión & $\begin{array}{c}\text { Síntomas de malestar } \\
\text { psicológico }\end{array}$ \\
\hline $\begin{array}{l}\text { "Yo estuve en el Ejército y } \\
\text { poco me afecta, pero lógica- } \\
\text { mente uno se estresa, llega } \\
\text { al patio y lo único que uno } \\
\text { hace es ver televisión". }\end{array}$ & $\begin{array}{l}\text { "Sí, porque uno tiene unos } \\
\text { días con mucha depresión, } \\
\text { mire yo estando aquí priva- } \\
\text { da de la libertad perdí a mi } \\
\text { hermana que me cuidaba a } \\
\text { mis hijos". }\end{array}$ & $\begin{array}{l}\text { "Hay una señora que parece } \\
\text { que fuera... pues nosotros } \\
\text { le decíamos la psiquiátrica, } \\
\text { pero esa señora estaba nor- } \\
\text { mal, normal... y estaba hasta } \\
\text { charlando, cuando dijo 'tengo } \\
\text { un mareo'y yo le dije 'recués- } \\
\text { tese'... nosotras prestándole } \\
\text { atención porque nos da ner- } \\
\text { vios... porque ella no duerme } \\
\text { en la noche, no duerme". }\end{array}$ \\
\hline $\begin{array}{l}\text { "Estrés por las peleas, por los } \\
\text { operativos porque le votan } \\
\text { todo a uno a la basura, todo } \\
\text { eso lo altera a uno". }\end{array}$ & $\begin{array}{l}\text { "En el patio llegó un señor } \\
\text { que está deprimido y vino } \\
\text { con una herida en la pierna } \\
\text { y van a tener que cortarle la } \\
\text { pierna, a la enfermera le da } \\
\text { fastidio hacerle curación, } \\
\text { mantiene con fiebre alta y } \\
\text { sicológicamente destruido } \\
\text { y hemos propuesto que este } \\
\text { señor necesita tratamiento } \\
\text { sicológico y clínico espe- } \\
\text { cial”. }\end{array}$ & $\begin{array}{l}\text { "Aquí existe una parte (in- } \\
\text { comprensible), cansancio ce- } \\
\text { rebral, enfermedad mental, } \\
\text { un tratamiento psiquiátrico, } \\
\text { un tratamiento que es perju- } \\
\text { dicial hacia la salud". }\end{array}$ \\
\hline \multirow[t]{2}{*}{$\begin{array}{l}\text { "Cómo es posible que aquí } \\
\text { se traiga gente enferma para } \\
\text { que se rehabiliten, y vengan } \\
\text { a delinquir y no salgan peor, } \\
\text { eso a uno le produce estrés". }\end{array}$} & $\begin{array}{l}\text { "Yo estoy en tratamiento de } \\
\text { depresión, acá lo único que } \\
\text { se consiguen son enferme- } \\
\text { dades". }\end{array}$ & $\begin{array}{l}\text { "Eso hace que me aparezca } \\
\text { una enfermedad que nunca } \\
\text { tenía, la droga esa... esa pa- } \\
\text { ra mantenerlo a uno dizque } \\
\text { dormido, eso es perjudicial". }\end{array}$ \\
\hline & $\begin{array}{l}\text { "La tristeza, ver el cambio, } \\
\text { el hacinamiento, revueltos } \\
\text { con otras personas de dife- } \\
\text { rente formas de proceder, } \\
\text { entonces el cambio sicoló- } \\
\text { gico es de un } 100 \% \text { más que } \\
\text { todo deprimente". }\end{array}$ & $\begin{array}{l}\text { "Si claro, su familia, sus nietos } \\
\text { - Pensar en la familia. } \\
\text { - Claro, pensar en la familia, } \\
\text { eso le trabaja el coco a uno, } \\
\text { ahí es donde vienen las en- } \\
\text { fermedades". }\end{array}$ \\
\hline
\end{tabular}




\begin{tabular}{|c|c|c|}
\hline \multicolumn{3}{|c|}{ Manifestación psicopatológica } \\
\hline Estrés & Depresión & $\begin{array}{c}\text { Síntomas de malestar } \\
\text { psicológico }\end{array}$ \\
\hline $\begin{array}{l}\text { "Aquí siempre se ha escu- } \\
\text { chado mucho más, es el es- } \\
\text { trés, el estrés de la persona". }\end{array}$ & $\begin{array}{l}\text { "La familia se afecta mucho, } \\
\text { psicológicamente las fami- } \\
\text { lias se afectan mucho... y } \\
\text { uno también". }\end{array}$ & $\begin{array}{l}\text { "Yo durante toda mi vida has- } \\
\text { ta mi vejez cometí un delito, } \\
\text { cometí un error, nada. Y venir } \\
\text { después de } 65 \text { años... eso es } \\
\text { duro. Yo los primeros días yo } \\
\text { lloraba, yo mantenía la cabe- } \\
\text { za encerrada, yo no veía para } \\
\text { dónde, ya luego uno se va } \\
\text { adaptando". }\end{array}$ \\
\hline \multirow[t]{2}{*}{$\begin{array}{l}\text { "Hay otro caso en el que los } \\
\text { mismos guardianes tienen } \\
\text { que cuidar de nosotros, nos } \\
\text { estresan mucho, hay unas } \\
\text { personas que viven muy } \\
\text { amargadas y que van a des- } \\
\text { cargar toda esa amargura } \\
\text { con nosotros". }\end{array}$} & & $\begin{array}{l}\text { "Pues nosotros siempre ve- } \\
\text { nimos enfermos, porque yo } \\
\text { tengo un problema psiquiátri- } \\
\text { co y mucho dolor de cabeza y } \\
\text { aquí no hay nadie que lo vea } \\
\text { a uno. Por más que uno llore, } \\
\text { salga y pida auxilio, no, como } \\
\text { le digo media ampolla de dipi- } \\
\text { rona y eso no alienta a nadie". }\end{array}$ \\
\hline & & $\begin{array}{l}\text { "Algunas se generan acá por } \\
\text { el encierro, las preocupacio- } \\
\text { nes. Por el hacinamiento". }\end{array}$ \\
\hline \multirow[t]{2}{*}{$\begin{array}{l}\text { "Aguante hambre. } \\
\text { Desde las } 3 \text { p. m. hasta el } \\
\text { otro día a las } 6 \text { a. m., eso } \\
\text { va artillando en el estado } \\
\text { de ánimo de uno en el... } \\
\text { en todo... ya uno se siente } \\
\text { incómodo, muchas veces } \\
\text { le da hasta rabia porque el } \\
\text { hambre da rabia". }\end{array}$} & & $\begin{array}{l}\text { "El ruido de la gente, la ha- } \\
\text { bladera, esa bulla traen pro- } \\
\text { blemas sicológicos al cerebro, } \\
\text { se siente como si la cabeza le } \\
\text { fuera a estallar". }\end{array}$ \\
\hline & & $\begin{array}{l}\text { En la sola entrada el cambio } \\
\text { es sicológico. }\end{array}$ \\
\hline
\end{tabular}

Fuente: grupos focales en los EPC visitados. 
Esta organización permitió relacionar particularidades que ameritan ser tenidas en cuenta como parte de la caracterización. En primera medida, los síntomas de estrés se asociaron con situaciones específicas del entorno que, en este caso, se refieren a las dinámicas de prisión frente a las cuales los AMPL no pueden hacer nada para modificarlas. En relación con lo anterior, se debe tener en cuenta que el estrés es una manifestación de ajuste ante un estímulo o evento considerado como negativo para el sujeto, por lo que se infiere que las dinámicas de prisión por sí mismas son fuente de estrés para esta población.

Los síntomas de depresión, por el contrario, estuvieron asociados a emociones, sentimientos y situaciones de los internos con respecto a las dificultades y la limitación de contacto con las personas cercanas o familiares. Lo anterior es relacional con el estudio de Pulido et al. (2009), el cual indica que hay una mayor cantidad de síntomas depresivos cuando los internos tienen poco contacto con sus hijos y familiares, y frente a la percepción de su propia salud. A partir de lo anterior, se percibe la importancia de desarrollar actividades que permitan el acercamiento, el restablecimiento o la creación de redes de apoyo con personas o instituciones para disminuir esos efectos de la prisión.

En la tercera columna aparecen síntomas que se relacionan con el malestar psicológico; se perciben como conductas que no se consideran normales o pensamientos y sentimientos no especificados o desagradables; se hace referencia a que el malestar psicológico es producto de la interacción cotidiana en prisión. En este mismo apartado aparecen percepciones negativas frente al tratamiento con medicación.

Es claro que los síntomas de estrés, depresión y malestar psicológico, desde la psicología, en primera instancia se pueden observar, en este contexto, como reacciones adaptativas al medio y a su condición de internamiento. No obstante, para que sean consideradas como psicopatológicas, es necesario contrastarlas con el factor tiempo, ya que se espera que a lo largo de la condena, estas sean "estabilizadas". Al respecto, en su estudio, Ruiz (2007) indica que se presentó una mayor sintomatología emocional asociada a llevar menor tiempo en prisión, enfrentar situaciones estresantes cotidianas y tener poco apoyo social. 


\section{Necesidad de atención integral}

El Código Penitenciario y Carcelario prevé que tanto la atención social como el tratamiento penitenciario deben responder a necesidades específicas de los internos. En este ejercicio investigativo, se encontraron una serie de carencias asociadas a aspectos psicológicos, físicos y de hábitos saludables, en correspondencia directa a las exigencias de atención por parte de los AMPL.

La solicitud de atención psicológica solo tiene lugar cuando se ve como necesaria, en situaciones límite como en el momento de ingreso al establecimiento o cuando hay un deterioro visible en el porte o la actitud del individuo. De otro lado, un Estado consciente de autocuidado atañe a la exigencia del desarrollo de actividades que impliquen movimiento físico, como un elemento primordial para disminuir los efectos del confinamiento. Seguidamente, los AMPL no tienen la posibilidad de modificar la alimentación de acuerdo con sus necesidades alimentarias específicas, y esto parece conjugarse con hábitos que son desfavorables para la salud. En algunos casos, da la impresión que viven una serie de restricciones alimenticias en la semana que son satisfechas en exceso los días de visita (tabla 22). En general, las 3 particularidades que se mencionan a continuación tienen un punto de encuentro: la ausencia de actividades de tipo preventivo para la salud mental y física de los AMPL.

Tabla 22. Referencias sobre necesidades de los adultos mayores privados de libertad

\begin{tabular}{|c|c|c|}
\hline $\begin{array}{l}\text { Referencias a la necesidad de } \\
\text { atención psicológica }\end{array}$ & $\begin{array}{c}\text { Referencias a la necesidad } \\
\text { de actividades de promoción } \\
\text { de la salud física }\end{array}$ & Otras necesidades \\
\hline $\begin{array}{l}\text { "Es la parte primordial que se } \\
\text { le debe trabajar a un interno } \\
\text { cuando llega a un sitio de } \\
\text { estos, esa es la parte primor- } \\
\text { dial, la parte psicológica". } \\
\text { "No hay nada de eso acá". }\end{array}$ & $\begin{array}{l}\text { "Es que no existe de hacer } \\
\text { un ejercicio, de hacer algo } \\
\text { para el AM, nosotros que } \\
\text { necesitamos hacer ejerci- } \\
\text { cio, moverse uno el cuerpo } \\
\text { de uno". }\end{array}$ & $\begin{array}{l}\text { "Aquí la única forma para } \\
\text { que lo saquen al médico rápi- } \\
\text { do es viéndolo a uno cortán- } \\
\text { dose, aunque yo no lo haría } \\
\text { ni a palo". }\end{array}$ \\
\hline
\end{tabular}




\begin{tabular}{|l|l|l|}
\hline $\begin{array}{c}\text { Referencias a la necesidad de } \\
\text { atención psicológica }\end{array}$ & $\begin{array}{c}\text { Referencias a la necesidad } \\
\text { de actividades de promoción } \\
\text { de la salud física }\end{array}$ & \multicolumn{1}{|c|}{ Otras necesidades } \\
\hline $\begin{array}{l}\text { "Mantiene con fiebre alta y } \\
\text { sicológicamente destruido } \\
\text { y hemos propuesto que este } \\
\text { señor necesita tratamiento } \\
\text { sicológico y clínico especial". }\end{array}$ & $\begin{array}{l}\text { y se afecta la movilidad". } \\
\text { co, hos cambiado el físi- }\end{array}$ & $\begin{array}{l}\text { "Él es hipertenso, come mu- } \\
\text { cho, le gusta mucho la grasa, } \\
\text { esas carnes gordas, el domin- } \\
\text { go 3 o 4 caseros". }\end{array}$ \\
\hline & $\begin{array}{l}\text { "Acá es acumulación de gra- } \\
\text { sas. Le dan a uno una sopas } \\
\text { que lo único que le echan es } \\
\text { grasa". }\end{array}$ \\
\hline
\end{tabular}

Fuente: grupos focales en los EPC visitados.

\section{Percepción de cambios experimentados en prisión}

Los internos manifestaron cambios que se han dado durante su estadía en prisión y no todos implican desmejoramiento, sino que están relacionados con lo que Paulus, Dzindolet y Valverde (citados en Becerra, Torres \& Ruiz, 2008) han descrito como prisionización, en relación con la adopción de modos y costumbres propias del ambiente carcelario como forma de adaptación a este.

$\mathrm{Al}$ respecto, se encontró que los internos resaltan, en su mayoría, cambios que favorecen la actividad intelectual, como el aumento de la lectura y la escritura, así como acciones direccionadas al autoconocimiento. En complemento, aparece la mención de experiencias de trasformación espiritual, en las que se asocia y visibiliza un estado de libertad, inclusive desde la apariencia física. Por otro lado, destacan cambios desfavorables en lo físico, relacionados con la alimentación y las condiciones ambientales como el hacinamiento. Finalmente, solo un participante manifestó que no percibe cambios en sus comportamientos a lo largo del tiempo: "En cuanto a mi comportamiento, es el mismo, no tengo nada que decir, ha sido el mismo en los 40 años" (grupo focal, EPMSC Bucaramanga, julio de 2013). Como ejemplo de lo anterior, se da a conocer la tabla 23. 
Tabla 23. Percepciones de cambios experimentados en prisión por los adultos mayores privados de la libertad

\begin{tabular}{|c|c|c|}
\hline Psicológicos & Fisiológicos & Espirituales \\
\hline $\begin{array}{l}\text { "Yo he aprendido aquí co- } \\
\text { nocimientos mejores, mo- } \\
\text { dos de vivir, he aprendido } \\
\text { a comportarme como un } \\
\text { ser humano con capacidad } \\
\text { intelectual". }\end{array}$ & $\begin{array}{l}\text { "Cuando yo llegué aquí, yo } \\
\text { no podía leer bien y de un } \\
\text { momento a otro ya puedo } \\
\text { leer muy bien, pero de cerca. } \\
\text { Mejoré de la vista”. }\end{array}$ & $\begin{array}{l}\text { "Cuando yo llegué aquí todo } \\
\text { se me derrumbó, me dije: 'yo } \\
\text { de esta no me salgo, si yo } \\
\text { no me muero, no aguanto', } \\
\text { yo le pedí tanto al señor de } \\
\text { rodillas y aquí estoy. Que día } \\
\text { vino un señor y me dijo: 'nos } \\
\text { vemos afuera' y yo le dije: } \\
\text { 'no señor, yo soy un inter- } \\
\text { no' y el señor me dijo: 'pero } \\
\text { usted parece que estuviera } \\
\text { libre' 'yo me siento libre, } \\
\text { conocí a cristo". }\end{array}$ \\
\hline $\begin{array}{l}\text { "Yo sentí el cambio, pero } \\
\text { viéndome en la oportuni- } \\
\text { dad de tener más tiempo de } \\
\text { escribir, de leer, para hacer } \\
\text { reflexiones. Se aprenden co- } \\
\text { sas para compartir con otros } \\
\text { allá afuera como referente } \\
\text { para que aprendan de algo". }\end{array}$ & $\begin{array}{l}\text { "Uno comía verduras, proteí- } \\
\text { nas, cosas que alimentan el } \\
\text { cerebro, entonces al no tener } \\
\text { uno una buena alimentación } \\
\text { no va tener una buena salud". }\end{array}$ & $\begin{array}{l}\text { "Si, lógico que sí, sobre todo } \\
\text { espiritualmente". }\end{array}$ \\
\hline $\begin{array}{l}\text { "Hay algo que se llama des- } \\
\text { pertar de la conciencia y eso } \\
\text { es un cambio muy impor- } \\
\text { tante". }\end{array}$ & $\begin{array}{l}\text { "Yo tengo osteoporosis y se } \\
\text { me ha complicado mucho la } \\
\text { situación". }\end{array}$ & \\
\hline $\begin{array}{l}\text { "Los cambios que he visto } \\
\text { son al revés, yo me sabía las } \\
\text { tablas al derecho y al revés, } \\
\text { ahora ya no coordino, he } \\
\text { perdido mucho la mente". }\end{array}$ & $\begin{array}{l}\text { "Del hacinamiento, por el } \\
\text { contacto con las demás per- } \\
\text { sonas, con los virus y las bac- } \\
\text { terias se vuelve uno más pro- } \\
\text { penso a perder defensas, en- } \\
\text { tonces cualquier enfermedad } \\
\text { lo ataca a uno más rápido". }\end{array}$ & \\
\hline
\end{tabular}

Fuente: grupos focales en los EPC visitados. 
De manera sucinta, se puede decir que existe un interés por parte de los AMPL por mostrar las necesidades que tienen con respecto a la atención en salud. Las enfermedades que asocian a su estancia en prisión son las mismas que sufren los AM en general, por lo que se confirma que la vejez se asocia a la enfermedad y, al parecer, el mal estado de salud en la cárcel aumenta por las condiciones de habitabilidad, la dificultad para el acceso a los servicios médicos y los tratamientos que se necesitan.

En cuanto al ajuste psicológico, producto de las realidades percibidas en prisión, se encuentra que el estrés, la depresión y la sintomatología psicológica son identificados por los AMPL como las principales afectaciones experimentadas. A partir de esta categorización, se analizan afirmaciones que establecen una relación causal entre estrés y situaciones propias de las dinámicas en los EPC como los horarios, la alimentación, el hacinamiento, entre otras. Entre tanto, la depresión se asocia con sentimientos generados por el alejamiento de las personas significativas, el rompimiento de relaciones o los problemas personales. No obstante, al hablar de los cambios en prisión, predomina una percepción favorable de estos, que dista de la adopción de costumbres carcelarias enmarcadas en la prisionización, y se enfocan en actividades de producción intelectual como la lectura, la escritura y otras orientadas al autoconocimiento; por lo anterior, es comprensible que siendo los síntomas de estrés y depresión constantes en la estadía en el establecimiento, solo perciben la necesidad de atención psicológica para eventos de crisis o como una forma de superar estados de estrés asociados a momentos fundamentales como el ingreso a la prisión y los cambios experimentados en todas las áreas de ajuste durante los primeros meses del internamiento.

\section{Condiciones sociales}

A continuación se describen cada uno de los elementos emergentes en las categorías sociológicas planteadas para el estudio: autopercepción del delincuente, estigmatización, expectativas de vida, imaginario social del delincuente, red de apoyo, solidaridad, asistencia social, aprendizajes 
en prisión, aspectos sociales de los delitos sexuales, espiritualidad, familia y significado otorgado a la prisión.

\section{Autopercepción del delincuente}

La autopercepción del delincuente se define en este estudio como la forma en que los AMPL entienden y conciben las personas que cometen un delito o que representan riesgo y peligro para la sociedad. Aunque en los grupos focales no se realizó una pregunta concreta sobre qué o quién es un delincuente, fue común encontrar en las respuestas a otras preguntas referencias a lo que debe y no debe considerarse como delincuencia. De esta manera, emergen los conceptos que se ilustran en la tabla 24.

Tabla 24. Aspectos asociados a la categoría autopercepción del delincuente

\begin{tabular}{|l|l|}
\hline \multicolumn{1}{|c|}{ Categoría } & \multicolumn{1}{c|}{ Aspectos asociados } \\
\hline \multirow{4}{*}{$\begin{array}{l}\text { Autopercepción } \\
\text { del delincuente }\end{array}$} & Justicia. \\
\cline { 2 - 2 } & Estigmatización. \\
\cline { 2 - 2 } & Juventud. \\
\cline { 2 - 2 } & Reincidencia. \\
\cline { 2 - 2 } & Problemática social. \\
\cline { 2 - 2 } & Gravedad del delito. \\
\cline { 2 - 2 } & Autorreconocimiento. \\
\hline
\end{tabular}

Fuente: elaboración propia.

\section{Justicia}

En cuanto a la justicia, muchos internos consideran que sus derechos han sido vulnerados, al ser condenados por un sistema de justicia que es esencialmente injusto. Se menciona, en varias oportunidades, el hecho de que hay personas que deberían estar presas y no lo están o que van a salir de prisión por beneficios que no merecen; al respecto, es recurrente la alusión a paramilitares y políticos corruptos: "Aquí la justicia es muy diferente para 
cada persona, es solo para los privilegiados de este país que matan y están allá asesorando al Gobierno" (grupo focal, EPMSC Cali, julio de 2013) . Igualmente, se afirma que delincuente no es el que delinque, sino el que se deja coger o al que se le imputa el delito. Se hace una mención especial al tema de los delitos sexuales, que son imputados en gran medida a los AM, y cuya sanción es percibida en muchos casos como injusta.

\section{Estigmatización}

Frente a la estigmatización, algunos participantes reconocen que así como ellos son estigmatizados por la sociedad, que construye falsos mitos a su alrededor, también ellos tenían una percepción negativa de las PPL antes de ingresar a prisión: "Uno tenía esa opinión de que el que iba a la cárcel era porque era muy malo" (grupo focal de mujeres, Complejo Carcelario y Penitenciario de Jamundí, julio de 2013); en ese sentido, la autopercepción del delincuente varía con el tiempo, las coyunturas y la propia experiencia. El hecho de estar en prisión no significa necesariamente ser un delincuente y el hecho de no estarlo no quiere decir no serlo.

\section{Juventud}

Por otro lado, la mayoría de los participantes establecen un vínculo entre juventud y delincuencia, lo que nuevamente demuestra que ellos no se consideran delincuentes. Se mencionan factores que favorecen este vínculo como las pautas de crianza, las necesidades, el abandono de los padres, la educación, las malas compañías y, sobre todo, la drogadicción. Para los participantes, es poco probable que un AM reincida, pero es muy probable que un joven que ha estado en prisión vuelva a estarlo en un futuro. De esta manera, la reincidencia es atribuida a los jóvenes, en mayor medida: "Lo que uno ve es mucho joven delincuente, en las cárceles hay un gran acumulado de jóvenes que no están trabajando, son delincuentes y eso es mano de obra perdida [...] y es muy difícil que se rehabiliten, porque esa población es muy joven. Hay personas de 29 años y tienen hasta cuatro entradas y ya tienen hijos y están por las mismas" (grupo focal, EPMSC Cali, julio de 2013). 
Esta relación que se establece entre juventud y delito es muy interesante para esta investigación pues, en términos de identidad, representa lo que nuestra población no es o no reconoce ser, ni en términos de grupo etario ni en términos de comisión del delito. Es importante reiterar, en este punto, la constante recurrencia a la "peligrosidad", que es imputada a la juventud y que se desliga del concepto de AM.

\section{Reincidencia}

La reincidencia también es atribuida a los jóvenes y los delincuentes. Se hace referencia permanente a los internos que tienen más de una entrada a prisión y que, por tanto, tienen una carrera delictiva. "Nosotros somos delincuentes, aunque en la calle no fuimos delincuentes, cometimos un error, más no hicimos carrera de delincuentes como hay muchos aquî" (grupo focal, Complejo Carcelario y Penitenciario de Jamundí, julio de 2013).

\section{Problemática social}

Este aspecto emergió en varias de las categorías que se establecieron, en diferentes contextos y como respuesta a lo indagado por los investigadores. Para algunos participantes, el problema no es que haya delincuentes, se reconoce que hay delincuentes y que muchos están en prisión, la cuestión radica en por qué los hay, por qué cada vez hay más y por qué hay tanta gente en prisión. "Hay una problemática, hay una superpoblación carcelaria, tenemos delincuentes en todas las cárceles y esto está reventado, hay una problemática social" (grupo focal, EPMSC Cali, julio de 2013).

\section{Gravedad del delito}

En materia de gravedad del delito, es muy recurrente, en los grupos focales, la referencia a internos que han cometido delitos graves, a gente que delinque y merece la prisión, y a la maldad. Así, se establece una especie de rango de tolerancia frente a los delitos, que en algunos casos son justificables, razonables o se pueden minimizar, mientras que hay otros sobre 
los que debe caer el peso de la ley y la sanción social. Esta relativización del delito, por lo general, apunta a que los punibles y cometidos en carne propia no contemplan una gravedad considerable, por lo que podrían ser tratados con otros mecanismos diferentes: "Hay gente que mata, pero ellos son los buenos y los 'violos' los malos" (grupo focal, Complejo Carcelario y Penitenciario de Jamundí, julio de 2013); esta situación nos lleva a pensar que al interior de la prisión también hay estigmatización por parte de los mismos internos frente al tipo de delito que se comete, la sanción y lo que se considera bueno o malo.

\section{Autorreconocimiento}

Con respecto al autorreconocimiento como delincuente, aunque son pocos los casos, algunos participantes aceptan la comisión del delito, demuestran arrepentimiento y reconocen haber violentado derechos ajenos con su accionar: "Cuando viajé con eso, sabía que no lo estaba haciendo bien, pero yo solo pensaba que era para el sustento de mi familia, pero de pronto no miré el daño que podía hacerle a otros. Ya con el tiempo va uno reflexionando y piensa... aunque le duela estar acá" (grupo focal de mujeres, Complejo Carcelario y Penitenciario de Jamundí, julio de 2013).

De esta manera, se construye dentro de los AMPL un imaginario de delincuente al que se le imputan prácticas, condicionantes y características específicas, que en general difieren de los constructos que tienen sobre sí mismos. No obstante, en algunos casos hay un reconocimiento de la comisión del delito y sus consecuencias.

\section{Estigmatización}

La categoría estigmatización se define, en este estudio, en concordancia con el planteamiento de Goffman (2006), como la serie de atributos desacreditadores impuestos a ciertas personas y que determinan las actitudes de los demás frente ellas. Se pueden mencionar 3 tipos de estigmas, notoriamente diferentes. En primer lugar, las abominaciones del cuerpo -las distintas 
deformidades físicas. Luego, los defectos de carácter del individuo que se perciben como falta de voluntad, pasiones tiránicas o antinaturales, creencias rígidas y falsas, deshonestidad; se infieren de conocidos informes sobre, por ejemplo, perturbaciones mentales, reclusiones, adicciones a las drogas, alcoholismo, homosexualidad, desempleo, intentos de suicidio y conductas políticas extremistas. Por último, existen los estigmas de raza, nación y religión, susceptibles de ser transmitidos por herencia y contaminar por igual a todos los miembros de una familia (Goffman, 2006, p. 14).

De esta manera, los estigmas marginan a quienes los poseen y los someten a duras prácticas de discriminación. Para diferenciar a quienes no poseen un estigma de quienes sí lo poseen, Goffman (2006) utiliza el término de los normales; por ende, un estigmatizado es lo mismo que un anormal. En el ámbito carcelario, se encuentran todo tipo de estigmas, relacionados con conductas reprochables, prácticas inaceptables, marcas corporales y aspectos culturales. Como veremos más adelante, muchos de estos estigmas también pueden extrapolarse a las familias de los internos, afectando de manera negativa diferentes aspectos de su vida (social, laboral, económico, etc.). De la información obtenida en campo se identificaron los siguientes aspectos asociados a la categoría estigmatización (tabla 25).

Tabla 25. Aspectos asociados a la categoría estigmatización

\begin{tabular}{|l|l|}
\hline \multicolumn{1}{|c|}{ Categoría } & \multicolumn{1}{c|}{ Aspectos asociados } \\
\hline \multirow{4}{*}{ Estigmatización } & Consecuencias para la familia. \\
\cline { 2 - 2 } & Actitud de la sociedad. \\
\cline { 2 - 2 } & Actitud de la familia. \\
\cline { 2 - 2 } & Homogeneización. \\
\cline { 2 - 2 } & Desconocimiento de la problemática social. \\
\hline
\end{tabular}

Fuente: elaboración propia.

\section{Consecuencias para la familia}

En cuanto a las consecuencias para la familia, en lo que se refiere a la estigmatización, la mayoría de AMPL afirman que muchos de sus familiares han 
perdido el trabajo u oportunidades laborales, que son víctimas de matoneo en el colegio y que reciben afrentas por el hecho de tener un familiar en prisión: "Mi hijo está en undécimo, ya terminaba este año y no volvió al colegio militar porque los compañeritos le decían 'qué va hermano... si usted tiene a su mamá en una cárcel”" (grupo focal de mujeres, Reclusión de Mujeres de Medellín, julio de 2013); de acuerdo con estos testimonios, el estigma es más fuerte en las mujeres que en los hombres, y pesa también más en sus familias. Las consecuencias de transferir estos estigmas a la familia son innumerables y, según los investigadores, estas acentúan problemáticas sociales y perpetúan círculos de pobreza.

\section{Actitud de la sociedad y de la familia}

La actitud de la sociedad, según los participantes, es extremadamente negativa; muchos reconocen la presencia de estigmas o etiquetas como "mata bruja" o "inepto social"; se afirma que el hecho de haber estado en prisión es algo que marca para toda la vida y limita las posibilidades de existencia, pues las oportunidades para reestablecer una vida social, laboral o económica son prácticamente inexistentes. En ocasiones, la actitud de la familia frente al AMPL también es negativa y, aunque no es el común de los casos, algunos internos afirman que sus familias se sienten avergonzadas de ellos, los niegan, los ocultan y los abandonan emocionalmente.

\section{Homogeneización}

Ligado al anterior aspecto, aparece el concepto de homogenización o generalización del AMPL; en este caso, independientemente de la historia de vida del sujeto, el delito cometido o las condiciones que lo llevaron a estar en prisión es tratado y concebido de la misma manera por la sociedad: como un delincuente y una amenaza: "Se nos estigmatiza y se nos generaliza como si todos fuéramos iguales, entonces nos califican como lo peor, como si todos fuéramos lo peor" (grupo focal, EPMSC Cali, julio de 2013); esta situación resulta ser bastante incómoda para la mayoría de los internos, quienes re- 
currentemente demuestran su inconformidad y desacuerdo; recalcan la individualidad de cada persona y las características particulares en cada caso.

\section{Desconocimiento de la problemática social}

Un aspecto que resulta muy interesante y que aparece en la información recabada en campo es el reconocimiento de que la estigmatización del AMPL puede obedecer al desconocimiento de la problemática social, pues se señala y se juzga sin analizar los contextos, las realidades, las coyunturas o las necesidades; al respecto, se afirma que "la reingeniería se debe dar en conjunto con la sociedad, el hecho de que se cometa un delito, no quiere decir que uno no se pueda reintegrar a la sociedad, es ahí donde la sociedad debe entender que es un problema social, producto de la desigualdad" (grupo focal, EPMSC Cali, julio de 2013).

\section{Expectativas de vida}

La categoría denominada expectativas de vida es definida, en este estudio, como lo que esperan hacer, tener o ser los AMPL en los años que les restan de vida. En este punto, se identificaron 12 subcategorías asociadas (tabla 26)

Tabla 26. Aspectos asociados a la categoría expectativas de vida

\begin{tabular}{|l|l|}
\hline \multicolumn{1}{|c|}{ Categoría } & \multicolumn{1}{c|}{ Aspectos asociados } \\
\hline \multirow{5}{*}{ Expectativas de vida } & Pensión. \\
\cline { 2 - 2 } & Trabajo. \\
\cline { 2 - 2 } & Segunda oportunidad de la sociedad. \\
\cline { 2 - 2 } & Familia. \\
\cline { 2 - 2 } & Libertad. \\
\cline { 2 - 2 } & Espiritualidad. \\
\cline { 2 - 2 } & Trabajo comunitario. \\
\cline { 2 - 2 } & Sociabilidad. \\
\hline
\end{tabular}




\begin{tabular}{|l|l|}
\hline \multicolumn{1}{|c|}{ Categoría } & \multicolumn{1}{c|}{ Aspectos asociados } \\
\hline \multirow{4}{*}{ Expectativas de vida } & Aplicar lo aprendido en prisión. \\
\cline { 2 - 2 } & No salir. \\
\cline { 2 - 2 } & Cambiar. \\
\cline { 2 - 2 } & Asistencia del Estado. \\
\cline { 2 - 2 } & Muerte. \\
\hline
\end{tabular}

Fuente: elaboración propia.

\section{Pensión}

Aunque la mayoría de las respuestas se concentran en los aspectos de trabajo y familia, es importante mencionar, también, las demás opiniones al respecto. Por ejemplo, una sola persona manifestó su interés por salir a disfrutar de su pensión, lo cual llama poderosamente la atención, tratándose de un AM que, al menos, en teoría debería tener acceso a este componente de la seguridad social. El hecho de que nadie más mencione este derecho se puede deber a que no todos pueden ejercerlo, bien sea porque siempre han estado en el ámbito de la informalidad, porque desde la cárcel no es posible seguir trabajando ni cotizando o, simplemente, porque se priorizan otros aspectos.

\section{Trabajo}

El trabajo, en cambio, se consolida como la expectativa de vida más mencionada; la mayoría de los participantes afirman querer seguir trabajando, retomar las actividades que realizaban antes del ingreso a la prisión, aportarle económicamente a la familia y conseguir el sustento para seguir viviendo: "Yo sí verdaderamente quiero salir de acá e irme a mi trabajito, porque andar con los hijos ya poco... ellos tienen su obligación y todo para que llegue uno a molestar. Yo lo que quiero es seguir trabajando hasta que sea capaz, hasta ya lo último" (grupo focal, EPMSC Bucaramanga, julio de 2013). Esta frase es muy ilustrativa pues muestra, por un lado, la necesidad de los AM de seguir trabajando para sobrevivir; por otro, el alejamiento de 
la familia y el peso de haber estado ausente, y, por último, el imaginario negativo de que los AM son un estorbo. Esta intención de seguir trabajando también es compatible con algunas sociedades antiguas, en las que la edad era un factor determinante de retiro, solo en el sentido en que no permitía la productividad. $\mathrm{Al}$ respecto:

Si bien se consideraba viejo a quien rebasaba bastante la edad normal de morirse, no se les daba un trato especial mientras fueran productivos. No había jubilación ni retiro, desde luego. Era el cuerpo lo que se retiraba. No había en cierto modo, una vejez social, sino solo una vejez biológica que tenía repercusiones sociales. (Alba, 1992, p. 18)

Así pues, el AMPL considera que está en capacidad física y mental para seguir trabajando y ubica este aspecto de su vida dentro de sus expectativas más importantes. Muchos de los participantes afirman haber trabajado toda su vida y no saber hacer otra cosa, por lo que es su única opción.

\section{Segunda oportunidad de la sociedad}

Resulta muy interesante encontrar una expectativa de vida que hace referencia a una segunda oportunidad de la sociedad; esta oportunidad se solicita en términos tanto de la edad como del delito: "Lo ven a uno viejo y creen que uno no puede salir, pero todavía nosotros somos útiles como para la sociedad, como para nosotros mismos, entonces que den esa oportunidad... que porque estamos viejos... pero no, nosotros tenemos ganas todavía, nos sentimos con fuerzas para empujar, entonces esperamos que nos den esa oportunidad" (grupo focal, Complejo Penitenciario y Carcelario de Ibagué, junio de 2013).

En diferentes referencias, se hace mención a una segunda oportunidad también para aludir a la posibilidad de cumplir una pena alternativa a la prisión, por lo general se solicita la prisión domiciliaria, el brazalete electrónico o la libertad condicional, abogando a los supuestos de la baja peligrosidad que representa un AM para la sociedad y la resocialización que viene implícita con muchos años de privación de la libertad y tratamiento. 


\section{Familia}

La familia es la expectativa más nombrada por los AMP; muchos añoran el calor del hogar, otros quieren salir para retomar las responsabilidades que abandonaron por el hecho de ingresar a prisión, muchos quieren recuperar el tiempo perdido, conocer familiares que no han visto nunca y otros desean cumplir una labor preventiva con sus familias, a través de sus testimonios e historias de vida: "Quiero llevarle, enseñarle a mis nietos y nietas todo lo que he aprendido, decirles que esta no es una vida adecuada" (grupo focal, EPMSC Bucaramanga, julio de 2013). Se reitera que la familia está presente en todos los ámbitos del AMPL; en la mayoría de los casos, esta se consolida como añoranza, apoyo, prioridad, culpabilidad, angustia o ausencia, todo depende del escenario y, por supuesto, de las variables que afectan cada caso en particular.

\section{Libertad}

Junto con la familia y el trabajo, la libertad es la expectativa de vida por excelencia; de hecho, ninguna de las dos es posible sin la libertad: "Yo creo que el principal sueño de todos es salir de acá" (grupo focal, Complejo Carcelario y Penitenciario Metropolitano de Bogotá, julio de 2013). La libertad es, pues, el prerrequisito para el cumplimiento de cualquier expectativa planteada; sin ella, todo es un sueño y una vana ilusión.

\section{Espiritualidad}

La espiritualidad se consolida como respuesta a muchos de los retos planteados por la prisión; es común, entonces, encontrar discursos que hacen referencia a varias religiones o dioses o a diferentes prácticas espirituales; muchos internos afirman haber encontrado a Dios en la prisión, por lo que dedican mucho tiempo a la oración y la predicación: "Yo creo que lo que debo llevar afuera es lo que aprendí acá, llevar la palabra de Dios, mostrar lo grande y maravilloso de su obra, eso le aportaría yo a la sociedad, el mensaje de Dios" (grupo focal, EPMSC Cali, julio de 2013). Así, encontramos 
una relación entre esta categoría y las expectativas de vida, por un lado, $y$, por el otro, con las redes de apoyo institucional que comprenden, en su mayoría, organizaciones y grupos de carácter religioso.

\section{Trabajo comunitario}

Varios internos afirman que al salir de prisión, quisieran realizar una especie de trabajo comunitario dirigido en ocasiones a PPL, pues son conscientes del apoyo y la compañía que requiere esta población, al haber sido parte de esta. Algunos participantes afirman que actualmente hay personas que realizan esta labor; quienes después de haber recuperado su libertad, realizan visitas y ejercen prácticas solidarias con las personas que siguen en prisión. Este aspecto es muy importante pues se cruza con la categoría denominada red de apoyo. Otros participantes afirman que quieren formar una institución de prevención o continuar con trabajos de tipo social que realizaban antes de perder su libertad.

\section{Sociabilidad}

En pocos casos se menciona el interés por recuperar la sociabilidad; es decir, compartir espacios y reuniones con amigos. Se menciona esta subcategoría porque emerge de la información recolectada, aunque no es una respuesta muy recurrente dentro de los participantes.

\section{Aplicar lo aprendido en la prisión}

Es muy recurrente, en cambio, encontrar dentro de las expectativas de los AMPL querer aplicar lo aprendido en la prisión, una vez obtengan su libertad. La mayoría de los participantes valoran mucho los conocimientos que adquieren en el área de educación y en los talleres; por ello, es muy común encontrar en las respuestas, sobre todo de las mujeres, un interés por generar emprendimientos y microempresas asociados a las labores que se desarrollan en la prisión: "A mí me gustaría poder salir y tener un cacharrito pa' vender pulseras y las cosas que he aprendido aquî" (grupo focal de mujeres, Complejo 
Carcelario y Penitenciario de Jamundí, julio de 2013). Este aspecto está relacionado con un hallazgo importante en materia de tratamiento que se abordará con mayor profundidad posteriormente, y que hace referencia a las oportunidades de aprendizaje fuera y dentro de la prisión, pues muchos de los participantes afirman que no sabían leer y escribir antes de ingresar a la prisión, y que fue allí donde aprendieron y, además, obtuvieron otros conocimientos a los que no habrían podido acceder fuera de la cárcel.

\section{No querer salir}

Este aspecto también se puede relacionar con lo manifestado por algunos pocos participantes, quienes afirman que no quieren salir de la prisión porque no cuentan con ninguna posibilidad de supervivencia afuera ni con nadie que los esté esperando: "Yo salgo y dónde voy a almorzar, dónde voy a vivir... ya con la edad que tengo, imagínese, yo salgo de ochenta y pico de años, tengo 72, me faltan 12 años todavía y salgo, ipara dónde salgo?, mejor evito eso" (grupo focal, EPMSC Medellín, julio de 2013).

\section{Muerte y cambio}

En este sentido, también se encontraron respuestas referentes a la muerte como única expectativa, como lo único a lo que se puede aspirar. Estos testimonios evidencian otra de las categorías que emerge recurrentemente de la información recolectada: la problemática social. Otra expectativa es cambiar, es decir, dejar la delincuencia, los vicios y las prácticas que los llevaron a estar en prisión.

\section{Imaginario social del delincuente}

La categoría denominada imaginario social del delincuente se define como la representación o las representaciones que, según los internos, tiene la sociedad de las personas que han cometido un delito o que han estado en una prisión. Se identificaron cuatro aspectos relacionados que, cabe anotar, tienen una connotación negativa (tabla 27). 
Tabla 27. Aspectos asociados a la categoría imaginario social del delincuente

\begin{tabular}{|l|l|}
\hline \multicolumn{1}{|c|}{ Categoría } & \multicolumn{1}{c|}{ Aspectos asociados } \\
\hline \multirow{3}{*}{$\begin{array}{l}\text { Imaginario social del } \\
\text { delincuente }\end{array}$} & No aptitud para vivir en sociedad. \\
\cline { 2 - 2 } & Amenaza. \\
\cline { 2 - 2 } & Desprecio. \\
\cline { 2 - 2 } & Homogeneización. \\
\hline
\end{tabular}

Fuente: elaboración propia.

\section{No aptitud para vivir en sociedad}

Los AMPL afirman que son considerados no aptos para vivir en sociedad; este aspecto se vincula estrechamente con la categoría estigmatización, pues apunta a homogeneizar a las PPL, independientemente de los móviles que llevaron a la comisión del delito, la historia de vida, las coyunturas y los contextos: "De pronto no todo el mundo delinque, pero no estamos ajenos de caer en esto... pero generalizan con el único hecho de que el que cae en la cárcel no es apto para la sociedad" (grupo focal, Complejo penitenciario y Carcelario de Ibagué, junio de 2013).

\section{Amenaza}

En ese sentido, también es recurrente generalizar el hecho de que las PPL representan una amenaza para el resto de la sociedad; es decir, para los individuos "normales". La pena, entonces, sigue cumpliendo una doble finalidad: por un lado, castiga al delincuente, y, por otro, lo somete a un tratamiento que lo hará mejor persona, que le permitirá vivir en sociedad, reduciendo o anulando su peligrosidad.

\section{Desprecio y homogeneización}

Como sujetos peligrosos y no aptos para vivir en comunidad, los privados de la libertad inspiran desprecio y son considerados como la escoria de la sociedad; todos son iguales, todos son delincuentes; hay, pues, un fuerte 
componente de homogeneización hacia el infractor. Frente a esta posición de la sociedad, los AMPL afirman que hay una gran inconciencia del común de la gente, que no se detiene a analizar las circunstancias y realidades que influyen, y enfatizan, además, en que todos sin excepción somos potenciales delincuentes.

\section{Red de apoyo}

La categoría denominada red de apoyo es definida, en este estudio, como el conjunto de instituciones, personas, grupos o instancias que brindan aportes materiales, emocionales o espirituales a las PPL, y que se consolidan como soporte y garante de necesidades. La familia, por supuesto, en la mayoría de los casos, representa el componente más fuerte de la red de apoyo de los AMPL, aunque también representa muchas otras cosas, por ello se analiza como categoría independiente. A la red de apoyo de los internos se relacionan los aspectos que se exponen en la tabla 28.

Tabla 28. Aspectos asociados a la categoría red de apoyo

\begin{tabular}{|l|l|}
\hline \multicolumn{1}{|c|}{ Categoría } & \multicolumn{1}{c|}{ Aspectos asociados } \\
\hline \multirow{4}{*}{ Red de apoyo } & Familia. \\
\cline { 2 - 2 } & Amigos. \\
\cline { 2 - 2 } & Acceso. \\
\cline { 2 - 2 } & Solidaridad. \\
\cline { 2 - 2 } & Estrategias al interior del penal. \\
\cline { 2 - 2 } & Convenios interinstitucionales. \\
\cline { 2 - 2 } & Eventos especiales. \\
\hline
\end{tabular}

Fuente: elaboración propia

\section{Familia}

Como se mencionó anteriormente, la familia se consolida como la base fundamental de la red de apoyo; de hecho, en la mayoría de los casos solo se 
cuenta con el apoyo de la familia para la solución de necesidades materiales y emocionales. Hay una valoración muy positiva por parte de los internos en lo que se refiere a la familia; sin embargo, también en ocasiones, se habla de abandono o desentendimiento. Algunos internos afirman que prefieren mantener a la familia alejada del ámbito penitenciario; por ello, solicitan a sus allegados no realizar visitas o comunicarse con ellos: "A mí no me gusta que mi familia, que mis hijos vengan, por la humillación que pasan afuera, las filas... yo les digo que vengan cada mes si pueden, pero no me gusta lo que pasan afuera" (grupo focal, EPMSC Cali, julio de 2013).

\section{Amigos}

Con respecto a los amigos, muchos internos aseguran que mantienen las relaciones con los amigos que tenían antes de ingresar a prisión; otros, por el contrario, denuncian un abandono de su parte, afirman que los amigos no existen en realidad, que las relaciones están mediadas por intereses y que las personas cambian por el tema de la prisión: "En la calle yo tenía amigos con los que viajaba, compartía... amigos entre comillas, porque caí acá y desaparecieron" (grupo focal, EPMSC Bucaramanga, julio de 2013). Esto se reafirma al observar lo encontrado en el total de la población, donde el mayor porcentaje de ese apoyo viene de la familia, en un $84 \%$, y solo el $1 \%$ se reconoce en los amigos (figura 27 ).

\section{Acceso}

Sin embargo, el abandono no solo responde a la decisión personal de los amigos, sino también a las dificultades de acceso que impone la prisión, en ese sentido se menciona la lejanía entre el EPC y el lugar de origen, las complicaciones de ingreso para las visitas y el límite de personas que puede recibir un interno en cada visita. 
Figura 27. Personas que brindan apoyo al adulto mayor privado de derechos

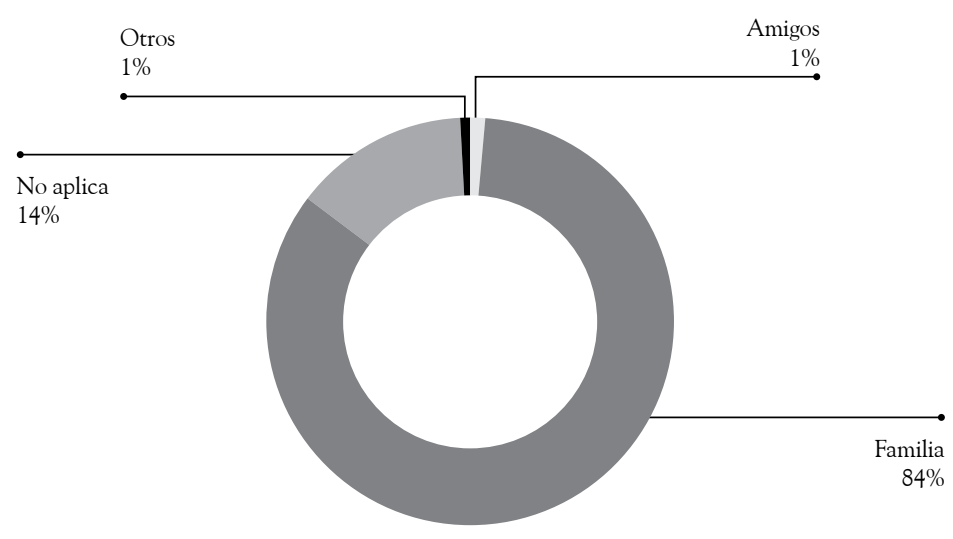

Fuente: Sisipec Web, censo condiciones excepcionales, 31 de julio de 2013. Cálculos de los autores.

\section{Solidaridad}

Los AMPL afirman que en ocasiones hay manifestaciones de solidaridad en el interior del penal y que es posible encontrar amigos en prisión; sin embargo, esta no es la constante, pues el ambiente de la prisión se torna hostil. Las buenas relaciones y el buen trato entre internos son más comunes en pabellones que albergan únicamente AM, así lo afirman los protagonistas. En este sentido, se considera vital mencionar la experiencia del pabellón de AMPL del EPMSC Cali (ERE), en el que se evidencian prácticas de autogestión y organización que han resultado muy funcionales y que permiten el fortalecimiento de la red de apoyo entre internos: "Todos aquí todos somos amigos, somos como una familia, aquí todos nos tratamos bien" (grupo focal, EPMSC Cali, julio de 2013).

\section{Estrategias en el interior del pena}

Las realidades vividas en prisión hacen que los internos desarrollen nuevas formas de comunicarse, de apoyarse y de sobrevivir, que se han denominado estrategias en el interior del penal. De esta manera, se fortalecen grupos, se generan identidades y se construyen códigos de comunicación que retan y superan las barreras del espacio y de la rutina. Un ejemplo muy interesante 
de esta situación es un lenguaje que se ha venido desarrollando en las cárceles que tienen pabellones tanto femeninos como masculinos, que consiste en comunicarse a través de símbolos realizados con las manos o incluso con implementos como toallas o telas. Los internos y el personal de guardia denominan a esta práctica "chateo", y a través de ella se relacionan hombres y mujeres a distancias muy largas y con toda clase de obstáculos. Al indagar en esta forma de comunicación, se encontró un interesante imaginario vinculado a los AMPL, quienes afirman que esas son cosas de muchachos y que ellos ya no están para enamorarse ni para aprender el sistema. "Ellos (los muchachos) crearon un lenguaje de señas, le dicen el e-mail" (grupo focal, Complejo Penitenciario y Carcelario de Ibagué, junio de 2013).

\section{Convenios interinstitucionales}

Los convenios interinstitucionales se consideran un aspecto fundamental de la red de apoyo, pues a través de ellos se subsanan algunas de las necesidades de los internos. Así, cada establecimiento gestiona convenios con universidades, ONG o entidades regionales, que prestan servicios de terapia ocupacional, fisioterapia, preescolar, psicología y capacitación, entre otros. No obstante, al indagar por las instituciones que hacen presencia en las cárceles, los internos solo reconocen las entidades de carácter religioso, que están presentes en todos los EPC. Al respecto, en las visitas realizadas a los diferentes EPC, se demuestra una presencia constante de diferentes iglesias y grupos religiosos, que se vincula directamente a la categoría espiritualidad que será abordada posteriormente.

\section{Eventos especiales}

Si bien no se consolidan como un componente fundamental de la red de apoyo, la celebración de fechas especiales en los establecimientos es muy importante para los internos, pues se rompe la rutina y se genera bienestar. Las fechas y eventos mencionados por los AMPL son la Virgen de las Mercedes, el Día de la Madre y la Navidad. Estas actividades concretas están 
vinculadas a otras tradiciones del ámbito carcelario, como los reinados o campeonatos, que se organizan por patios.

\section{Solidaridad}

Esta categoría es definida en nuestro caso como la presencia de unión y colaboración entre internos de un EPC, bien sea de manera permanente o coyuntural. De este modo, se identifican los siguientes 5 aspectos asociados (tabla 29).

Tabla 29. Aspectos asociados a la categoría solidaridad

\begin{tabular}{|l|l|}
\hline \multicolumn{1}{|c|}{ Categoría } & \multicolumn{1}{c|}{ Aspectos asociados } \\
\hline \multirow{4}{*}{ Solidaridad } & Apoyo. \\
\cline { 2 - 2 } & Autogestión. \\
\cline { 2 - 2 } & Espacios físicos. \\
\cline { 2 - 2 } & Capacitación. \\
\cline { 2 - 2 } & Oferta de servicios. \\
\hline
\end{tabular}

Fuente: elaboración propia.

\section{Apoyo}

La solidaridad inmediatamente se asocia al apoyo. Varios de los participantes afirman haber recibido o brindado manifestaciones o gestos de colaboración en el interior del penal, que se refieren sobre todo a buen trato y compañerismo. Es importante recalcar que no todos los AMPL hablan de solidaridad y que es más común encontrar referencia al concepto en los testimonios obtenidos en EPC, que cuentan con pabellones exclusivos para AM. El siguiente es un ejemplo de ello, que se encontró en el pabellón Años Dorados de la cárcel de mujeres de Jamundí: "Aquí la que sabe le enseña a la que no sabe..., una no tiene y la otra le da, así es con los útiles de aseo, con las cosas personales" (grupo focal de mujeres, Complejo Carcelario y Penitenciario de Jamundí, julio de 2013). Así pues, el enfoque diferencial por grupo etario favorece la convivencia y la colaboración entre internos. 


\section{Autogestión}

Igualmente, en este tipo de pabellones se identificaron algunas prácticas de autogestión que van enfocadas al bienestar de los internos. Así, en el pabellón de AMPL de EPMSC Cali, hay clases permanentes en diferentes materias que son impartidas por los mismos internos; asimismo, hay una oferta permanente de actividades lúdicas y manuales, hay ciertas normas que se consensan y se respetan e incluso se habla de un "plan padrino" que consiste en adquirir bienes y útiles personales y de aseo para los que no tienen la posibilidad de adquirirlos.

Desde luego, hay muchos gestos de solidaridad, incluso aquí tenemos un programa de padrinos, donde los que tienen más comodidad apadrinan a los que no tienen nada para comprar sus cosas de aseo, que antes lo hacía el INPEC, pero que debido a los problemas económicos que tiene (o no se sabe por qué) ya no dan nada. Entonces esa es la forma de ayudar a esas personas que no tienen nada, a través de ese apadrinamiento y que se ha comentado aquí con los mismos internos. Es una iniciativa de nosotros. (Grupo focal, EPMSC Cali, julio de 2013)

\section{Espacios físicos}

Los espacios físicos son determinantes para que la solidaridad sea posible en el ámbito penitenciario. Los pabellones exclusivos para AMPL manejan unas rutinas diferentes a las de los demás pabellones; en algunos casos, las celdas están abiertas y se puede ingresar y salir de ellas cuando se desee. Allí la convivencia es más sencilla, no son muy ruidosos y el consumo de sustancias psicoactivas es menor o inexistente. Por ello, los internos consideran estos pabellones como espacios realmente privilegiados, algunos incluso afirman que por sus características parecen más un hogar geriátrico que una prisión. En cualquier caso, el AMPL está sujeto a las características propias de una institución total. 
Una institución total puede definirse como un lugar de residencia y trabajo, donde un gran número de individuos en igual situación, aislados de la sociedad por un periodo apreciable de tiempo, comparten en su encierro una rutina diaria, administrada formalmente. Las cárceles sirven como ejemplo notorio, pero ha de advertirse que el mismo carácter intrínseco de prisión tienen otras instituciones, cuyos miembros no ha quebrantado ninguna ley. (Goffman, 2001, p. 13)

Junto a las cárceles encontramos entonces los internados y asilos de cualquier índole, que impliquen el aislamiento, la imposición de una normativa particular y el control del tiempo de los internos. El tema de las instituciones totalizantes, así definidas por Goffman (2001), es fundamental en este estudio, pues se consolidan como respuesta a muchas de las condiciones presentadas por nuestra población objeto. Por un lado, esta población enfrenta las vicisitudes de su edad, que muchas veces implica el cese de actividades económicas, el deterioro físico, que acarrea enfermedades y situaciones crónicas que pueden generar discapacidad. Es decir, la sociedad ha ofrecido históricamente pocas alternativas frente a las conductas o condiciones llamadas "anormales", que se restringen al encierro, el exilio o el exterminio. Se impone la institución totalizante como remedio a la discapacidad, la enfermedad, la ancianidad y el delito, condiciones que están presentes en mayor o menor grado en la población que nos ocupa.

\section{Capacitación}

Dentro de las manifestaciones de solidaridad en el interior del penal, se menciona la capacitación que muchos de los internos imparten a sus compañeros. De esta manera, se enseña a leer, a escribir, a realizar operaciones matemáticas, diversas materias y oficios.

A las que sabemos trabajar por ejemplo los químicos, para hacer el límpido, los ambientadores, la crema de manos, el champú, que nos den la oportunidad de enseñarle a las compañeras que lo quisieran aprender, porque yo eso lo propuse cuando estaba en el Buen Pastor y me dijeron 
que lo iban a estudiar, pero todavía estoy esperando la respuesta. (Grupo focal de mujeres, Complejo Carcelario y Penitenciario de Jamundí, julio de 2013)

En este testimonio particular, se menciona la iniciativa de una de las internas por compartir sus conocimientos en un área específica, que de ser tenida en cuenta podría resolver necesidades ocupacionales, laborales y de redención de las internas.

\section{Oferta de servicios}

En esta misma línea, algunos internos afirman ofrecer servicios en campos específicos, muchos de ellos tienen conocimientos en el área de la salud, por lo que realizan consultas médicas, recetan medicamentos y dan consejos sobre buenas prácticas; otros son verdaderos guías espirituales, que comparten la palabra y el testimonio con los internos interesados; hay también abogados que elaboran derechos de petición y memoriales. Así, no solo se comparten conocimientos, sino que estos se ponen al servicio de los compañeros que los requieren.

\section{Asistencia social}

Esta categoría se define en el presente estudio como la cantidad y el tipo de servicios que reciben los AMPL por parte de instituciones públicas, privadas u organizaciones civiles. Es muy importante mencionar que la categoría se declaró prácticamente desierta, ya que los internos en general no reconocen ningún tipo de asistencia que llegue a las cárceles; por el contrario, denuncian abandono, desinterés y olvido. Este hecho fue contrastado en campo, pues en todas las visitas realizadas solo fue posible identificar instituciones de carácter religioso que prestan sus servicios y que se mantienen constantes en todos los EPC. Efectivamente, se asocian solo 2 aspectos a esta categoría (tabla 30). 
Tabla 30. Aspectos asociados a la categoría asistencia social

\begin{tabular}{|c|l|}
\hline \multicolumn{1}{|c|}{ Categoría } & \multicolumn{1}{|c|}{ Aspectos asociados } \\
\hline \multirow{2}{*}{ Asistencia social } & Asistencia religiosa. \\
\cline { 2 - 2 } & Caridad. \\
\hline
\end{tabular}

Fuente: elaboración propia.

La presencia de las iglesias e instituciones religiosas es permanente e incluso hay días específicos de visita para cada religión. La caridad en cambio se vive de manera esporádica: "Sí, claro, por ejemplo en una fecha determinada viene una señora y trae pasabocas" (grupo focal, establecimiento EC Bogotá, La Modelo, mayo de 2013). Por lo demás, toda la atención que requieren los internos recae sobre la familia y por supuesto sobre el EPC.

\section{Aprendizajes en prisión}

En esta categoría se definen la experiencia, los conocimientos, las prácticas y los comportamientos adquiridos en prisión. La mayoría de las veces los AMPL hacen referencia a lo que han aprendido en las áreas educativa y laboral, pero también se encuentran referencias a aspectos de carácter espiritual y moral. Se asocian a la categoría 5 aspectos (tabla 31).

Tabla 31. Aspectos asociados a la categoría aprendizajes en prisión

\begin{tabular}{|l|l|}
\hline \multicolumn{1}{|c|}{ Categoría } & \multicolumn{1}{c|}{ Aspectos asociados } \\
\hline \multirow{4}{*}{ Aprendizajes en prisión } & Solidaridad. \\
\cline { 2 - 2 } & Tratamiento. \\
\cline { 2 - 2 } & Reflexión. \\
\cline { 2 - 2 } & Resocialización. \\
\cline { 2 - 2 } & Valorar. \\
\hline
\end{tabular}

Fuente: elaboración propia. 


\section{Solidaridad y tratamiento}

La estancia en prisión genera solidaridad, como se documentó anteriormente. Para algunos internos, esta solidaridad se consolida como aprendizaje, pues no es fácil conformar lazos solidarios en un espacio tan agresivo como el de la prisión. El tratamiento penitenciario que reciben los internos es valorado muy positivamente, y en ese sentido se asocia inmediatamente con los aprendizajes, con aquellos conocimientos y oficios que no se conocían antes de prisión. De allí que el tratamiento también se consolide como "expectativa de vida", toda vez que permite al individuo desempeñarse en áreas o tareas a las que antes no tenía acceso.

\section{Reflexión y resocialización}

Los aprendizajes también se asocian a la reflexión y la espiritualidad, los AMPL afirman llegar a conocerse mejor en prisión, acercarse más a Dios y a los seres queridos, pensar en el significado de la vida y ser conscientes de los propios errores, lo que conlleva un cambio interior. Este cambio, por supuesto, se asocia a la resocialización, y así, en ocasiones, el cumplimiento de la pena en prisión permite la corrección de conductas indeseadas o inapropiadas; por tanto, genera individuos aptos para vivir en sociedad. Sin embargo, esta resocialización no se adjudica al tratamiento penitenciario, sino a la decisión personal de cambio que surge como resultado de largas jornadas de reflexión y conocimiento de sí mismo.

\section{Valorar}

En ese sentido, también es frecuente escuchar entre los participantes que en prisión se aprende a valorar todo lo que se tenía afuera: la comida, la familia, los amigos, la libertad y el tiempo. "He aprendido a conocer más a la gente, a tratar, a ayudar, a ser solidario y he aprendido también de la gente, es una experiencia enriquecedora" (grupo focal, EPMSC Cali, julio de 2013). 


\section{Aspectos sociales de los delitos sexuales}

Esta categoría resulta fundamental para nuestro estudio pues representa la doble estigmatización de la que se hablaba anteriormente, que consolida al AMPL como un individuo dos veces "anormal", en razón de su edad y del delito. El imaginario que circunda al AM que comete un delito o al que se le imputa un delito es el delito sexual, de allí que tanto en el ámbito penitenciario como en otros espacios se afirme que "todo viejo es violo". Se identifican tres aspectos relacionados a esta categoría: estigmatización, justicia y falsa imputación.

Tabla 32. Aspectos asociados a la categoría aspectos sociales de los delitos sexuales

\begin{tabular}{|l|l|}
\hline \multicolumn{1}{|c|}{ Categoría } & \multicolumn{1}{c|}{ Aspectos asociados } \\
\hline \multirow{2}{*}{$\begin{array}{l}\text { Aspectos sociales de los } \\
\text { delitos sexuales }\end{array}$} & Estigmatización. \\
\cline { 2 - 2 } & Justicia. \\
\cline { 2 - 2 } & Falsa imputación. \\
\hline
\end{tabular}

Fuente: elaboración propia.

\section{Estigmatización}

En cuanto a la estigmatización, se afirma que "muchas personas creen que uno está en la cárcel es por violación de menores y eso no es así. Aquí los jóvenes le dicen a uno violo y no todos estamos aquí por eso, la mayoría de la juventud y la misma guardia creen que uno está aquí por eso" (grupo focal, Complejo Carcelario y Penitenciario de Jamundí, julio de 2013). Así, independientemente del caso y sin conocimiento de las situaciones particulares, se imputa en general al AMPL un delito de tipo sexual.

\section{Justicia y falsa imputación}

Algunos internos refirieron el tema de justicia, por considerar que la ley de delitos sexuales es poco clara y tiene un espectro tan amplio que cata- 
loga como delito algunos comportamientos o actitudes que no lo son. Esta disyuntiva es acorde con el tercer aspecto identificado, la falsa imputación, pues la mayoría de los AMPL a quienes se les imputan delitos sexuales afirman no haber cometido el delito y, por el contrario, suelen hablar de montajes o engaños. "Están condenando arbitraria y corruptamente a gente de la tercera edad que no ha cometido ninguna falta y la juzgan y la meten a esta cárcel por primera vez. Yo por ejemplo vengo de una familia muy decente, muy humilde y muy respetuosa y mire lo que me está pasando ahorita por las malas lenguas de una mujer" (grupo focal, Complejo Carcelario y Penitenciario de Bogotá, julio de 2013).

La negación de este tipo de delitos es común en diferentes EPC y se mantiene también en diferentes países. En España, por ejemplo, de acuerdo con los resultados de una investigación sobre delitos de tipo sexual, se afirma que: "Aproximadamente el $56 \%$ de las personas que cometen delitos sexuales niega totalmente la autoría de los hechos. Su tendencia es el de atribuirlo a montajes o a que ellas querían y después se vengaron" (Castro et al., 2009, p. 44).

Por otro lado, los AMPL suelen restar importancia a los delitos sexuales, afirmando que hay otros delitos realmente graves que son condenados de manera más ligera y con penas más amables. Es decir, no hay un reconocimiento del delito, bien sea porque el acto no es considerado inadecuado o porque se niega su comisión, o se culpa tanto a las instancias de justicia como a las víctimas, proclamando inocencia y reclamando un trato justo. Otro factor fundamental en este punto es el género, toda vez que los delitos sexuales son cometidos en su mayoría por hombres. Al respecto, de acuerdo con datos oficiales (Inpec, 2013), en el 99\% de estos casos, se encuentra sindicado o condenado un hombre (tabla 33).

\section{Espiritualidad}

Esta categoría se define como toda práctica de tipo religioso o autorreflexivo de los AMPL, adquirida en ocasiones en prisión o fortalecida allí. Así, es muy recurrente encontrar en los discursos de los participantes referencias a 
Tabla 33. Principales delitos sexuales por género

\begin{tabular}{|l|c|c|c|c|}
\hline \multirow{2}{*}{ Delito } & \multicolumn{2}{c|}{ Hombres } & \multicolumn{2}{c|}{ Mujeres } \\
\cline { 2 - 5 } & Sindicados & Condenados & Sindicadas & Condenadas \\
\hline Actos sexuales con menor de 14 años & 2053 & 3133 & 24 & 25 \\
\hline $\begin{array}{l}\text { Acceso carnal abusivo con menor } \\
\text { de 14 años }\end{array}$ & 1476 & 2446 & 21 & 17 \\
\hline Acceso carnal violento & 743 & 2107 & 9 & 7 \\
\hline
\end{tabular}

Fuente: elaboración propia basada en datos del Inpec (2013).

dioses, a las religiones o a diferentes convicciones espirituales. Se asocian a esta categoría los aspectos que se dan a conocer en la tabla 34.

Tabla 34. Aspectos asociados a la categoría espiritualidad

\begin{tabular}{|l|l|}
\hline \multicolumn{1}{|c|}{ Categoría } & \multicolumn{1}{c|}{ Aspectos asociados } \\
\hline \multirow{4}{*}{ Espiritualidad } & Cotidianidad. \\
\cline { 2 - 2 } & Apoyo. \\
\cline { 2 - 2 } & Expectativa de vida. \\
\cline { 2 - 2 } & Arrepentimiento. \\
\cline { 2 - 2 } & Resocialización. \\
\cline { 2 - 2 } & Importancia. \\
\hline
\end{tabular}

Fuente: elaboración propia.

$\mathrm{Al}$ indagar por las rutinas propias de prisión, muchos AMPL afirman que como parte de su cotidianidad oran, rezan y estudian la palabra de Dios; algunos encuentran su único apoyo en Dios, a quien consideran su único amigo, su padre, su esperanza y su felicidad. Otros participantes afirman que su expectativa de vida está dirigida a predicar la palabra de Dios y pregonar su ejemplo; otros pocos reconocen sentir arrepentimiento y buscar consuelo y perdón en Dios. Muchos adjudican su resocialización al acercamiento que han tenido a Dios, más que al tratamiento que han recibido por parte del Inpec, e igualmente afirman que Dios es lo más importante de su vida.

La espiritualidad se asocia a la categoría de aprendizaje en prisión, "es una cosa muy fuerte porque uno no está acostumbrado, y mucho menos a 
la edad de uno, a una cárcel; son cosas de la vida, que da uno un paso mal, pero yo en medio de ese conflicto y todas esas cosas me acerqué a mi dios, que ha sido el que me dio toda la fortaleza para seguir adelante y que me ha ayudado a construir una familia aquí en la cárcel" (grupo focal, EPMSC Acacias, mayo de 2013). Asimismo, la espiritualidad se relaciona con la categoría familia, pues también esta se consolida como bastión principal de apoyo; con la categoría expectativa de vida, referenciada anteriormente, y con la categoría asistencia social, pues, como se mencionó en el apartado correspondiente, prácticamente la única asistencia social que reciben los AMPL está vinculada a organizaciones o instituciones de carácter religioso.

\section{Familia}

Esta categoría se define como el grupo de personas con algún grado de consanguinidad con la persona privada de la libertad. Es una de las categorías más importantes, pues todos los AMPL hacen referencia a esta, en diferentes momentos de la conversación. Se asocian a ella los siguientes aspectos (tabla 35).

Tabla 35. Aspectos asociados a la categoría familia

\begin{tabular}{|l|l|}
\hline \multicolumn{1}{|c|}{ Categoría } & \multicolumn{1}{|c|}{ Aspectos asociados } \\
\hline \multirow{5}{*}{ Familia } & Desgaste. \\
\cline { 2 - 2 } & Abandono. \\
\cline { 2 - 2 } & Experiencia. \\
\cline { 2 - 2 } & Maltrato en el EPC. \\
\cline { 2 - 2 } & Apoyo. \\
\hline & Lejanía. \\
\cline { 2 - 2 } & Muerte. \\
\hline & Problemas psicológicos. \\
\hline & Destrucción. \\
\hline & Problemas legales. \\
\hline
\end{tabular}




\begin{tabular}{|l|l|}
\hline \multicolumn{1}{|c|}{ Categoría } & \multicolumn{1}{c|}{ Aspectos asociados } \\
\hline \multirow{4}{*}{ Familia } & Ausencia. \\
\cline { 2 - 2 } & Necesidades económicas. \\
\cline { 2 - 2 } & Dependencia. \\
\cline { 2 - 2 } & Ocultamiento. \\
\hline
\end{tabular}

Fuente: elaboración propia.

\section{Desgaste y abandono}

Algunos participantes afirman que aunque inicialmente contaban con el apoyo de sus familias, con el tiempo se ha venido sufriendo un proceso de desgaste; es decir, las visitas, las llamadas telefónicas y la correspondencia ya no son tan frecuentes: "el contacto familiar, yo no sé si es por estar acá, y eso lo he comentado con algunos amigos, las familias con el correr del tiempo no sé si es que se cansan, o si es por temor o por vergüenza que se van alejando, eso no es como al principio..., las familias se van alejando" (grupo focal, Complejo Carcelario y Penitenciario Metropolitano de Cúcuta, julio de 2013). Este fenómeno está estrechamente ligado a un proceso de abandono que, sin embargo, se presenta desde el principio en algunos casos. Muchos internos excusan a su familia al indicar que no tienen tiempo y dinero, que tienen muchas otras obligaciones y que por estos motivos no pueden estar pendientes de ellos.

\section{Experiencia}

Algunos AMPL afirman que sus casos particulares y su experiencia personal servirán de ejemplo para que en el futuro ningún miembro de sus familias tenga que pasar por una cárcel; "esto es experiencia, sirve uno de ejemplo para que los nietos no caigan en esto" (grupo focal EPMSC Cali, julio de 2013). 


\section{Maltrato en el EPC}

Algunos de los participantes hacen referencia al maltrato que reciben sus familiares en prisión; así, es común escuchar quejas frente a los acontecimientos que ocurren los días de visita, que ellos califican como humillaciones, gritos y brusquedad.

\section{Apoyo}

La mayoría de los participantes afirman encontrar apoyo en sus familias, y son estas las que sin duda sustentan la vida de sus familiares en prisión. En este punto, es importante hacer una diferenciación de género, pues aunque la mayoría de los hombres afirman haberse acercado más a sus seres queridos, las mujeres manifiestan mucha preocupación por no estar afuera, respondiendo por sus hijos y nietos, que en muchas ocasiones son menores de edad. Al respecto, se encuentra que: "La mayoría de mujeres, que suelen vivir en estrecha relación con su núcleo familiar, al ingresar a la prisión son abandonadas por sus parientes, lo que genera mayor angustia, tanto por la situación de abandono, como por la ausencia de su entorno, en el que desempeñaban un rol central" (Briceño-Donn, 2006, p. 18).

\section{Lejanía}

La lejanía es considerada como una de las mayores dificultades para la conservación y el cuidado de las relaciones familiares. Muchos AMPL atribuyen a la misma la ruptura o el debilitamiento de los lazos familiares. En el caso particular de las mujeres del Complejo Penitenciario y Carcelario de Jamundí, se encontró que la mayoría provienen de Bogotá y que hace muchos años que no pueden ver a sus hijos o que han perdido contacto con ellos: "nosotras todas venimos de Bogotá..., ella nunca ha tenido visitas". Al respecto, las internas son conscientes de que están privadas de la libertad y que están cumpliendo una pena, pero también reconocen que "no por el hecho de estar encerradas, tenemos que estar lejos de nuestras familias" (grupo focal de mujeres, Complejo Carcelario y Penitenciario de 
Jamundí, julio de 2013). Este aspecto es muy importante, pues la privación de la libertad, como respuesta a la infracción de la ley, limita o entorpece el goce efectivo de otros derechos que no deberían estar asociados a la pena, en este caso, el derecho a la familia.

Esta situación de lejanía con respecto a la familia dificulta por supuesto las visitas y se complejiza con la escasez de recursos económicos, manifestada por muchos de los participantes. Por este motivo, muchos de ellos solicitan un traslado a otro establecimiento más cercano a su lugar de origen o al lugar en el que habitan sus familias, donde no estén aislados de los suyos, pues se declaran muy solos y en ocasiones manifiestan no conocer a algunos de sus hijos o nietos. Al respecto:

Cuando el acceso a los establecimientos de detención y penitenciarios se hace extremadamente difícil u oneroso para los familiares, al punto de imposibilitar el contacto regular, se afecta inevitablemente el derecho de ambas partes a mantener relaciones familiares. Por lo que, dependiendo de las particularidades del caso este hecho podría constituir una violación al derecho a la protección de familia, y eventualmente de otros derechos, como el derecho a la integridad personal o al debido proceso. (Comisión Interamericana de Derechos Humanos, 2011, p. 223)

\section{Muerte y problemas psicológicos}

Algunos de los participantes mencionan la muerte al evocar a sus familias, pues han perdido a muchos de sus seres queridos estando en prisión, y manifiestan no haber podido despedirse de ellos o verlos por última vez. Al respecto, en algunos EPC se presenta la posibilidad de dar un último adiós a los seres queridos, mediante un trámite que permite el ingreso del féretro a las instalaciones: "sí, así sean 30 minutos se los traen, se los permiten ver, ellas lo único que tienen que hacer, cuando se enteran que su familiar falleció, es una solicitud ante dirección y que digan a qué hora van a traer al ser querido" (grupo focal de mujeres, Coped, Pedregral de Medellín, julio de 2013). Las muertes que se referencian son principalmente las del padre o la madre, aunque también se habla de hermanos e, incluso, de hijos. Por 
otro lado, algunos AMPL afirman que miembros de sus familias han tenido que enfrentar problemas psicológicos derivados de su privación de la libertad: "sí, a uno de mis hijos le entró una depresión por el hecho de estar yo en las condiciones que estaba, no salía..., y él murió..., se dejó llevar por la depresión" (grupo focal de mujeres, Complejo Carcelario y Penitenciario de Jamundí, julio de 2013).

\section{Destrucción y problemas legales}

En muchos casos, la privación de la libertad se equipara a la destrucción de la familia y es demoledora tanto para el privado, como para los demás miembros del hogar: "se está perdiendo un núcleo familiar, los afectados no somos nosotros solos, toda nuestra familia se está afectando" (grupo focal, Complejo Penitenciario y Carcelario de Ibagué, junio de 2013). Incluso, en ocasiones se afirma en los grupos focales que algunos miembros del grupo familiar comienzan a tener problemas legales, al involucrarse en venganzas o retaliaciones, para con quienes llevaron a su familiar a prisión o al incurrir en nuevos delitos, como escapatoria a su situación.

\section{Ausencia}

La ausencia del privado de la libertad en su hogar es difícil de abordar, pues en ocasiones este representaba un rol esencial en su familia, bien sea moral o económico, lo que genera cambios abruptos en las dinámicas cotidianas. Por otro lado, en algunos casos se trata de ausencias permanentes e incomprensibles; esto sucede principalmente con los nuevos miembros de la familia que pueden no conocer en persona a su familiar privado de la libertad, pero que saben de su existencia como algo etéreo y difuso.

\section{Necesidades económicas}

Las necesidades económicas de la familia son casi una constante en los AMPL. La mayoría manifiesta no tener recursos suficientes para suplir sus necesidades básicas, lo que dificulta la cohesión familiar: "para venir aquí 
necesitan plata, por eso mejor nos comunicamos por teléfono" (grupo focal, Complejo Carcelario y Penitenciario de Jamundí, julio de 2013).

La mayoría de las veces, el privado de la libertad constituía un aporte fundamental para la familia en términos económicos, de allí que se manifieste preocupación por el presente y futuro de las familias al no poder aportar desde prisión. Efectivamente, el ingreso de un miembro de la familia a prisión implica en muchas oportunidades una disminución en el recurso económico, pues es una persona menos que trabaja y devenga.

\section{Dependencia}

Este tema de las necesidades económicas está entonces estrechamente ligado a la dependencia, pues el sustento de muchas de las familias estaba a cargo del privado de la libertad. Este aspecto es bastante llamativo, pues aunque se trata de AM, muchos afirman ser los directamente responsables de sus hijos y de sus nietos. "En el caso mío, yo soy madre cabeza de familia, mi hijo menor tiene 18 años y está solo porque está apenas estudiando y si yo no hago algo para pagarle sus estudios no va poder estudiar y está solo en la casa enfermo, no come y nadie está pendiente de él" (grupo focal, Reclusión de Mujeres de Bogotá, julio de 2013). La dependencia entonces no solo es de tipo económico, sino también afectiva y moral.

\section{Ocultamiento}

Respecto al ocultamiento, algunos AMPL afirman que muchos de sus familiares desconocen su paradero y situación actual, ellos prefieren mentir al respecto e inventar una realidad paralela: "estamos cansados de esperarte, ¿cuándo es que vas a llegar? Muy pronto, mi bebé, muy pronto..., ella cree que estoy de trabajo, ella no sabe que estoy aquî" (grupo focal, EPMSC Medellín, julio de 2013).

La familia, como una de las categorías principales del estudio, está estrechamente vinculada a la categoría de expectativa de vida, pues es casi una constante que el sueño de todo AMPL sea retornar al hogar, recuperar el tiempo perdido con sus seres queridos y pasar sus últimos días con ellos; 
así como a la categoría red de apoyo, pues como se ilustró anteriormente, es en la familia donde se encuentra el sustento moral, espiritual y económico. También está vinculada a la categoría estigmatización, pues los significados otorgados al delincuente se hacen extensivos para los miembros de su hogar, y a la categoría significado otorgado a prisión, ya que para muchos la prisión significa el fin y la destrucción de la familia.

\section{Significado otorgado a prisión}

La categoría denominada significado otorgado a prisión está definida por las implicaciones y efectos que trae la prisión a la vida de los individuos. Se identificaron seis aspectos asociados a esta categoría (tabla 36).

Tabla 36. Aspectos asociados a la categoría significado otorgado a prisión

\begin{tabular}{|l|l|}
\hline \multicolumn{1}{|c|}{ Categoría } & \multicolumn{1}{c|}{ Aspectos asociados } \\
\hline \multirow{4}{*}{$\begin{array}{l}\text { Significado otorgado a } \\
\text { prisión }\end{array}$} & Pérdida de tiempo. \\
\cline { 2 - 2 } & Hostilidad. \\
\cline { 2 - 2 } & Supervivencia. \\
\cline { 2 - 2 } & Oportunidad. \\
\cline { 2 - 2 } & Abandono. \\
\cline { 2 - 2 } & Muerte. \\
\hline
\end{tabular}

Fuente: elaboración propia.

Muchos de los participantes, lejos de reconocer las bondades de la resocialización, afirman que la prisión es una pérdida de tiempo y que no acarrea nada positivo en sus vidas; por otro lado, algunos afirman que en prisión han encontrado un ambiente hostil con el que no estaban familiarizados y que, por tanto, ha sido muy difícil de adaptar a sus vidas. Otros reconocen que la prisión representa una segunda oportunidad, al permitir espacios de reflexión, arrepentimiento, aprendizaje, experiencia y resocialización: "yo no lo tomo como un castigo, sino como una nueva oportunidad que me da la vida para salir adelante" (grupo focal EPMSC Cali, julio de 
2013). Esta posición no es la más común y son más frecuentes las respuestas que vinculan la prisión al abandono y al olvido: "no tenemos un cariño ni nada, es plena soledad" (grupo focal, Complejo Penitenciario y Carcelario de Ibagué, junio de 2013). Igualmente, en algunos casos la prisión se equipara con la muerte, pues acaba con las expectativas e ilusiones: "apenas me condenaron yo sentí que el corazón me falló, iba yo a respirar y no podía, me puse lívido, me fui de lado, y la misma secretaria del juez fue y me trajo agua. Ya fue cuando salí al patio, cuando me asignaron celda, que dije: a partir de hoy estoy muerto y me metí en la cabeza que había muerto para todo el mundo, para la familia y eso..." (grupo focal, Complejo Penitenciario y Carcelario de Ibagué, junio de 2013).

\section{Condiciones económicas}

La tercera condición tiene que ver con el bienestar económico, que es analizado con la disponibilidad de ingresos con la cual cuentan los AMPL, o la asignación que tienen para su atención. Se percibe que estando fuera o dentro de un EPC las condiciones económicas de los AM en general no son las mejores, principalmente porque tienen limitaciones para su autocuidado y tendrían una dependencia económica que, junto con el deterioro que sufre su cuerpo, les impediría en ocasiones la movilidad o el mantenerse activos en el mundo laboral, producto del proceso de envejecimiento.

Sin embargo, esta situación es contraria a lo que dejan ver las cifras de participación en el mercado laboral, que registra la dinámica del empleo, el desempleo y subempleo, donde se refleja que los AM de 60 años se mantienen laboralmente activos, principalmente en las áreas rurales, donde las coberturas en seguridad social son más bajas (Ministerio de Salud y Protección Social, 2008). De acuerdo con la tasa de ocupación, que es el indicador porcentual entre la población ocupada y el número de personas que integran la población en edad de trabajar, las personas mayores de 60 años se ubican con tasas del 51,3\% para hombres y $21,7 \%$ para mujeres, teniendo tasas de desempleo bajas: $6 \%$ para los hombres y $4,8 \%$ para las mujeres (DANE, 2012). Esto refleja que la población mayor de 60 años 
en Colombia se mantiene laboralmente activa, aunque no quiere decir que implique remuneración económica, debido a que los ingresos de estas personas caen proporcionalmente con la edad, y en la mayoría el Sistema General de Pensiones no los cubre. Según la Encuesta de Calidad de Vida (DANE, 2012), la cobertura pensional alcanza al 21,8\% de estas personas en las zonas urbanas y al $5 \%$ en las zonas rurales, donde generalmente no existe una fuente de ingresos fija.

Esa es la situación general externa, pero iqué ocurre cuando un AM es privado de su libertad? Básicamente lo que se encontró en los EPC es una dependencia casi absoluta de esta población, que si tenía algún ingreso por fuera de la cárcel, en el interior desaparece y entra a depender del apoyo económico que le dé principalmente la familia (figura 28).

Figura 28. Tipo de apoyo que recibe el adulto mayor privado de libertad

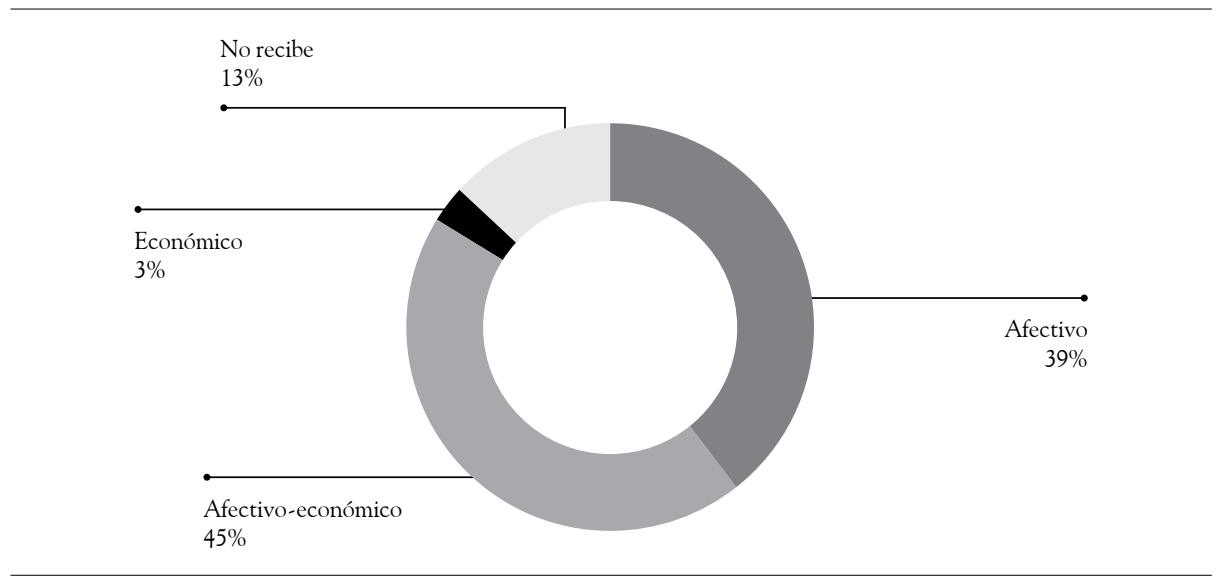

Fuente: Sisipec Web, censo condiciones excepcionales, 31 de julio de 2013. Cálculos de los autores.

En ese contexto, acorde con la realidad que se presenta por fuera de los EPC, donde la principal fuente de ingresos para los AM son los aportes familiares, se indagó sobre el presupuesto que les es asignado a los AMPL como parte de los grupos de condiciones excepcionales en el Inpec. Allí se evidenció que de acuerdo con el crecimiento que se ha tenido de esta población, la asignación presupuestal también se incrementa (figura 29). 
Figura 29. Presupuesto asignado a población en condiciones excepcionales y adultos mayores privados de la libertad 2009-2013

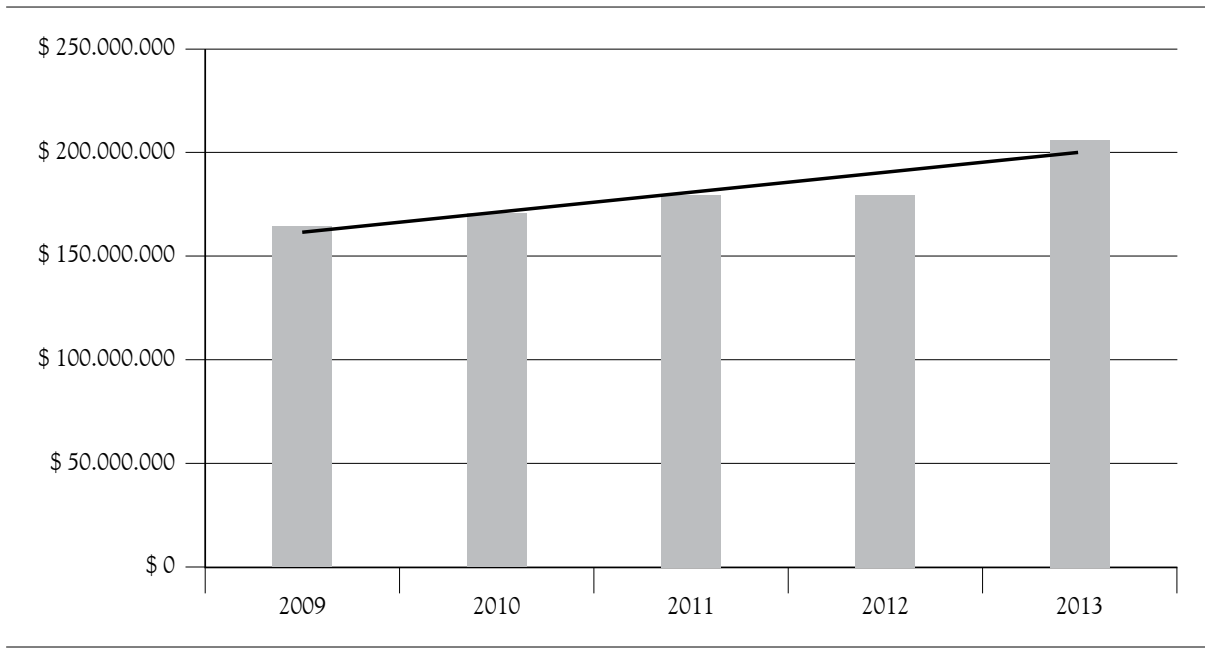

Fuente: Plan de Compras del Inpec para cada vigencia, Sisipec Web, censo condiciones excepcionales, 31 de julio de 2013. Cálculos de los autores.

En los últimos 5 años el incremento en la asignación presupuestal para atender la población en condiciones excepcionales (PCE) aumentó; sin embargo, al revisar cuánto le corresponde de esa asignación a los AMPL y qué porcentaje pertenece al total de esa población, se encontró que los resultados son un poco menos alentadores, debido a que les corresponde una asignación según el tamaño de la misma población frente al general distribuido para el total de la población (figura 30).

De acuerdo con la asignación presupuestal, se puede inferir que a los AMPL mayores de 60 años en 2013 -que correspondían al 16,85\% del total de este tipo de población- les fueron asignados ese año cerca de \$35.000.000 para la atención en programas que se organizan en los EPC. En consecuencia, cada AMPL tuvo una asignación presupuestal de $\$ 20.284$ durante todo el año 2013, para que el EPC donde se encontraba recluido le diera la atención en los programas establecidos. El resto de los recursos que requiere la población fueron conseguidos por la red de apoyo disponible. 
Figura 30. Presupuesto asignado para adultos mayores privados de la libertad vs. presupuesto para la población en condiciones excepcionales

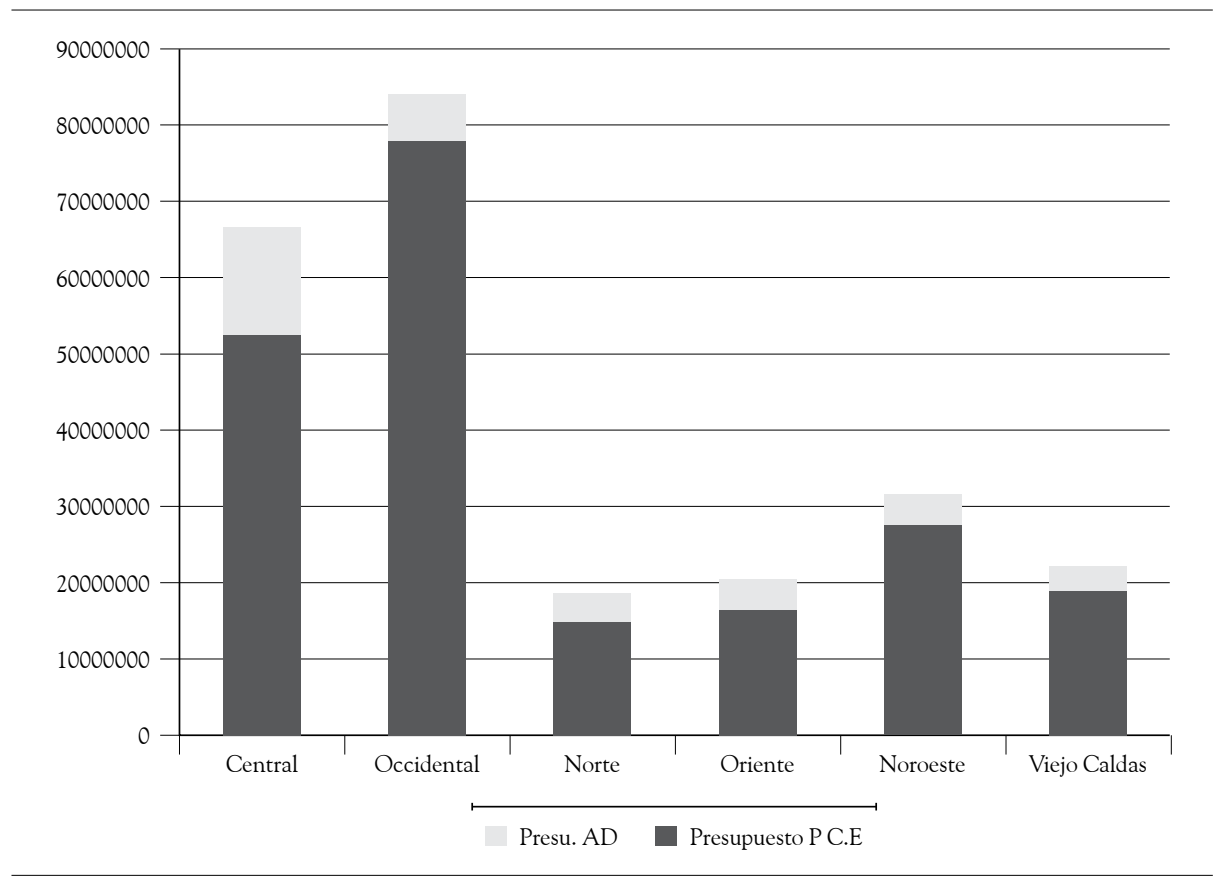

Fuente: Plan de Compras del Inpec para cada vigencia, 31 de julio de 2013. Cálculos de los autores.

La evidente escasez de recursos para atender al total de la población carcelaria del país no es ajena al limitado presupuesto para atender a los AMPL. Es notable la intención, el profesionalismo y las ganas de los funcionarios del Inpec por atender al total de la población AMPL; sin embargo, una cosa es lo que se desea y otra lo que se puede hacer con los recursos que se tienen. El propio personal de la Subdirección de Atención Psicosocial, de la Dirección de Atención y Tratamiento del Inpec es consciente de ello al manifestar lo siguiente:

[...] aún no se ha trabajado con el tema de la red de apoyo familiar del interno adulto mayor a la hora de recuperar la libertad, no hay estructuración del plan ocupacional que responda a las características propias de la población de tercera edad, no se cuenta con los espacios ni la infraestructura adecuada para ubicar a esta población (por ejemplo, celdas acondicionadas). No hay personal suficiente ni adecuado para 
atender esta población, como terapeutas ocupacionales, fisioterapeutas, gerontólogos, entre otros; los profesionales que hay en su mayoría psicólogos y trabajadores sociales atienden a toda la población en general y no hay un servicio especializado para esta población. De otra parte, se está empezando un trabajo en esta dirección para establecer políticas de atención a la población de tercera edad que se ajusten a las necesidades reales del contexto. Se han realizado algunos contactos, pero es una tarea que está empezando.

Esto hace pensar que en los EPC los funcionarios que laboran allí sienten una frustración profesional, al saber que se puede hacer más, pero los recursos y la sobrepoblación no se los permite.

\section{Condiciones jurídicas}

Finalmente, la cuarta condición reúne aquellos factores que determinan los aspectos legales a los que se enfrenta esta población en la actualidad, y se observan las principales adecuaciones típicas por las cuales los AMPL se encuentran recluidos en los EPC, dentro de las que se destacan los delitos contra la libertad, la integridad y la formación sexual, contemplados en el título IV, capítulo I del CP, como acceso carnal violento, acto sexual violento, acceso carnal o acto sexual en persona puesta en incapacidad de resistir. Asimismo, los relacionados en el capítulo II de los actos sexuales abusivos: acceso carnal abusivo con menor de catorce años, actos sexuales con menor de catorce años, acceso carnal o acto sexual abusivo con incapacidad de resistir y acoso sexual. A pesar de darse un alto porcentaje de privaciones de la libertad, como se dijo, por esta clase de conductas punibles, se reportan otras contra la vida e integridad personal, la libertad individual y otras garantías, el patrimonio económico, la administración pública, entre otras.

Sin embargo, se evidenció en el trabajo de campo que un gran porcentaje de los AMPL no tienen claridad acerca del tipo penal en el que incurrieron, en el caso de delitos sexuales, por ejemplo, algunos asocian acceso carnal con otras infracciones descritas en el mismo título, circunstancia que 
resta claridad a la pena dado que al no precisar cuál fue realmente el delito que se cometió, no se identifican los derechos transgredidos.

Hasta que cae uno, me da dolor que uno tenga que pagar ocho años por eso, bueno ya casi me voy, pero digo: yo por qué tengo que vivir esta situación, porque le hace falta a uno mucha información del mismo Gobierno, de decirle a la mujer que no se meta con este... a uno de hombre también. Es de decirle a uno que el acceso carnal da 60 años como dice la difunta que en paz descanse, doña Gilma, uno llega al patio y lo señalan que uno es un violo, entonces el otro señor está por un secuestro..., a ese no le dicen nada. (Grupo focal EPC de Cúcuta, julio de 2013)

Con alguna frecuencia los AMPL manifiestan ser "víctimas" de componendas, falsedades y arbitrariedades que generaron su estancia en la cárcel:

Yo trabajaba en la casa y llegó una muchacha que me decía que por qué no le regalaba 1000 pesos, yo se los di y entonces en eso ella llegó a la casa y fue un vecino y llamó a la Policía. Yo tenía la puerta abierta, yo no estoy haciendo nada...ella entró a tomar agua, entonces llamaron y llegó un bus..., a mí me dejaron. A los dos meses estaba la familia en Bogotá y llegó la Fiscalía, me buscaron por la mañana y yo estaba trabajando y llegaron por la tarde y me dijeron que estaba preso. Resulta que la abuela de la china..., me tienen por manoseo, me dieron 13 años y seis meses, esa no la debo. (Grupo focal EPC de Cúcuta, julio de 2013)

Al observar el tipo de defensa que tienen los AMPL se encontró que en su gran mayoría son asistidos jurídicamente por defensores de oficio, hoy públicos, en más de un $92 \%$ de los casos, tanto en mujeres como en hombres. Esto resulta entendible ante la imposibilidad económica que la gran mayoría padece, con el acoso de las multas exageradas, impagables, que por demás no tienen ningún sentido en relación con la pobreza e insolvencia de la gran mayoría de los condenados; las afugias de sus seres queridos cuando todavía se cuenta con ellos o las propias en el interior del establecimiento, donde nada se produce, nada se cosecha (figura 31). 
Figura 31. Asistencia jurídica que reciben los adultos mayores privados de la libertad

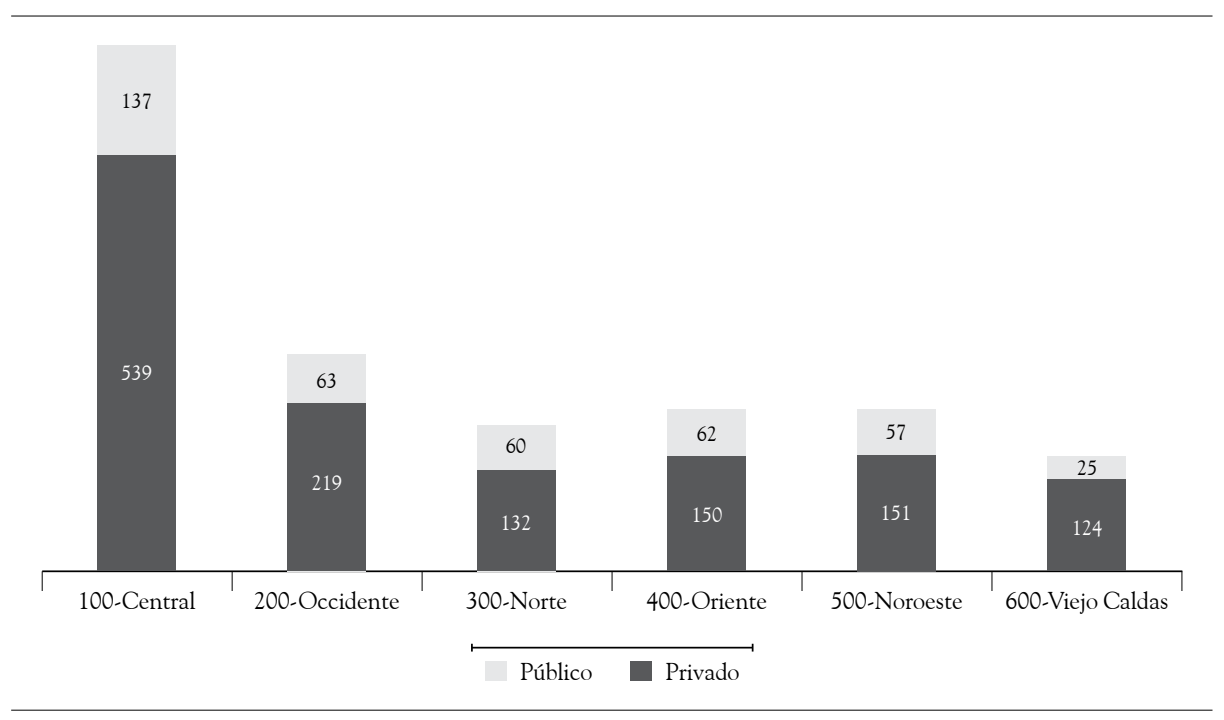

Fuente: Sisipec Web, censo condiciones excepcionales, 31 de julio de 2013. Cálculos de los autores.

Junto con ello, muchas veces son los propios operadores judiciales quienes los irrespetan, los ofenden y los maltratan. El juez tiene mucho poder de interpretación, la aplicación de la ley debería ser más estricta, más concreta. iQue el juez cumpla la ley! Conforme a lo expresado, el operador de justicia no está dando aplicación a principios como el del in dubio pro reo, el favor rei, el pro homine, este último reconocido en la Convención Americana sobre Derechos Humanos en su artículo 39. Igualmente, se observó que en los EPC visitados la mayoría de las personas internas AMPL están condenadas y, en una menor proporción, se encuentran sindicadas, imputadas y acusadas (figura 32).

Los AMPL consideran que la acumulación de penas no se hace en forma correcta, situación que les prolonga aún más su estancia en prisión, mutando en ocasiones a una cadena perpetua. Insisten en que las penas son demasiado extensas, exageradas, inexplicables por no tener nada de proporcionales, ni de racionales. La libertad condicional o el brazalete no llegan nunca y la domiciliaria es casi que una utopía. Por alta que haya sido la condena, estiman que debería tener algún grado de flexibilidad, considerando el buen comportamiento personal que se tenga dentro del reclusorio. 
Figura 32. Situación jurídica de los adultos mayores privados de la libertad

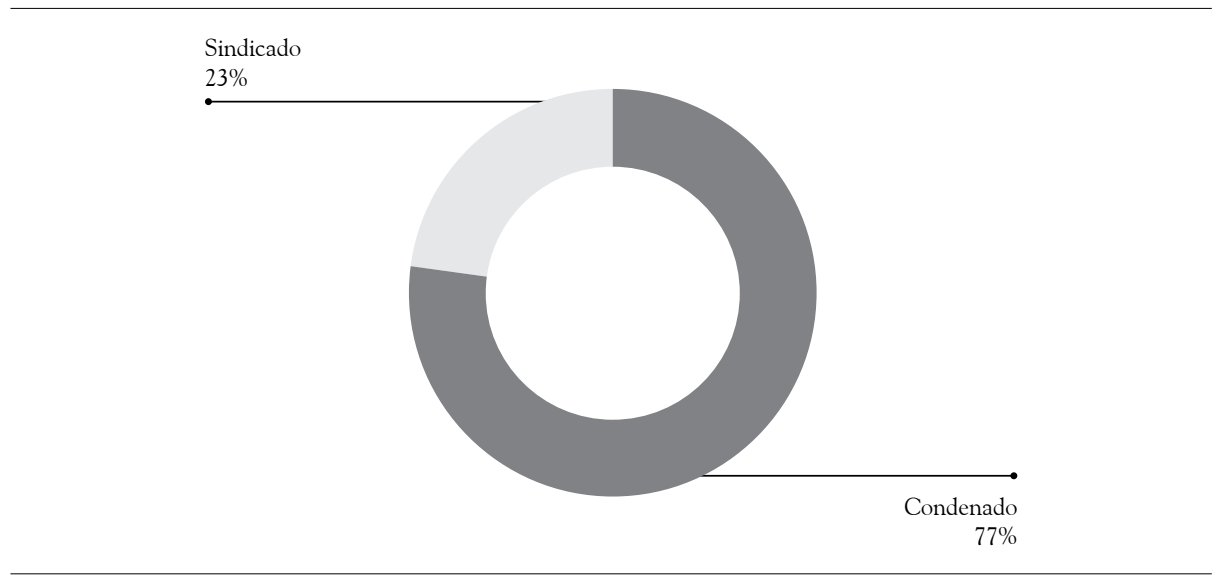

Fuente: Sisipec Web, censo condiciones excepcionales, 31 de julio de 2013. Cálculos de los autores.

Los permisos se perciben por los AMPL como un premio cuando ya se ha cumplido cierta parte de la pena y se ha tenido buen comportamiento, de manera que si en esas condiciones no se dan, dicha negativa se ve como una afrenta, como una respuesta arbitraria. Igualmente, quienes han trasegado varios EPC del país no se explican por qué el trato diferente en relación con los permisos, siendo que la ley es una sola, máxime cuando consideran que el permiso es el único mecanismo establecido que en algo ayuda al recluso a preparase para la libertad, para volver a la sociedad.

Gran parte desea obtener permisos, porque perciben que no son "un peligro para la sociedad"; por el contrario, los AMPL se consideran como personas pacíficas, no conflictivas, sin vicios, que no delinquen en el interior de los EPC, donde se dan hurtos, lesiones y hasta homicidios. Manifiestan por ello el rechazo en su gran mayoría a ser mezclados con otros reclusos de menor edad, porque consideran que estos son portadores de estas malas prácticas, además de ser algunos ruidosos, agresivos e intolerantes. Sin dejar de mencionar el comportamiento sexualmente escandaloso e inapropiado por parte de miembros de las comunidades LGBTI, lo cual aumenta su estado de vulnerabilidad. Se dice que: 
La vulnerabilidad coloca a quien la padece en una situación de desventaja en el ejercicio pleno de sus derechos y libertades [...] esta circunstancia viola los derechos de los miembros más débiles de la sociedad y los margina, razón por la cual el Estado tiene la responsabilidad de proteger a estas personas, quienes frecuentemente desconocen cuáles son sus derechos, ignoran los medios para hacerlos valer y carecen de los recursos necesarios para acudir ante los sistemas de justicia. (Arriagada Peñailillo, 2006)

No obstante lo anterior, los AM no tienen claro cuáles son sus derechos, no saben cómo ejercerlos y demandarlos, condición que revela su vulnerabilidad y que impide la exigencia de un trato diferencial, en el ámbito de la privación de la libertad. Salvo en algunos casos en los que se separan de los demás reclusos, no hay ningún tipo de diferencia respecto al AM por parte del legislador, del juez o de quien ejecuta la pena. Igualmente, la mayoría de los AMPL desconocen que existan leyes especiales para el AM, y tienen claro que se rebaja o se descuenta pena con trabajo o estudio, pero manifiestan que las certificaciones no son fáciles, por lo que en ocasiones se pierde el tiempo redimido. "En la cárcel se roban los descuentos" (grupo Focal, EPMSC ERE Cúcuta, julio de 2013). El trabajo no es remunerado, solo excepcionalmente. Algunos de los participantes manifiestan que se les han vulnerado sus derechos, y los que mayoritariamente señalan son acceso a la justicia, debido proceso, defensa, familia, salud, trabajo, educación y resocialización.

\section{Acceso a la justicia (artículo $29 \mathrm{CN}$ )}

Principalmente por no tener recursos económicos, se considera que la ley sigue siendo un "perro que solo muerde a los de ruana", que el preacuerdo es una trampa, un engaño; se aceptan responsabilidades para obtener alguna rebaja muchas veces sin haber cometido el delito, como penas excesivas, falsos positivos judiciales. Los trámites para el reconocimiento de la rebaja son muy demorados y engorrosos. 


\section{Debido proceso (artículo $29 \mathrm{CN}$ )}

Se sienten engañados con los preacuerdos y la aceptación de cargos a los cuales accedieron buscando una pronta libertad o rebaja significativa, aún en eventos de franca inocencia bajo el entendido de que por su situación social y económica no se les haría justicia. Hay quienes consideran que la justicia no investiga, que el juez está cargado de prejuicios, aspecto que quita objetividad e imparcialidad, que frente a ciertos señalamientos como los relacionados con conductas sexuales no hay nada que hacer, puesto que basta la denuncia para ser condenados. Esta situación se agrava cuando la persona ha sido juzgada y condenada en contumacia.

\section{Defensa (artículos 29 y $34 \mathrm{CN}$ )}

Ausencia o falta de defensa no solamente en relación con la defensa técnica, por cuanto informan que es muy poco o nada lo que hace el defensor por ellos; incluso hay quienes manifiestan que son condenados por sus propios abogados, cuando les sugieren o los convencen de llegar a un preacuerdo o aceptación de cargos. En lo que toca a la defensa material, señalan que el juez no los dejó hablar, que ni el juez ni el abogado los dejó defenderse. La acumulación de penas no se hace correctamente y esto degenera en verdaderas cadenas perpetuas.

\section{Familia (artículo $44 \mathrm{CN}$ )}

La reclusión alejada de la familia hace que esta se pierda en dos sentidos: para el recluso cuando es marginado del grupo familiar o cuando menores, ancianos o personas con discapacidad se ven afectados con la privación de la libertad de quien veía por ellos. De ahí que la Corte Constitucional ponga límites a la privación de la libertad como medida cautelar, condición que se deben replicar para la condena, de subsistir dichas circunstancias al momento de proferirse el fallo o ejecutarse, salvo en los eventos contemplados en el artículo 27 de la Ley 1142 de 2007, que adicionó el artículo 314 del CPP. En estos artículos, de ninguna manera procede la domiciliaria. La familia, 
sin embargo, sigue siendo el soporte de muchas PPL para seguir adelante, lo mismo que la esperanza de recuperar algún día la libertad perdida.

\section{Salud (artículo $44 \mathrm{CN}$ )}

A pesar de que se trata de una población bastante necesitada, no cuenta con una asistencia médica y farmacológica: "uno también ve esas colas de esos pobres viejitos para ir a recoger una medicina, eso es abandono, uno ve morir al viejito con la tutela en el bolsillo y nada, no lo atendieron" (grupo focal, Coiba Ibagué, junio de 2013). La mayoría de la veces la alimentación que se suministra no es la apropiada para enfrentar sus problemas de salud y sus condiciones se agravan por el hacinamiento, causante de epidemias y generador de espacios no adecuados para las personas de edad avanzada. Estos reclamos realizados en los grupos focales, frente a la atención y la calidad de la salud, contrastan con los estándares internacionales, como se observa en el apartado denominado "Caracterización de los adultos mayores privados de la libertad". Así pues, la percepción que tienen los AMPL de la atención en salud es negativa, lo cual es bastante delicado considerando que este grupo representa un riesgo mayor de adquirir problemas de salud, que se suman a la condición de hacinamiento en la que se encuentran.

\section{Trabajo (artículo $25 \mathrm{CN}$ )}

Ese derecho y esa obligación no están prohibidos o excluidos en los centros carcelarios y penitenciarios; por el contrario, es allí donde la ocupación debe ser plena para todos los reclusos, considerando que el trabajo es un medio para alcanzar la resocialización del Código Penitenciario y Carcelario de Colombia (Ley 65 de 1993, artículo 10), mientras que el ocio sigue siendo causa de todos los vicios.

\section{Educación (artículos 44 y $67 \mathrm{CN}$ )}

El Inpec no cuenta con los recursos necesarios para tal fin, en 2007 apenas se le destinaba a dicho rubro el 1,6\% de su presupuesto, sin que haya evidencia 
del mejor aprovechamiento de estos recursos (Serge Jiménez, 2007). Situación que bien se refleja en la realidad, por cuanto son los propios reclusos los que manifiestan su frustración total frente a la resocialización: "la cárcel no resocializa a nadie, solo se aprenden mañas", "la cárcel no enseña nada bueno, un oficio, un arte, una manera de ganarse la vida honradamente" (grupo focal, Coiba Ibagué, junio de 2013). De esta manera, ven la estancia en la cárcel como una pérdida de tiempo, un abandono llevado al extremo, pues se consideran tratados como animales, únicamente comiendo y durmiendo en las peores condiciones, de allí que igualmente vean las penas a las que son sometidos como muy altas y absurdas desde todo punto de vista.

\section{Resocialización}

Así no esté expresamente consagrado, protuberantemente vulnerado resulta este derecho del penado dentro del SPCC, que hace de esa sola posibilidad una meta muy difícil de alcanzar. Por otro lado, se puede establecer que los AMPL solo reconocen el delito cuando aceptan sus culpas e indican haber infringido la ley, afectando derechos ajenos con su comportamiento. Sin embargo, no tienen precisa su conducta delictuosa, quienes han cometido el delito no entienden la tipificación que se les adjudicó, y existe entonces una clara justificación en la inoperancia del sistema judicial. Así las cosas, como las crueles penas de los siglos pasados, como el suplicio de la rueda o descuartizar o cortar a hachazos los miembros del cuerpo, la prisión no ha logrado disminuir la criminalidad, por lo que cada delito es ya por el solo hecho de existir una prueba en contra de la eficacia que estas políticas de prevención general persiguen mediante el incremento de las penas. 